\title{
Improving Diet in Low-Income Neighborhoods \\ Leveraging the Food Environment for Change
}

Christina Y. Huang

This document was submitted as a dissertation in April 2016 in partial fulfillment of the requirements of the doctoral degree in public policy analysis at the Pardee RAND Graduate School. The faculty committee

that supervised and approved the dissertation consisted of Jeanne

Ringel (Chair), Tamara Dubowitz, and Karen Flórez.

Supported by the Anne and James Rothenberg Dissertation Award and James I.J. Wang Dissertation Award. 
For more information on this publication, visit http://www.rand.org/pubs/rgs_dissertations/RGSD372.html

To my parents for creating a lifetime of opportunities - this success is all yours.

Published by the RAND Corporation, Santa Monica, Calif.

(C) Copyright 2016 RAND Corporation

RAND $^{\circledR}$ is a registered trademark

\section{Limited Print and Electronic Distribution Rights}

This document and trademark(s) contained herein are protected by law. This representation of RAND intellectual property is provided for noncommercial use only. Unauthorized posting of this publication online is prohibited. Permission is given to duplicate this document for personal use only, as long as it is unaltered and complete. Permission is required from RAND to reproduce, or reuse in another form, any of its research documents for commercial use. For information on reprint and linking permissions, please visit www.rand.org/pubs/permissions.html.

The RAND Corporation is a research organization that develops solutions to public policy challenges to help make communities throughout the world safer and more secure, healthier and more prosperous. RAND is nonprofit, nonpartisan, and committed to the public interest.

RAND's publications do not necessarily reflect the opinions of its research clients and sponsors.

Support RAND

Make a tax-deductible charitable contribution at www.rand.org/giving/contribute

www.rand.org 


\section{Abstract}

Chronic diseases are a serious public health problem in America, but risk for many chronic diseases can be modified by diet. The "food environment" (the physical environment, or settings, in which there are opportunities to eat or buy foods) has been identified as having a potential impact on diet and health outcomes. Recent policies propose changing the food environment, for example, building new supermarkets in poor neighborhoods. This dissertation examines the role of the food environment as a policy lever to improve diet, with a focus on sugar sweetened beverage (SSB) consumption.

Using data from the Pittsburgh Hill/Homewood Research on Eating, Shopping \& Health (PHRESH) study, I looked at whether aspects of the food environment - distance, density, shopping frequency, and store characteristics - were associated with adult SSB consumption and whether these relationships changed over time. I found no longitudinal associations and only one cross-sectional association between eating at fast food restaurants and higher SSB consumption.

In a subset of PHRESH participants with children (5-13 years old), I examined the role of the food environment on children's SSB consumption by considering whether in-store marketing characteristics influence both children's "pestering" and parents' purchase decisions about junk foods. The in-store marketing characteristics were not related to child or parent behaviors, however, frequency of children's pestering and home availability of soda were both positively associated with child soda consumption.

Finally, I described how the public discusses different policies to change the food environment by analyzing online comments about a policy to decrease access to unhealthy foods (by limiting portion sizes of SSBs) and a policy to increase access to healthy foods (by expanding infrastructure for food stores). Comments about limiting portion sizes used negative language and frequently used words like "freedom", "rights", and "choice", while comments about expanding food stores used narrative language and suggested barriers to healthy eating.

Taken together, this dissertation provides a better understanding of the food environment, identifies needs for future research, and offers policymakers recommendations for how to improve diet and health for a vulnerable population. 



\section{Table of Contents}

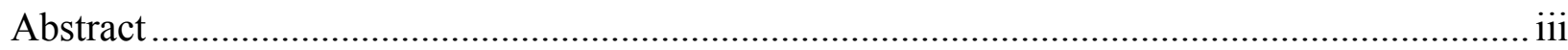

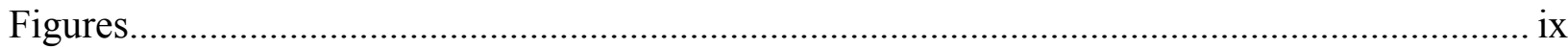

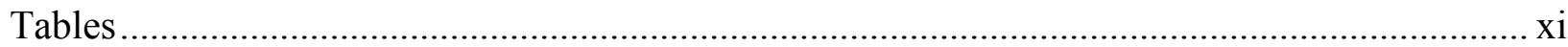

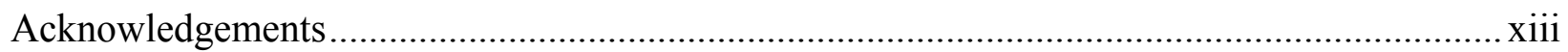

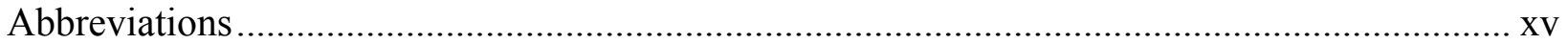

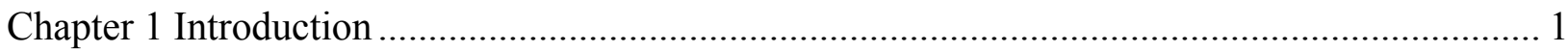

Chapter 2 Background and Literature Review............................................................... 4

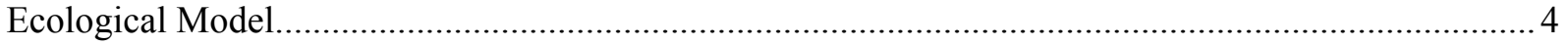

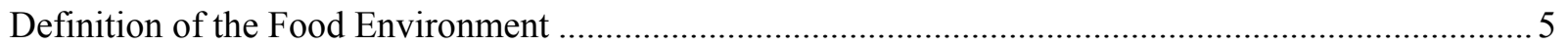

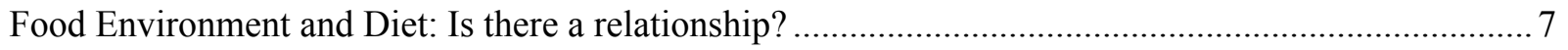

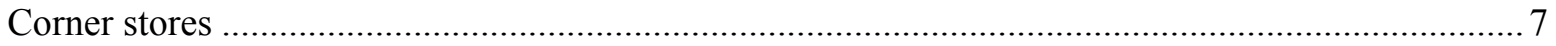

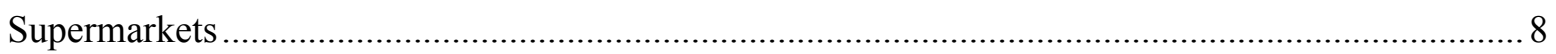

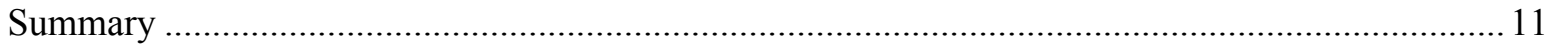

Chapter 3 Sugar-Sweetened Beverage Consumption and the Food Environment ...................... 12

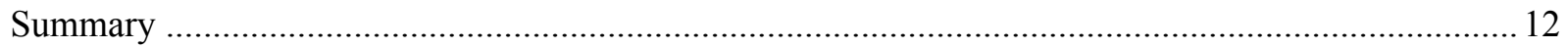

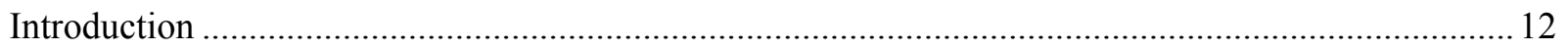

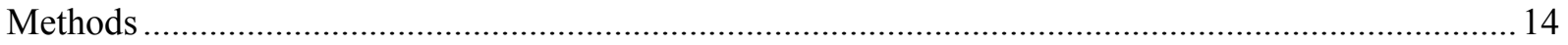

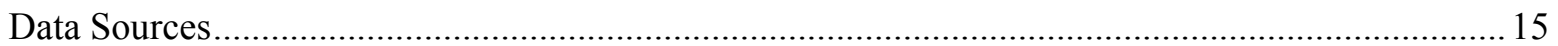

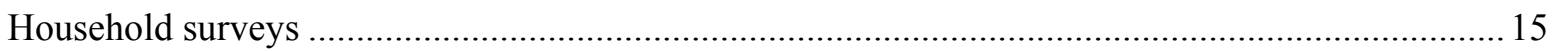

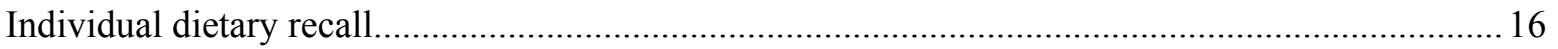

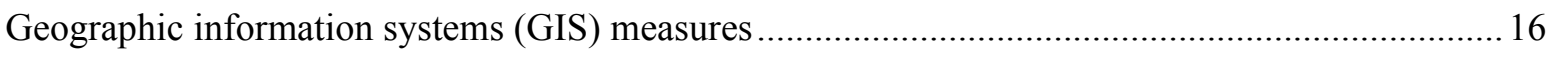

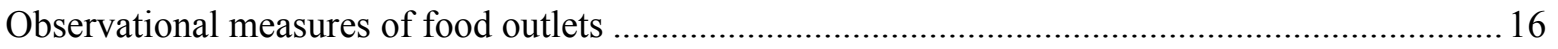

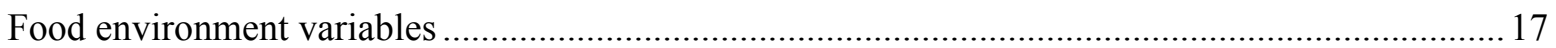

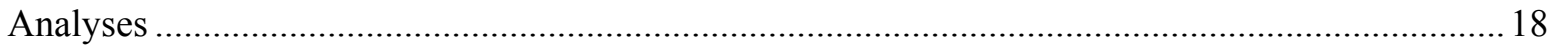

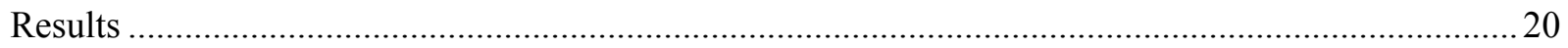

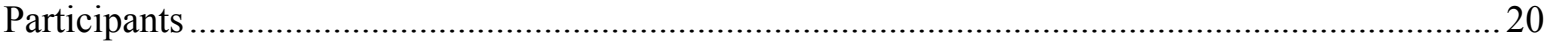

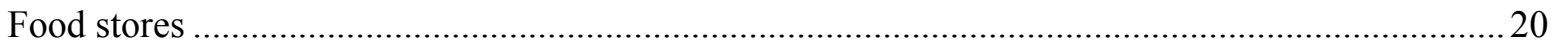

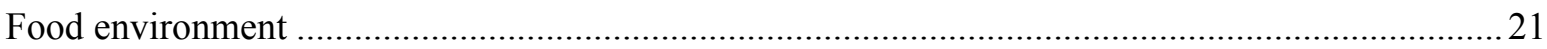

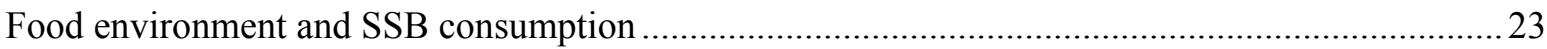

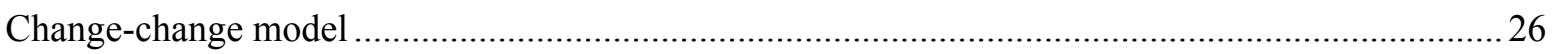

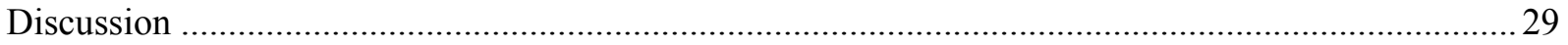

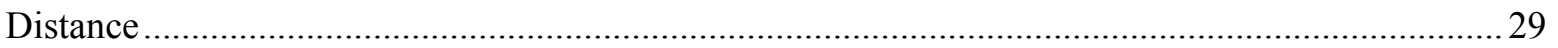

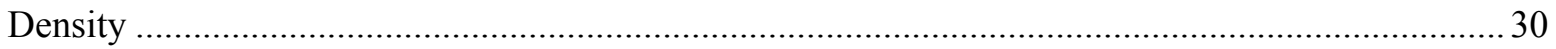

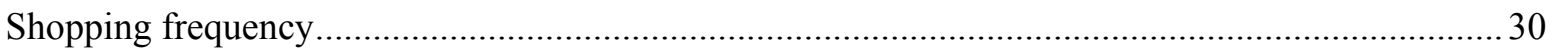

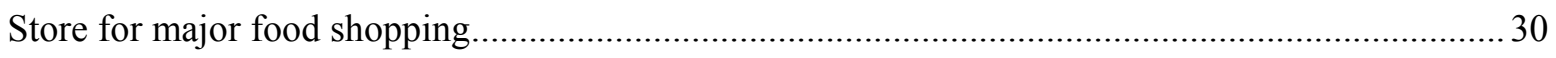

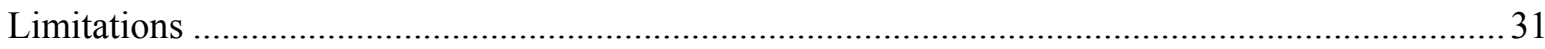

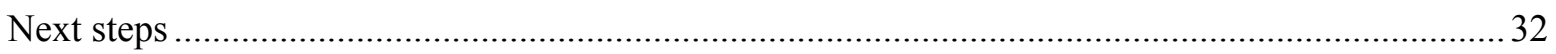




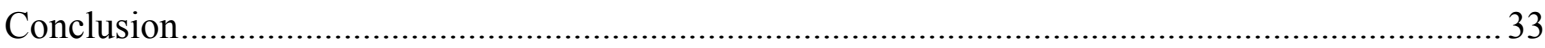

Chapter 4 In-store Marketing Practices and Children's Diet................................................ 34

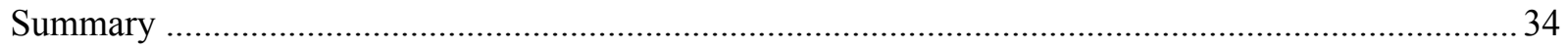

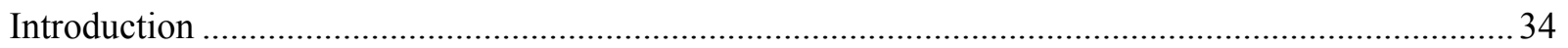

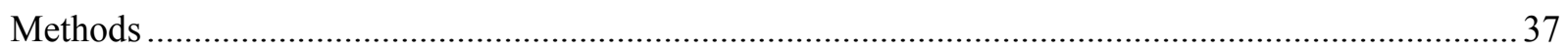

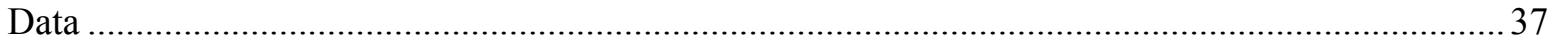

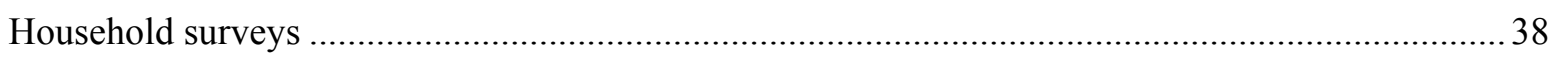

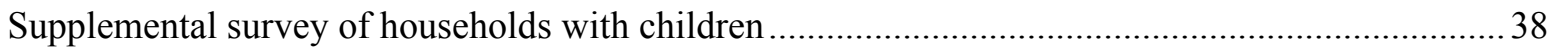

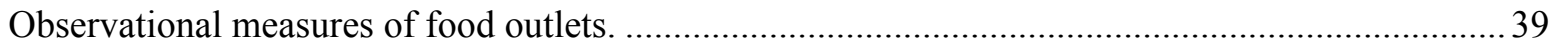

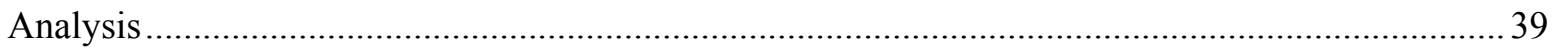

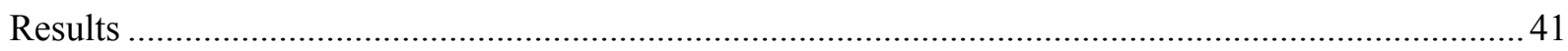

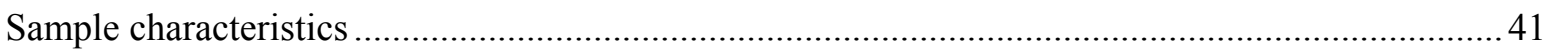

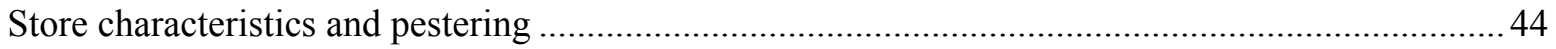

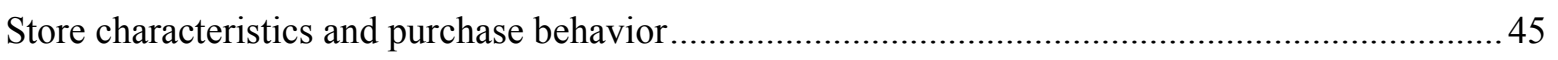

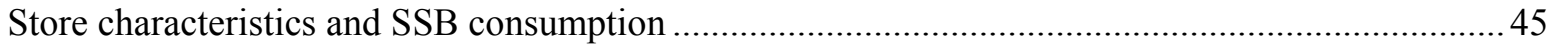

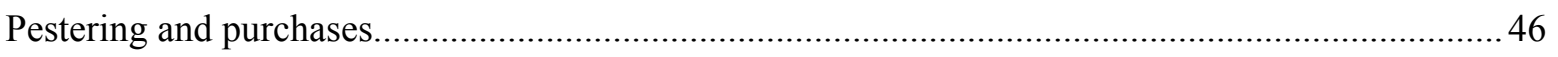

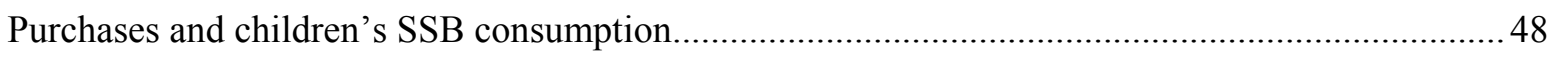

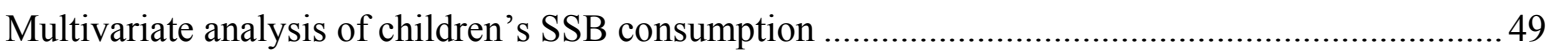

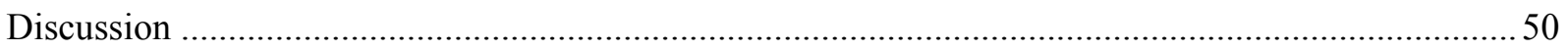

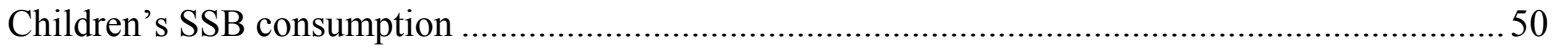

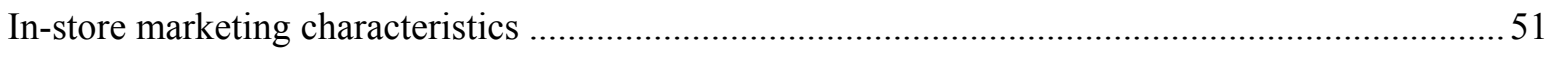

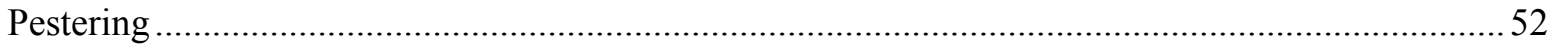

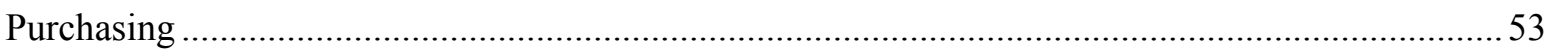

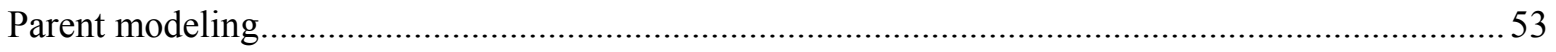

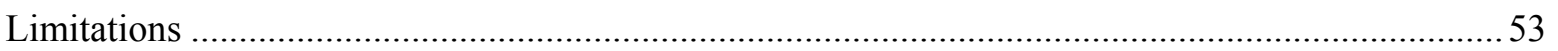

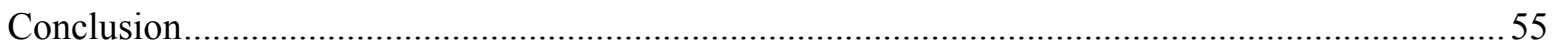

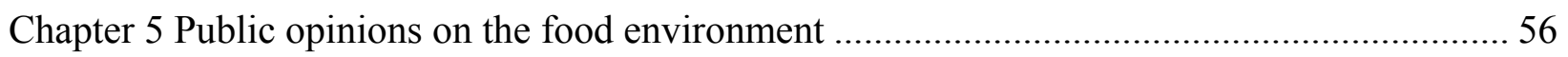

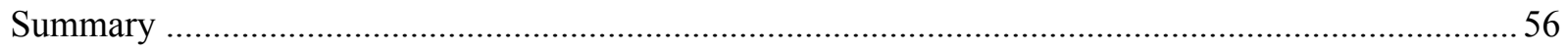

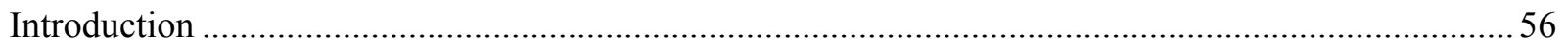

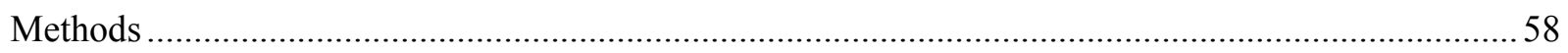

Data source

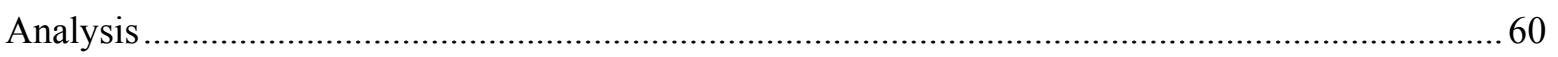

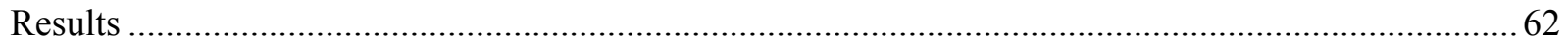

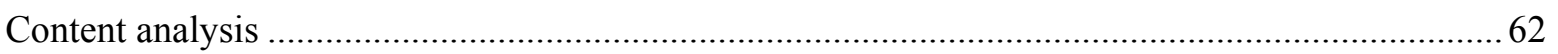

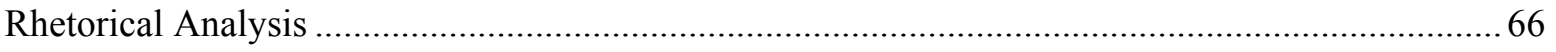

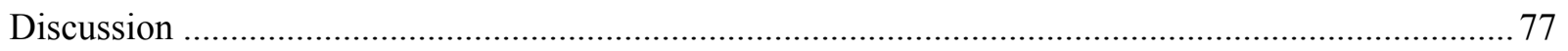

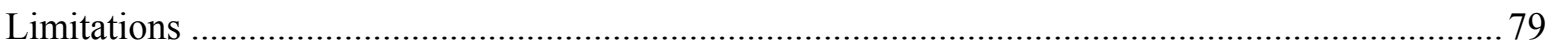

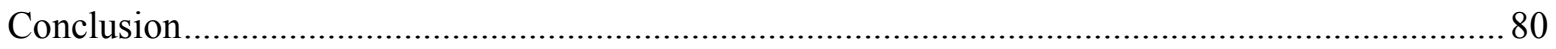

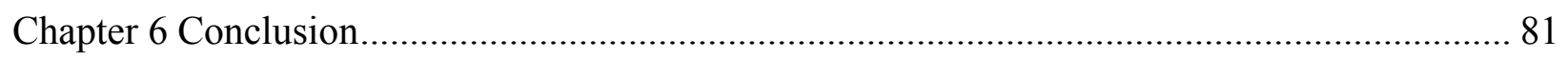

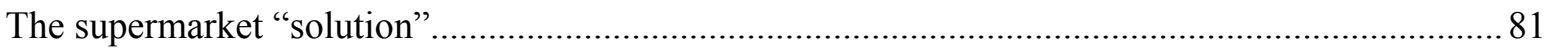

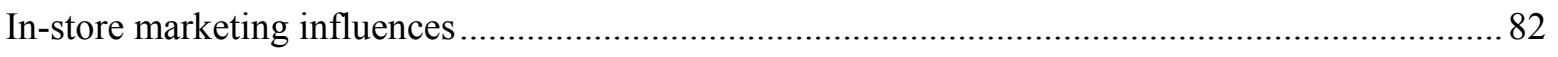

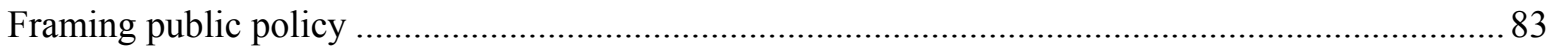




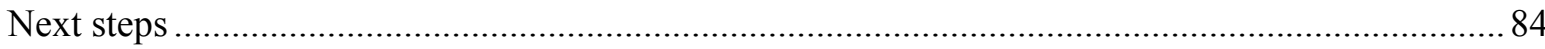

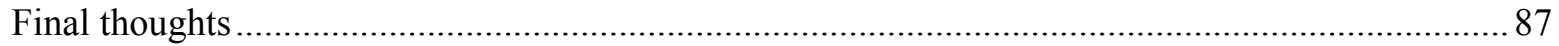

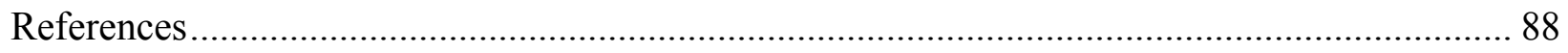

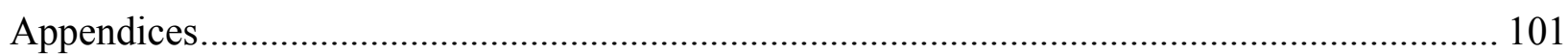

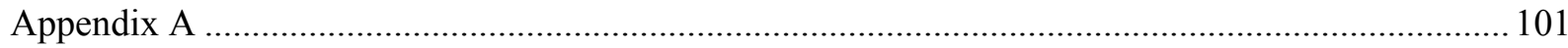

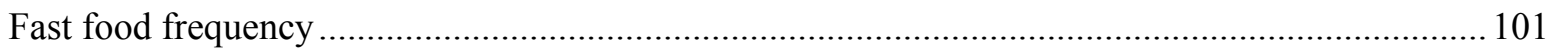

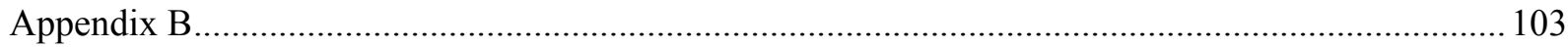

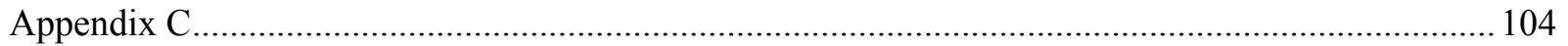





\section{Figures}

Figure 2-1. Ecological framework for healthy eating, from Story M, Kaphingst KM, Robinson-

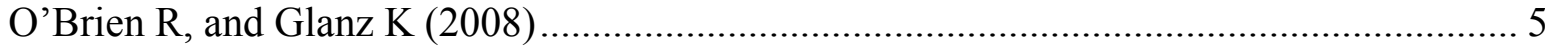

Figure 2-2. Model of Community Nutrition Environments, from Glanz K, Sallis JF, Saelens BE,

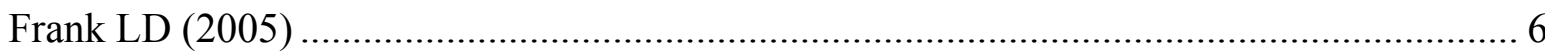

Figure 4-1 Logic model of unhealthy food promotion effects from Kelly B, King L, Chapman K,

Boyland E, Bauman AE, and Baur LA (2015) .............................................................. 36 



\section{Tables}

Table 3-1. Baseline characteristics of PHRESH sample $(n=821)$ 20

Table 3-2 Characteristics of food outlets with complete observational audits ( $\mathrm{n}=81$ ), PHRESH

2011 21

Table 3-3. Characteristics of the food environment of PHRESH sample $(n=821)$ in 2011........ 22

Table 3-4. Average marginal effects of food environment on SSB intake (oz), PHRESH 2011 . 24

Table 3-5. Odds ratios of food environment variables and moderate SSB consumption (12 oz or

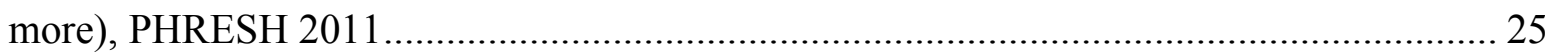

Table 3-6. Change-change model of food environment and SSB consumption (oz), 2011-2014 28

Table 4-1. Characteristics of the study sample

Table 4-2. Description of stores where participants did major food shopping and in-store marketing strategies 43

Table 4-3. Associations between in-store marketing characteristics and pestering................... 44

Table 4-4. Associations between in-store marketing characteristics and purchases (parent purchases and home availability)

Table 4-5. Associations between in-store marketing characteristics and children's SSB consumption 46

Table 4-6. Associations between children's pestering and frequency of parent purchases......... 47

Table 4-7. Associations between children's pestering and home availability of foods.............. 48

Table 4-8. Associations between purchases and children's SSB consumption......................... 49

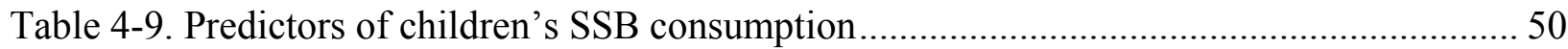

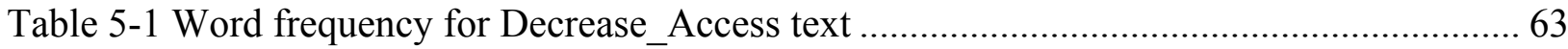

Table 5-2 Collocated words in the Decrease_Access text related to words conveying excess .... 63

Table 5-3. Themes from Decrease_Access n-gram analysis ................................................. 64

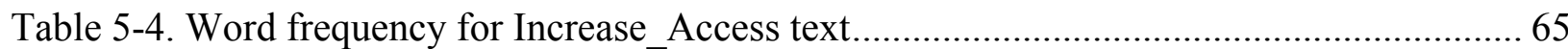

Table 5-5. Collocated words in the Increase_Access text ................................................65

Table 5-6. Themes from Increase_Access n-gram analysis.................................................. 66

Table 5-7. Average percent frequencies for clusters in Increase_Access and Decrease_Access texts

Table 5-8. Average percent frequencies of word classes in Decrease_Access and

Increase_Access texts for classes greater than 1 (10 occurrences per 1,000 words) 70

Table 5-9. Differences in frequency distributions of word classes in Decrease_Access and

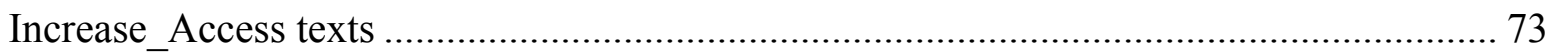

Table 5-10. Factors identified through exploratory factor analysis ...................................... 75

Table A-1. Associations between the food environment and frequency of going to a fast food

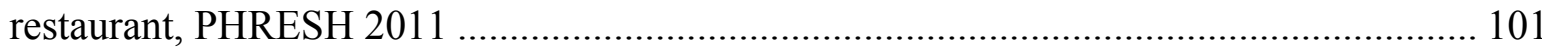


Table B-1. Factor loading for one factor maximum likelihood solution ............................... 103

Table C-1. Association between food promotion factors and total SSB consumption.............. 104 


\section{Acknowledgements}

I am eternally thankful for the support of the many people I encountered throughout my $\mathrm{PhD}$ process. This dissertation was generously funded by the Anne and James Rothenberg Award and David I.J. Wang Award and I am grateful to Jim Lovelace and his family for providing scholarship support.

My committee members, Jeanne Ringel, Tamara Dubowitz, and Karen Flórez were incredibly patient in helping me learn and grow and believing in me, always. Jeanne led the way as my dissertation chair by being an incredible mentor who taught me invaluable skills and showed me what it means to be a good researcher. I am so grateful to Tamara who implemented such an ambitious project with PHRESH and then had the generosity to let a graduate student take on a piece of it. Karen has been an incredible source of support throughout my time at RAND and I am thankful for our many conversations that motivated me and this research. I am honored that Mary Story served as my outside reader and provided incredibly helpful comments that strengthened the research.

My sincerest respect and gratitude to the entire PHRESH team, especially Bonnie GhoshDastidar, Casey Hunter, and Robin Beckman, for talking through these ideas and answering my many questions! I am deeply appreciative of Paul Heaton and Bill Marcellino for allowing me to develop my ideas in their classes and for their critical feedback.

Thanks to the many colleagues and peers who encouraged me to start this program and to the PRGS and RAND communities for fostering the skills and confidence necessary to finish it. A very special thanks to all the dissertation accountability groups and study buddies throughout the years. Nono Ayivi-Guedehoussou helped me get through that very difficult first year... and then every subsequent year since.

I am forever indebted to my family for instilling in me a love of learning and for their unwavering support every step of the way. My family and friends have been incredibly understanding throughout graduate school and this would not be possible without them. Finally, I thank Domingo and Emerald for their inspiration and unconditional love each day. 



\section{Abbreviations}

$\begin{array}{ll}\text { AME } & \text { Average marginal effect } \\ \text { ASA24 } & \text { Automated Self-administered 24-hour Dietary Recall } \\ \text { BMI } & \text { Body mass index } \\ \text { BTG } & \text { Bridging the Gap } \\ \text { EFA } & \text { Exploratory factory analysis } \\ \text { FNDDS } & \text { Food and Nutrient Database for Dietary Studies } \\ \text { FROWN } & \text { Freiburg-Brown corpus of American English } \\ \text { GIS } & \text { Geographic information systems } \\ \text { HFFI } & \text { Healthy Food Financing Initiative } \\ \text { HHI } & \text { Herfindahl-Hirschman Index } \\ \text { HHS } & \text { Health and Human Services } \\ \text { mRFEI } & \text { Modified Retail Food Environment Index } \\ \text { NCI } & \text { National Cancer Institute } \\ \text { NEMS } & \text { Nutrition Environment Measures Survey } \\ \text { NEMS-S } & \text { Nutrition Environment Measures Survey for Stores } \\ \text { NHANES } & \text { National Health and Nutrition Examination Survey } \\ \text { NYC } & \text { New York City } \\ \text { OLS } & \text { Ordinary least squares } \\ \text { OR } & \text { Odds ratio } \\ \text { PHRESH } & \text { Pittsburgh Hill/Homewood Research on Eating, Shopping \& Health } \\ \text { pOR } & \text { Proportional odds ratio } \\ \text { SSB } & \text { Sugar-sweetened beverage } \\ \text { UK } & \text { United Kingdom } \\ \text { US } & \text { United States of America } \\ \text { USDA } & \text { World Health Organization } \\ \text { WHO } & \end{array}$





\section{Chapter 1 Introduction}

Chronic disease is a serious public health issue in the United States. Approximately half of adults (ages 18+) in the United States have at least one common chronic condition such as heart disease, hypertension, stroke, diabetes, or cancer. ${ }^{1}$ Seven of the top ten causes of death are due to chronic diseases, most notably heart disease and cancer. ${ }^{2}$ More than $80 \%$ of all health care dollars are spent on patients with chronic conditions and even more costs may accrue through lost productivity. ${ }^{3}$

The burden of chronic disease disproportionately affects vulnerable groups within the US. Income is inversely related to rates of chronic disease - adults with a household income less than $\$ 35 \mathrm{k}$ had the highest rates of hypertension, heart disease, diabetes and stroke. ${ }^{4}$ In addition, racial and ethnic minorities have higher prevalence rates of chronic conditions such as hypertension and diabetes compared to whites. ${ }^{5,6}$ Outcomes for the vulnerable groups are also worse, possibly exacerbated by factors such as poor access to care. ${ }^{7-9}$ For example, racial and ethnic minorities with diabetes have worse glycemic control and blood pressure than non-Hispanic whites with diabetes and the mortality rate from hypertension for blacks is more than twice that of whites. ${ }^{10,11}$

Diet is a key modifiable risk factor for chronic diseases. The USDA's Dietary Guidelines for Americans recommends following a healthy eating pattern across the lifespan and choosing a variety of nutrient-dense foods across all food groups (including vegetables, fruits, grains, fatfree or low-fat dairy, and protein foods) and limited intake of saturated fats, sodium, added sugars, and sodium. ${ }^{12}$ Research has found that consuming fruits and vegetables reduces the risk of heart disease by $20 \% .{ }^{13}$ Diets high in whole grains can reduce the risk of heart disease, Type 2 diabetes, and colorectal cancer by as much as $20-30 \% .{ }^{14}$ Yet, the typical American eats approximately one serving of fruit and one and one half servings of vegetables each day. ${ }^{15}$ Meanwhile, adults continue to consume added sugars, such as those from sugar-sweetened beverages (SSBs) such as soda, in excess of the recommended limits, despite evidence that added sugars are linked to poor health outcomes in the general population. ${ }^{16,17}$ In one randomized study, consumption of SSBs over six months increased cholesterol, liver fat, skeletal muscle fat, and visceral fat in overweight subjects. ${ }^{18}$ There is additional evidence that reducing SSB consumption results in weight loss for heavier individuals, who are more at risk for chronic diseases. $^{19-21}$

Reducing risk of chronic diseases requires changing behaviors that notoriously difficult to alter. $^{22}$ For decades, improving nutrition was traditionally viewed as an individual problem requiring individual behavior change. In recent years, a new paradigm for health promotion - the population health approach - has emerged. The focus has shifted away from individual behavior change towards creating healthy communities by "improving the conditions in which we live, learn, work and play." 23 The potential benefits of a healthy community are at least two-fold. 
First, an intervention at the community level can reach more people than individual interventions (e.g., a nutritionist has a limited caseload and services can be expensive). Secondly, changing the community environment, may facilitate sustainability by providing the appropriate circumstances and cues to encourage positive health behaviors. Although the idea of healthy communities holds much promise, researchers and policymakers still need to understand the mechanisms and nuances of what makes communities and their residents healthy.

One aspect of the community that has been of particular interest to the research community is the physical and structural characteristics of the community. Green spaces such as parks, for example, can provide residents with opportunities for physical activity. Similarly, features of the community such as the number of fast food restaurants and the presence of a supermarket, are believed to present residents with options for healthy and unhealthy eating.

The food environment (typically defined as the physical environment, or settings, in which individuals are exposed to opportunities to eat or buy food) is a critical dimension that sets the foundation for diet and subsequent health outcomes. Many policymakers are pursuing actions to address limitations of the food environment. First Lady Michelle Obama pledged to eliminate areas without access to fresh, healthy, and affordable food, also known as "food deserts," as part of her campaign to end childhood obesity and the Healthy Food Financing Initiative (HFFI) encourages businesses to establish or expand supermarkets in low-resource neighborhoods to allow neighborhood residents greater access to healthy food choices. ${ }^{24,25}$ However, questions remain as to which features of the food environment are most important and how to accurately measure these settings. Moreover, it's unclear if and how changing the food environment will affect people's diets.

This dissertation examines the role of the food environment as a policy lever to improve diet, with a focus on sugar sweetened beverage (SSB) consumption and low-income black neighborhoods in Pittsburgh, PA. I look at different measures of the food environment and their relation to SSB consumption in adults over a 3-year period. I next look at whether in-store marketing characteristics are part of a hierarchy of unhealthy food promotion effects that influence children's SSB consumption. Then I conduct a text analysis of online comments to explore why certain policies might be popular among the public. Understanding the role of the food environment can help policymakers determine where and how to intervene to improve diet and health for a vulnerable population.

This dissertation is a monograph organized into six chapters:

1. Introduction

2. Background and literature review of the food environment and research to date

3. The food environment and sugar-sweetened beverage consumption - an analysis to identify and quantify these relationships

4. In-store marketing practices and children's sugar-sweetened beverage consumption - an examination of how the food environment may influence children's food requests, parent purchases, and children's diet 
5. Public opinions on the food environment - a case study of word usage about strategies to improve diet through increasing and decreasing food access

6. Conclusion of the findings and implications 


\section{Chapter 2 Background and Literature Review}

In this chapter, I review the underlying framework for this research, the ecological model, and then define the food environment and summarize the research to date. I review studies that have measured the community nutrition environment, the consumer nutrition environment, and the realized food environment, to establish gaps in the literature that this dissertation intends to address.

\section{Ecological Model}

Ecological models or frameworks focus on the role of contextual factors and their influence on individual behaviors. Such models can help conceptualize how to build healthy communities through multiple "spheres of influence" or levels impacting a central behavior of interest, such as smoking or physical activity. Typical models have four levels -individual, social, physical, and macro. The individual level includes intrapersonal factors, such as demographics and cognitions, which affect behaviors through motivations, self-efficacy, and expectations. The social level includes interpersonal relationships between family, friends, peers, and neighbors who affect individual behavior through modeling, social norms, and support. At the physical level, the way the environment is constructed may create barriers or opportunities that make it easier or harder to access or engage in certain behaviors. Finally, at the macro-level, "upstream" policies create large-scale systems, cultural norms, and sectors that govern the limits of healthy communities. According to this model, although the levels are nested, all the levels interact with each other (e.g., a person is influenced by the norms of her social network, but her attitudes also help define the group norms). The ecological model is a way to organize how to think about predictors of health behaviors and has been used to describe the influences of a person's dietary behaviors (see Figure 2-1). ${ }^{26}$ 


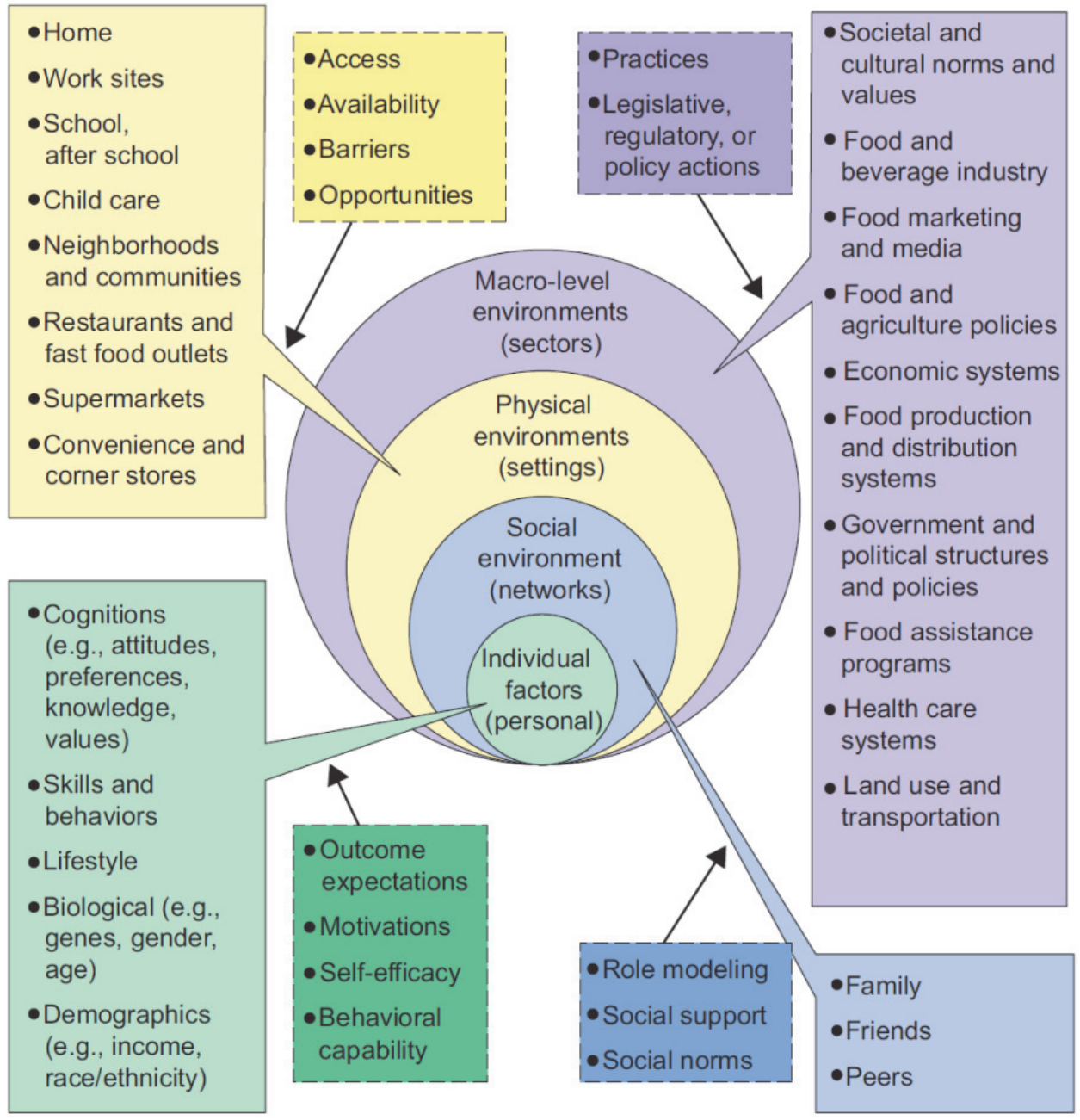

Figure 2-1. Ecological framework for healthy eating, from Story M, Kaphingst KM, RobinsonO'Brien R, and Glanz K (2008)

\section{Definition of the Food Environment}

The term food environment is specific to the physical environment, or settings, in which individuals are exposed to opportunities to eat or buy foods, such as a person's home, work or school, and food stores (e.g., supermarkets, convenience stores) and food outlets (e.g., restaurants, fast food). Glanz and colleagues have further conceptualized the food environment as the community nutrition environment and the consumer nutrition environment (see Figure 2-2). ${ }^{27}$ The community nutrition environment pertains to the distribution of food sources at the community level, such as the density of stores, whereas the consumer nutrition environment pertains to what the consumer faces - namely, the characteristics of those stores, such as product availability, quality and price. Both constructs can be measured in multiple ways. 


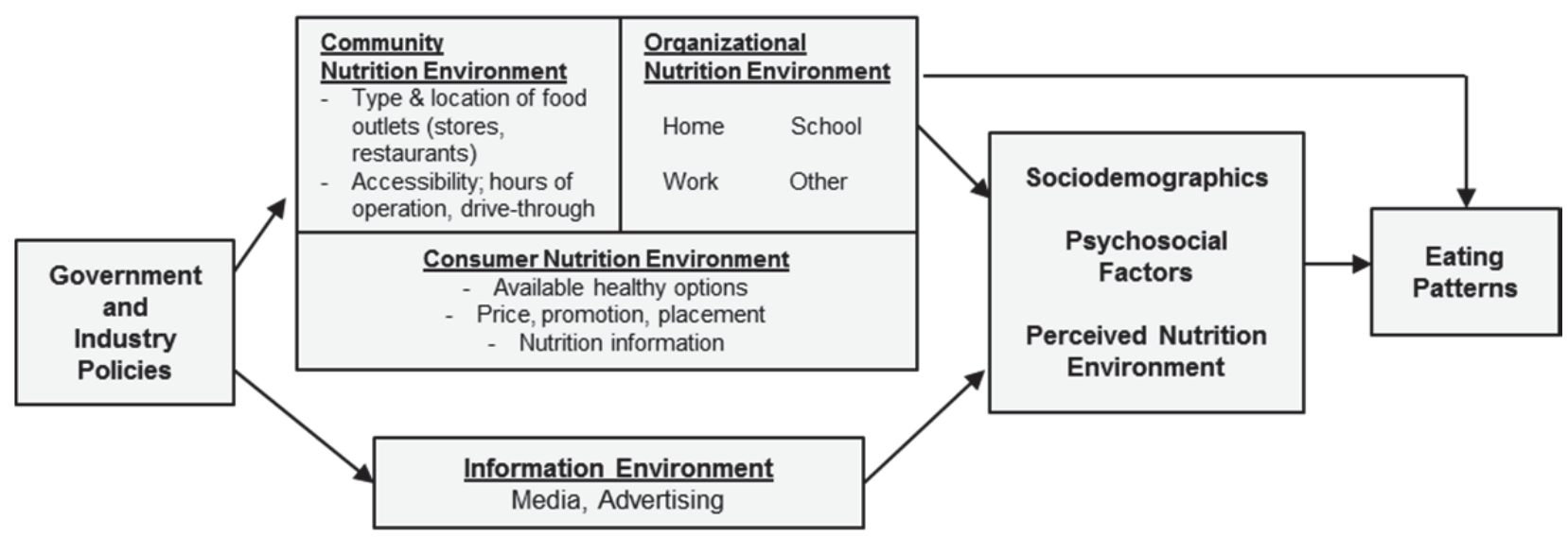

Figure 2-2. Model of Community Nutrition Environments, from Glanz K, Sallis JF, Saelens BE, Frank LD (2005)

The community nutrition environment has mainly been studied in the U.S. by examining the "type" and location of food outlets. Food outlets include both retail food stores and restaurants. Retail food stores that have commonly been studied include supermarkets and small grocery stores or convenience stores. Supermarkets - large chain stores that sell a large variety of foods and provide additional services such as bakeries, butchers, and delis - are generally considered "more healthy" retailers while convenience stores are perceived as "less healthy" retailers. Restaurants are frequently categorized as either sit-down or fast food, a distinction based on whether orders are taken and paid for at the table (sit-down) or at the counter (fast food). The location of food outlets can be assessed with density or proximity measures. ${ }^{28}$ Density is typically defined as the number of food outlets within a prescribed area (e.g., census tract, residential buffer) and proximity is either a geographic distance or travel time. Examples of community nutrition environment measures include presence of a convenience store within a respondent's zip code, number of fast food outlets in a $0.5 \mathrm{mi}$ buffer around a residential address, and street distance to the closest supermarket. Community nutrition environment measures are often used in research studies due to the ease of measurement - business directories and government listings often provide information necessary to categorize the type of store (through industry categories or codes) as well as the location (through street addresses). However, these secondary data sources result in biased findings based on inaccurate counts and misclassification of food stores. ${ }^{29}$

The consumer nutrition environment has been defined as "what consumers encounter within and around a retail food outlet." 27 These measures are typically assessed observationally with a 
standardized tool or audit, such as the Nutrition Environment Measures Survey (NEMS) or the Communities of Excellence in Nutrition, Physical Activity and Obesity Prevention $\left(\mathrm{CX}^{3}\right)$ Field Survey. ${ }^{30-32}$ Characteristics relevant to food stores might include availability, price, and quality or the marketing mix of 4 P's - product, price, placement, and promotion. Common food items or categories assessed in food stores include fruits, vegetables, meat, milk, whole grains, snack foods, and sugar sweetened beverages (SSBs). Characteristics relevant to restaurants are less common in the literature, but might include availability of healthy options and nutrition information, such as calorie labels. While the community nutrition environment measures assume that venues within a category (e.g., supermarket, fast food) are identical, the consumer nutrition environment measures are able to capture variation between outlets, such as if the price of produce is higher at Supermarket A than Supermarket B or if Restaurant C has 5 salad options when Restaurant D offers none. The consumer nutrition environment is more difficult to quantify and observational assessments are more time-consuming and expensive, however, these measures can potentially explain variation in consumer outcomes as well as provide suggestions for small-scale interventions (e.g., putting healthy items near the register).

The rapid development of this field of study has resulted in a large number of instruments, however no singular tool has been adopted for universal use. Ohri-Vachaspati and Leviton have pointed out the added complexity stemming from different groups - researchers, practitioners, and community organizations - creating and using the measures for divergent purposes. ${ }^{33}$ Furthermore, few studies have compared the growing number of measures assessing the food environment and although a number of measures have high reliability, the validity of how well these measures capture which characteristics of the food environment is unknown. ${ }^{33,34}$

\section{Food Environment and Diet: Is there a relationship?}

Following an ecological model, the food environment may impact dietary behaviors by making certain opportunities for food more or less accessible. However, whether and to what extent elements of the food environment affect diet is still an unanswered empirical question.

\section{Corner stores}

Interventions in corner stores - small businesses, often in urban neighborhoods, that sell a limited number of foods and convenience items - have provided a substantial amount of information about how changes in the food environment might impact diet. Policies such as the HFFI encourage both new infrastructure (e.g., supermarket construction) as well as improvements in existing infrastructure, such as the expansion of corner stores to provide fresh produce. Corner stores in particular may be an important intervention point for improving the diets of urban shoppers. Surveys of more than 9000 customers at almost 200 corner stores in Philadelphia found that most corner store purchases were for high calorie, low nutrition foods

such as SSBs, chips, and candy. ${ }^{35}$ A smaller study in New York City found similar results. ${ }^{36}$ 
However, this is little evidence to support the effectiveness of corner store interventions. A structured review of corner store interventions found mixed evidence - four studies found increases in overall sales or individual purchases of healthy foods while two studies found no effect. ${ }^{37}$ A more recent intervention study not included in the review found no changes in calories, nutrient content, or purchase amount one year after a corner store intervention. ${ }^{38}$ While a few groups have attempted to address these limitations through quasi-experimental and randomized study design, the empirical support for such interventions remains weak. ${ }^{39,40}$ One study, which followed students at schools where nearby corner stores received an intervention and students at schools where nearby corner stores did not receive an intervention, found no differences in students' weight or nutritional content of purchases after one year. ${ }^{39}$ Another study looked at customers of tiendas (Latino food stores) that received an intervention to promote fruits and vegetables and found customers from stores who received the intervention first reported almost one more serving of fruits and vegetables after four months, although this trend was only marginally significant. ${ }^{40}$

\section{Supermarkets}

Corner stores may be a source of convenience or snack foods for urban shoppers, but supermarkets tend to be the place where people do their major food shopping. In one study, 95\% of participants did their primary food shopping at a chain supermarket. ${ }^{41}$ Researchers in Philadelphia found having a high quality supermarket (as measured by the NEMS-S) and valuing convenience and price were associated with increased prevalence of shopping closest to home. ${ }^{41}$ Randomizing supermarkets to study their effects is unfeasible; instead, researchers have typically taken advantage of natural experiments or longitudinal data.

\section{Quasi-experimental studies}

Only a handful of natural experiments have been conducted to date. One study in the UK found no effect of a new full-service supermarket in a low-resource community on dietary patterns compared to a similar "control" community, however the sample of respondents completing the mail-in survey already demonstrated above average fruit and vegetable consumption at the start. ${ }^{42}$ An earlier study, also in the UK, found that respondents who started shopping at the new supermarket consumed 23\% more fruits and vegetables than they had previously, but this study lacked a comparison group. ${ }^{43}$ A more recent natural experiment in Philadelphia (PA) found that residents' perceptions of the food environment, but not eating habits, changed after the introduction of a supermarket, although the 6-month follow-up period may have been too short to expect large changes in dietary behaviors. ${ }^{44}$ A similar study in Pittsburgh (PA) also found changes in perceptions, but an improvement in diet quality could not be attributed to shopping at the new supermarket. ${ }^{45}$ 


\section{Longitudinal studies}

One longitudinal study using the Coronary Artery Risk Development in Young Adults (CARDIA) cohort looked at the availability of fast food chains, supermarkets, and small grocers around people's residences and their diets over a 15 -year period. ${ }^{46}$ The researchers found a relationship between more fast food availability and more fast food frequency, but not supermarkets and diet quality. ${ }^{46}$ In a structural equation analysis of the same cohort, researchers found no relationship between availability of supermarkets and convenience stores and dietary behaviors, including SSB intake. ${ }^{47}$ A study of adolescents in London, England looked at retail food outlets (including food stores and fast food) near the adolescents' schools over a 4-year period and found very small but significant effects indicating that further distance to a retail food outlet promotes healthy diet behaviors (such as fruit and vegetable intake and breakfast consumption) and further distance to a fast food outlet discourages unhealthy diet behaviors (such as consumption of fried foods, SSBs, and snacks). ${ }^{48}$

\section{Cross-sectional studies}

With the exception of the studies just discussed, the vast majority of research has been crosssectional in nature, lending the findings to associations at best. Further, the multiple ways of defining and measuring the food environment has produced a heterogeneous body of literature that is briefly summarized below.

\section{Community nutrition environment}

The community nutrition environment has been most studied in relation to diet, but no consistent relationship has emerged.

Black, Moon, and Baird (2013) examined over 40 original research articles examining relationships between the community nutrition environment and adult diet. ${ }^{49}$ Among 31 articles using measures of density (e.g., presence or number of food outlets within a specified area), 20 of the studies identified at least one significant positive association between density and diet in the expected direction (e.g., greater density of green grocers is associated with better dietary quality). Thirteen of 24 articles reviewed had no significant association between proximity (distance from the participant's home to the food outlet) and diet. Overall, these studies often tested multiple environmental measures and/or dietary outcomes, the majority of which had had no association.

Engler-Stringer et al. (2014) focused on 26 studies of children under 18 years of age. ${ }^{50}$ Sixteen of these studies used GIS-based measures for the food environment, either using the participant's home or school address as the reference location. The reviewed studies did not consistently find associations between the food environment and diet. For example, of the 15 studies that measured availability (presence, counts, or density) of food stores, four had null findings and 11 had significant findings, however three of those had associations in the unexpected direction. Similarly, of the 14 studies that examined proximity, three had null 
findings and 11 showed associations, but five of those studies had associations with an inconsistent direction.

\section{Consumer nutrition environment}

Several studies have used observational audits to document the availability, price, and quality of different products as a measure of the consumer nutrition environment, but these studies also yield mixed results.

In their recent review, Black, Moon, and Baird (2013) also examined 20 studies using instore audits. ${ }^{49}$ Eleven studies examined 38 possible relationships between in-store availability of foods and dietary quality and found only 9 associations in the expected direction as well as 2 in the unexpected direction. Price yielded an even more complicated story -28 outcomes were examined and 12 demonstrated no relationships with price, five showed relationships in the expected direction, and 11 reported relationships in the unexpected direction (that better diets were associated with healthy foods being more expensive).

Studies have used different tools to measures the consumer nutrition environment. A common method is to measure the amount of space within food stores (shelf space) dedicated to certain products. These results have also been mixed. In one study, each additional meter of vegetable shelf space was associated with consumption of 0.35 additional servings of vegetables, but no similar association was found for fruit. ${ }^{51}$ Studies using checklists that record the presence or number of certain food products, have similar inconsistencies. Edmonds and colleagues (2008) looked at both store and restaurant availability of fruit, vegetables, and fruit juices, and found a positive relationship between fruit juices and restaurant availability only. ${ }^{52}$ Izumi and colleagues found that residents in neighborhoods with stores carrying five or more types of dark green and orange vegetables consumed 0.17 more servings of these vegetables than residents in neighborhoods without such stores. ${ }^{53}$ Two studies used a composite measure of food store quality, the Nutrition Environment Measures Survey for Stores (NEMS-S), but neither found associations with diet. ${ }^{54,55}$

\section{Realized vs. potential food environment}

Another source of variation in the literature may be due to how the food outlets are linked to individual diets. Almost all studies use measures of the potential environment by defining the food environment as all outlets within geographical boundaries, such as buffers around an individual's residence of a certain distance (e.g., $0.5 \mathrm{mi}$ ) or a predefined area (e.g., census tract, zipcode). However, the realized environment, considers only the food outlets the individual reports shopping at or patronizing. One limitation of examining the realized environment is potential selection bias - people who drive 10 miles to go to a supermarket are likely different from their neighbors who take the bus to the closest store. Still, considering the characteristics of the realized environment is important to understanding the full range of opportunities available 
to a person. Few studies have looked at the realized environment in relation to individual diet. $^{41,56-59}$

Both Cannuscio et al. (2013) and Aggrawal et al. (2014) found that approximately one-third of people do their primary shopping at the supermarket closest to them. ${ }^{41,57}$ Distance to the primary food store was not related to diet. ${ }^{56-58}$ For example, Fuller et al. (2013) found that distance, even when stratified by mode of transportation, was not associated with fruit and vegetable consumption. ${ }^{56}$

A few studies used consumer nutrition environment measures to assess the realized food environment. ${ }^{57-59}$ In two of the three studies, store characteristics predicted dietary intake. ${ }^{57,59}$ Aggrawal et al. (2014) found that participants who shopped at high cost supermarkets (assessed by pricing items in a market basket) consumed 0.76 more servings of fruits and vegetables than participants shopping at low cost supermarkets. ${ }^{57}$ Gustafson and colleagues asked 121 adults in Lexington (KY) where they did their primary food shopping and found that adults who did their shopping at specialty stores and farmers markets were more likely to consume fruits and vegetables 2 or more times a day $(\mathrm{OR}=1.60,95 \% \mathrm{CI}: 1.21,2.79)$ and adults who shopped at super centers were less likely to consume sweetened beverages $(\mathrm{OR}=0.27,95 \% \mathrm{CI}: 0.09,0.83) .{ }^{59} \mathrm{In}$ contrast, one study found no significant relationship between proximity to the preferred food store and fruit and vegetable intake. ${ }^{58}$

\section{Summary}

To date, there is no clear picture of the relationship between the food environment and diet. Studies have varied in how they define the food environment, the outcomes of interest, and the methods of testing the associations. The goal of this dissertation is to further the research in this field by examining multiple characteristics of the food environment using rich data from a natural experiment. This research will help inform whether there is a relationship between the food environment and diet, as well as what aspects of the food environment are important whether the consumer, community, realized, or potential characteristics are most strongly linked. Taken together, the empirical analyses and examination of public opinions, will help identify meaningful policy levers for improving diet at a population level. 


\section{Chapter 3 Sugar-Sweetened Beverage Consumption and the Food Environment}

\section{Summary}

Introduction. Americans consume more than the recommended daily amount of added sugars, often from sugar-sweetened beverages (SSBs). Researchers have examined the relationship between the food environment (typically defined as the physical environment, or settings, in which individuals are exposed to opportunities to eat or buy food) and SSB consumption with mixed results.

Methods. This study examines whether four dimensions of the food environment - distance from the participant's residence, store and restaurant density, shopping frequency, and characteristics of the store for major food shopping - are associated with SSB consumption by capitalizing on data from the Pittsburgh Hill/Homewood Research on Eating, Shopping \& Health (PHRESH) study. PHRESH data includes household surveys from a randomly selected cohort, including 24-hr dietary recalls (averaged over two time points) and observational audits of all food retail outlets in the neighborhood as well as venues where residents reported doing their major food shopping for two time points (2011 and 2014).

Results. More than 25 food environment variables across the four domains were tested for cross-sectional associations at baseline. Only the frequency of going to a fast food restaurant was positively associated with SSB consumption, however this relationship did not hold in the longitudinal analyses examining the changes in the food environment and changes in SSB consumption between 2011 and 2014.

Conclusion. Policies such as the Healthy Food Financing Initiative (HFFI) which provides technical and financial assistance for food retail infrastructure may not improve SSB consumption. Future research on new policies that change the food environment may shed light on what factors reduce SSB consumption.

\section{Introduction}

Americans consume between 12-16 percent of their daily calorie intake in added sugars. ${ }^{16}$ Health officials and medical professionals advise consuming less than $5-10 \%$ of daily calories from added sugars. ${ }^{12}$ One common source of these calories is from sugar-sweetened beverages (SSBs) such as carbonated sodas and fruit-flavored juice drinks, which may contain up to 10 teaspoons of sugar (140 calories) in a 12-oz can. Frequent consumption of sugar-sweetened beverages is linked to numerous health risks and poor health outcomes, such as type 2 diabetes, high blood pressure, and weight gain. ${ }^{17,60}$ Although SSB consumption has declined in recent 
years, Americans are still consuming more added sugars than recommended with the majority of these added sugars coming from SSBs. ${ }^{16,61,62}$

There has been much effort in recent years to draw attention to the negative consequences of SSB consumption through education campaigns and SSB-specific legislation designed to reduce SSB consumption, such as taxes on SSBs and the so-called "soda ban. ${ }^{, 63-65}$ New York City, for example, has addressed SSB consumption through a variety of approaches resulting in decreases in the number of adults and high school students drinking SSBs each day. ${ }^{63}$ In 2011, Multnomah County (Portland) launched a mass media campaign that resulted in raising awareness about the amount of added sugars in beverages. ${ }^{66}$ More recently, Mexico became the largest jurisdiction to pass a soda tax, and evaluations to date indicate success in reducing SSB purchases by $6-12 \%$ in the year following implementation. ${ }^{67}$ In a country where the annual per capita consumption of soft drinks is $137 \mathrm{~L}$ (or 36.2 gallons), ${ }^{68}$ this reduction is likely to have substantial public health benefits.

There has been considerably less attention to the potential unintended effects of other food policies on SSB consumption. For example, policymakers have proposed building new supermarkets in so-called "food deserts" - low-income neighborhoods with poor geographic access to supermarkets - based on a large body of cross-sectional research identifying a link between closer proximity to supermarkets and positive health and diet outcomes. ${ }^{24}$ However, the few longitudinal studies that have looked at causality have found no relationship between new neighborhood supermarkets and weight outcomes; ${ }^{43-45}$ although one study did see higher dietary quality after the supermarket opened, this could not be attributed to use of the supermarket. ${ }^{45}$ It's still not clear whether adding supermarkets will result in improving health and it's quite possible that supermarkets could make outcomes worse. Rapid transitions away from traditional fresh or wet markets to supermarkets could also increase the supply of processed and energy-dense goods at low prices, and encourage diets linked to chronic diseases; ${ }^{69,70}$ however these changes are often observed in developing nation settings where the effects of modernization, urbanization, and/or general economic growth are difficult to separate from that of the retail food environment.

Measuring the food environment (typically defined as the physical environment, or settings, in which individuals are exposed to opportunities to eat or buy food) has previously involved many different measures and methodologies. ${ }^{49,71,72}$ Although the food environment extend broadly to settings including schools, workplaces, and early child care centers, ${ }^{26}$ most commonly, researchers have used residence-based measures of the food environment that look at distance (e.g., miles to the nearest supermarket) and density (e.g., number of supermarkets within a 1-mile radius) of stores in the geographic area where people live. A few have looked at storelevel measures, such as in-store product availability and relative price of foods, however it is rare for studies to examine both simultaneously.

Although there have been many studies of the relationship of general community and consumer food environment measures and SSB intake, they seldom look specifically at the environment related to SSBs, such as the marketing of or availability of SSBs. Those that have 
are typically studies of children and adolescents and measured aspects of the home environment or school environment, such as whether SSBs were available in vending machines. ${ }^{73,74}$

Fewer studies have looked at the effect of the SSB environment on adults. One study of adults looked at a worksite-based weight-loss intervention study where the SSB environment was evaluated with the Checklist of Health Promotion Environments at Worksites (CHEW) and documented the number of soft drink vending machines, number of regular soda slots, number of water coolers, and number of water fountains on site. ${ }^{75}$ The study found that both the number of water coolers and soft drink vending machines were associated with slightly higher SSB intake.

The overall effect of food marketing on adult outcomes has been less studied than for children's outcomes. One systematic review found only nine experimental studies of the effects of commercial food advertising on food-related outcomes such as intake and willingness to pay, and was not able to make any definitive conclusions. ${ }^{76}$ Health research on in-store marketing strategies is even more uncommon. Cohen and colleagues looked cross-sectionally at the exposure to end aisle displays, special floor displays, cash register displays, and price reductions by store type and shopping type (major or convenience) and found no association with overall diet, but a few associations with BMI. ${ }^{77}$

Research on alcohol and tobacco marketing may provide additional insight on how to measure exposure to unhealthful products. One review of audit methods for point of sale tobacco marketing described the use of "marketing mix" principles - the 4 P's of product, promotion, placement, and price - in assessing the tobacco marketing environment. ${ }^{78}$ These audit tools measured the presence and variety of tobacco products as well as the presence, count, or scaled measure of advertisements, signs, displays, branded items, shelving, promotional gifts, and size of advertisements.

As more jurisdictions look to policies that change the food environment to reduce obesity and improve diet, it's important to evaluate whether, and to what extent, the food environment is related to SSB consumption. This study builds upon the previous literature and combines both community and consumer measures of the food environment to describe the opportunities for buying and consuming SSBs in two low-income neighborhoods in Pittsburgh, PA. This study then investigates what aspects of the food environment are associated with SSB consumption and does the environment and SSB consumption change over time using a unique data set that follows individuals and their environments over three years.

\section{Methods}

Data comes from a larger study, the RAND Pittsburgh Hill/Homewood Research on Eating, Shopping \& Health (PHRESH), a natural experiment longitudinally examining the impact of a new full-service supermarket on diet and obesity in a predominantly low-income, African American, urban neighborhood in Pittsburgh. PHRESH is a five-year study funded by the National Institutes for Health and the National Cancer Institute (R01CA149105 NIH/NCI; PI: 
Tamara Dubowitz). The study capitalizes on a natural experiment whereby the Hill District, an area comprised of six census tracts located 100-250 ft. above its bordering neighborhoods, received a new $\$ 8.5 \mathrm{M}$ community development project, consisting mainly of a full-service supermarket. This development project was a large, public-private collaboration funded in part by the Healthy Food Financing Initiative. The Homewood neighborhood, comparable in demographic and geographic isolation, did not receive an investment or have a full-service supermarket, thereby serving as a comparison. Data from these analyses consist of two parts: 1) observational measures of food stores and restaurants, and 2) household surveys that included two administrations of 24 hour individual dietary recalls and questions about neighborhood perceptions, social support, and health beliefs. PHRESH field staff were selected in conjunction with community partners and participated in a week-long training, including practice sessions with all of the measurement instruments, and completed a certification process prior to data collection. Data were collected in 2011 (baseline) and in 2014 (follow-up) approximately six to fourteen months after the opening of a new supermarket in the Hill neighborhood. At follow-up, 831 of the 1,272 individual households who participated at baseline were re-interviewed (65.3\%). All study protocols were approved by the RAND Corporation's Institutional Review Board.

\section{Data Sources}

\section{Household surveys}

Households from the two neighborhoods were randomly selected based on geographic location within the neighborhood; data collectors enrolled households through in-person door-todoor recruitment at baseline between May and October of 2011. The primary food shopper in the household was invited to complete a questionnaire and dietary recall. Households closer to the site of the new supermarket (within 0.25 miles) were oversampled. A total of 1,372 households participated in the baseline data collection and 831 of those households participated in the follow-up data collection (65.3\%). The questionnaire included six domains (neighborhood, food availability and purchasing, food security, demographics, sociocultural and psychosocial factors, and health status).

Sociodemographic characteristics included in this analysis include age, race (whether the participant identifies as black/African American), highest level or education (less than high school, high school graduate, some college, or college graduate), marital status (never married, married or living with a partner, or widowed or divorced), whether there are any children (under 18 years) living in the household, and total household income adjusted for the number of people living in the household.

Participants provided the name and address of the stores they visited most often for major food shopping, fruit and vegetable shopping, and convenience or small food shopping, as well as the number of times they visited these stores in the past month. Participants were also asked 
general questions about how often they go to different types of stores when they bought food and how often they went to different types of restaurants when they bought meals outside the home.

Individual dietary recall

Trained PHRESH staff assisted respondents with completing the dietary recall on a laptop following completion of the household survey. The dietary recall was collected using the Automated Self-administered 24-hour Dietary Recall (ASA24), a web-based tool created by the National Cancer Institute (NCI). More details on the development and validity of the ASA24 can be found elsewhere. ${ }^{79}$ The ASA24 builds from the USDA's Automated Multiple-Pass Method (AMPM) and follows the following steps. First, respondents are asked to create a list of foods and drinks consumed during each meal and snack. Second, respondents are asked about potential gaps during the 24-hour period. In the third step, respondents return to their list of foods and are asked for clarifying details (e.g., portion size, cooking preparation). During the final review, respondents are prompted to review their list of foods and add or edit as necessary. There is one more "last chance" opportunity to add or edit after the final review. Finally, respondents are asked whether the amount of food consumed was typical. A second 24-hour dietary recall was administered 7-10 days later. Dietary recall data was averaged and total SSB intake (in ounces) for each individual was calculated based on the sum of reported portion sizes for drinks matching the Food and Nutrient Database for Dietary Studies (FNDDS) food codes for regular soft drinks, fruit drinks, and presweetened teas. Participants with total SSB intake of 12 ounces or more per day were classified as "SSB drinkers." Twelve ounces corresponds to a typical can of soda and has been used as a benchmark in other research. ${ }^{80}$

Geographic information systems (GIS) measures

Spatial or GIS measures were also calculated relative to the participant's residence. Survey participants were asked for their home address and the name and location of their store for major food shopping for street network distance measures. Addresses of all food stores and restaurants within the neighborhood were obtained through field census by trained staff. Addresses were geocoded to a position along the street network using the 10.0 U.S. Streets Address Locator within ArcGIS 10 (ESRI, Redlands CA). Street network distances in miles were computed from each participant's home to each food store and restaurant, using the shortest route participants could drive along the existing road network.

\section{Observational measures of food outlets}

Data were collected on all food stores and restaurants in the two neighborhoods using adapted versions of the Bridging the Gap (BTG) food store and restaurant observational audit forms. ${ }^{81}$ Audits were also completed in the ten food stores outside of each neighborhood that residents reported shopping at most frequently at time of the interview. 
The Food Store Observation Form assessed availability, pricing, and in-store marketing of common foods, including SSBs, at food stores such as supermarkets, convenience stores, and supercenters/wholesale clubs. The Restaurant Observation Form assessed availability of foods and beverages, marketing features, and provision of nutrition information in fast food and sitdown food service establishments.

For this study, aspects of the store used in our analysis included the store type (e.g., supermarket, convenience store), whether SSBs were available at checkout, whether SSBs were visible from the main entrance, the number of in-store displays promoting SSBs, and the relative price of common items. Restaurant characteristics showed little variability in terms of SSB availability and marketing, and thus were not used.

If a store was not audited, we assigned store type based on store name and publically available information and assumed no marketing strategies (i.e., values of zero for all variables) - this assumption could affect analyses using the characteristics of the store for major food shopping, however is a conservative assumption that would underestimate an effect. If a store existed during both data collection time points (2011 and 2014), but was not audited during one of the time points (a total of three stores at baseline and three stores at follow-up), the store type and marketing strategies were assumed to be the same in both years (e.g., no SSBS available at checkout in both years) so that it does not contribute to estimates of change. Restaurants were classified as fast food restaurants if orders were placed, paid for, and picked up at the counter, based on the Restaurant Observation Form and a review of publically availability information, such as whether there were

\section{Food environment variables}

Food environment variables were derived from combining information from the household surveys, geolocation, and audits mentioned above. We looked at four dimensions of the food environment - distance from the participant's residence, store and restaurant density, shopping frequency, and characteristics of the store for major food shopping.

Distance: Distance was calculated to the nearest food store, nearest supermarket, nearest corner store, nearest restaurant, nearest fast food restaurant, from the participant's residence. Information from the observational measures of food outlets was used to identify stores with SSBs at check-out, SSBs visible from the main entrance, and SSB displays, and the distance to the closest store with that characteristic were calculated, respectively, to create three variables. Distance to the closest store with SSB marketing was the distance to the closest store with any of the three SSB marketing characteristics (checkout, main entrance, or display) as a fourth variable.

Store and restaurant density: Density was calculated as the count of specific outlets within a radius of the individual's residence. Density of stores, supermarkets, corner stores, stores with any SSB marketing, stores with SSBs at checkout, stores with SSBs visible from the main entrance, stores with any SSB displays, restaurants, and fast food restaurants was calculated as 
the number of outlets within a 0.25 mile buffer. The buffer size of 0.25 mile was selected to be consistent with other literature and matches the typical distance considered walkable. ${ }^{82-85}$ The modified Retail Food Environment Index (mRFEI) has been used as a way to calculate the relative density of healthy food outlets in a region. The mRFEI was calculated for each participant's $0.25 \mathrm{mi}$ buffer as:

$\mathrm{mRFEI}=\frac{\# \text { of supermarkets, supercenters, wholesale, and farmstand retailers }}{\# \text { of supermarkets, supercenters, } \text { wholesale, farmstand, convenience, and fast food retailers }} \times 100$

Shopping frequency: Frequency was recorded based on self-report of going to supermarkets, convenience stores, neighborhood stores in the household survey. For each type of store, participants were asked "When you want to buy food, how often do you go to (type of store)?" and provided examples of the type of store. Response options included: $1=$ "Never", $2=$ "Occasionally", 3 = "Sometimes", and 4 = "Often". Participants were also asked "When you buy a meal, how often do you go to a fast food restaurant?" Response options included: 1 = "Never", $2=$ "Less than once a week", 3 = "1-2 times a week", 4 = "3-5 times a week", and 5 ="More than 5 times a week." The latter two categories were collapsed into one category representing fast food frequency of "3 or more times a week."

Characteristics of the store for major food shopping: Store characteristics were based on the primary store where participants indicated doing their major food shopping in the household survey. The store was classified as a full-service supermarket based on store observation and meeting the following criteria: 1) sells fresh meat, 2) has a large variety of fresh fruit and vegetables, 3) has at least two staffed services (i.e., combination of butcher, bakery, and/or deli). The number of SSB displays came from the total number of end-aisle displays, special floor displays, price reductions/promotions, and cash register displays promoting SSBs that were counted during the store observation. If a display was an end-aisle display and a price reduction/promotion display, it counted as both. Exposure to SSB displays was calculated as the number of SSB displays at a participant's main store for food shopping multiplied by the number of times a participant shopped at that store in the past month. The observer recorded whether the store had SSBs at checkout or SSBs visible from the main entrance was based on the store observation. Prices from common staple items, junk foods, and fruits and vegetables were used to create a standardize price index for stores where participants indicated they did their major food shopping. A more detailed explanation of the standard price index is available elsewhere. ${ }^{86}$ Stores were characterized as low-price or high-price depending on whether the price index was below or above the median, respectively.

\section{Analyses}

We used regression analyses to test associations between each food environment variable with SSB consumption at baseline. General linearized models with a gamma family and log link were used for models with SSB consumption as the continuous outcome due to its long right-tail or skew. Logistic regressions were used when the SSB consumption outcome was binary (i.e., 
moderate SSB drinker). The average marginal effect (AME), which represents the average instantaneous rate of change and can approximate the change in the outcome with a one-unit change in the predictor, were also calculated.

We also employed a change-change model to quantify whether changes in the food environment variable were associated with changes in SSB consumption. Change-change models have been used to explore how changes in diet are associated with changes in weight. ${ }^{87-89}$ These models assume that changes have the same effect regardless of the initial characteristics (e.g., changes in SSB environment variables will have the same effect on consumption regardless of how much the individual was consuming at the baseline).

Changes were calculated as the Post (2014) value minus the Baseline (2011) value. The change-change model is as follows:

$$
\Delta Y_{i}=\beta_{0}+\beta \Delta X_{i}+\gamma Z_{i}+\varepsilon_{i}
$$

$\Delta Y_{i}=$ change in sugar-sweetened beverage consumption for participant $i$ (Time $2-$ Time 1$)$

$Z_{i}=$ vector of demographic variables for participant $i$ (e.g., race, sex)

$\Delta X_{i}=$ change in SSB food environment variables(e.g., number of SSB displays) for participant $i$ (Time 2 - Time 1)

$\beta_{0}=$ intercept

$\beta=$ vector of slope coefficients for each change in SSB food environment variable

$\gamma=$ vector of slope coefficients for demographic variables

$\varepsilon_{i}=$ unobserved error

Missing values for age, income, and education were imputed with the software IVEWare in SAS macros (version 0.2, 2009, Software Survey Methodology Program at the University of Michigan's Survey Research Center, Institute for Social Research, Ann Arbor). Attrition weights were calculated as the inverse probability of response at follow-up given sociodemographic and baseline characteristics. We used Bonferroni's correction to account for inflation of type 1 error rate due to multiple hypotheses testing. Hill and Homewood participants were pooled together for all analyses. All analyses were conducted in Stata (version 11, Statacorp). All analyses include control variables for sex, African American, whether children in household (0/1), highest education level, marital status, age, and adjusted income. In addition, analyses including consumer food environment characteristics control for whether the store for major food shopping was a full-service supermarket. 


\section{Results}

\section{Participants}

A total 811 individual completed 2011 and 2014 surveys and provided geographic information (home address). Participants were predominantly female (78\%) with a mean age of 54.6 years. Participants were very low-income, with an average per capita household income of $\$ 13,412$. Participants consumed, on average, 12 ounces of SSBs daily, however a quarter (28\%) of participants reported zero SSB consumption. Additional sociodemographic factors are described in Table 3-1.

Table 3-1. Baseline characteristics of PHRESH sample ( $n=821)$

\begin{tabular}{|c|c|c|}
\hline & Frequency & $\%$ \\
\hline Female & 636 & 77.5 \\
\hline \multicolumn{3}{|l|}{ Race } \\
\hline Black/African American & 777 & 95.5 \\
\hline Other & 37 & 4.5 \\
\hline Any children in household & 222 & 27.0 \\
\hline \multicolumn{3}{|l|}{ Education } \\
\hline Less than HS & 100 & 12.2 \\
\hline HS graduate & 329 & 40.1 \\
\hline Some college & 273 & 33.3 \\
\hline College graduate & 119 & 14.5 \\
\hline \multicolumn{3}{|l|}{ Marital status } \\
\hline Never married & 141 & 17.3 \\
\hline Married / Living with a partner & 337 & 41.2 \\
\hline Widowed / Divorced & 339 & 41.5 \\
\hline Mean age in years ${ }^{a}$ & 54.6 & 15.7 \\
\hline Mean annual household income $(\$)^{a}$ & $13,412.2$ & $13,515.5$ \\
\hline Mean no. trips to main food store, past month ${ }^{a}$ & 2.2 & 1.6 \\
\hline \multicolumn{3}{|l|}{ SSB consumption } \\
\hline Mean SSB consumption day (oz) ${ }^{a}$ & 11.7 & 13.5 \\
\hline Non-consumer & 229 & 27.8 \\
\hline Moderate consumer ( $12 \mathrm{oz}$ or more) & 339 & 41.3 \\
\hline
\end{tabular}

\section{Food stores}

Forty food stores were included in the observational audit (see Table 3-2). The food stores included 24 food stores in the Hill District and Homewood neighborhoods, and 16 that were located outside of both neighborhoods. The 16 food stores outside the neighborhoods were the most common stores where participants indicated they did their major food shopping. All of the 
stores in the Hill and Homewood neighborhoods were corner stores (either chain convenience or neighborhood stores), except for one seasonal fruit and vegetable stand in the Hill District and one dollar store, also in the Hill District. The eight supermarkets that were included in the audit were all located outside of the neighborhood.

Marketing of SSBs in food stores was widespread across neighborhoods and establishments. Having SSBs at the checkout and having SSBs visible from the main entrance was fairly common across all stores. Food stores outside of the neighborhood had more SSB displays on average.

Forty-one restaurants in the Hill and Homewood Districts were assessed. More than half $(n=24,59 \%)$ were fast food establishments. The remaining restaurants were bar/lounges or cafeterias.

Table 3-2 Characteristics of food outlets with complete observational audits ( $n=81$ ), PHRESH 2011

\begin{tabular}{lccc} 
& $\begin{array}{c}\text { Outside the } \\
\text { Inside the } \\
\text { neighborhood } \\
\text { (Hill and } \\
\text { Homewood) }\end{array}$ & $\begin{array}{c}\text { (store for } \\
\text { neighborhood } \\
\text { major food } \\
\text { shopping) }\end{array}$ & Total \\
\hline \hline Food stores, no. & 11 & 16 & 40 \\
Full-service supermarket & $0 \%$ & $50 \%$ & $20 \%$ \\
Corner store† & $92 \%$ & $0 \%$ & $55 \%$ \\
Other produce store†† & $4 \%$ & $38 \%$ & $18 \%$ \\
Mean no. of SSB displays & 0.75 & 15.5 & 6.7 \\
with SSB at check out & $79 \%$ & $75 \%$ & $78 \%$ \\
with SSB visible from main & $58 \%$ & $69 \%$ & $63 \%$ \\
Restaurants, no. & 41 & - & - \\
Fast food & $59 \%$ & - & - \\
\hline
\end{tabular}

$\dagger$ chain convenience or neighborhood store

†† includes supercenters, wholesale clubs, discount grocers, farmstands, specialty markets

\section{Food environment}

Table 3-3 reports the average food environment for participants, including distance, density, shopping frequency, and store characteristics. On average, participants were 1.60 miles away from the closest supermarket (the USDA definition of a low-access community is "at least 500 persons and/or at least $33 \%$ of the census tract's population live more than one mile from a supermarket or large grocery store"). The typical participant had at least one food store (usually a small neighborhood store) and one restaurant within walking distance ( 0.25 miles). The average modified Retail Food Environment Index (mRFEI) for the $0.25 \mathrm{mi}$ buffer was 10.5 . A score of 100 indicates that all food outlets are considered to be more healthy, therefore a score of 10 
indicates only $10 \%$ of the food outlets are healthy and $90 \%$ are comprised of less healthy venues such as convenience stores and fast food restaurants.

The majority of participants visited a supermarket for their major food shopping (80\%). The stores where participants shopped had 19 advertising displays for SSBS, on average, and almost all had SSBs for sale at the checkout (95\%). Approximately 58\% of participants shopped at a store where SSBs were visible from the main entrance. The majority (68\%) of participants shopped at a store with a high price index, indicating that the cost of common staple items, junk foods, and fruits and vegetables was higher than the median price across the sample of audited stores.

Table 3-3. Characteristics of the food environment of PHRESH sample (n=821) in 2011

\begin{tabular}{|c|c|c|}
\hline & Mean & $\mathrm{SD}$ \\
\hline \multicolumn{3}{|l|}{ Distance (miles) to closest } \\
\hline Food store & 0.24 & 0.19 \\
\hline Supermarket & 1.60 & 0.25 \\
\hline Corner store $†$ & 0.25 & 0.19 \\
\hline Store with SSB marketing & 0.28 & 0.19 \\
\hline SSB at check out & 0.31 & 0.19 \\
\hline SSB visible from main & 0.34 & 0.22 \\
\hline Any SSB displays & 0.43 & 0.29 \\
\hline Restaurant, any type & 0.29 & 0.25 \\
\hline Restaurant, fast food & 0.35 & 0.24 \\
\hline \multicolumn{3}{|l|}{ Density (counts within 0.25 miles) } \\
\hline Food stores & 1.39 & 1.66 \\
\hline Supermarkets & 0.00 & \\
\hline Corner storest & 0.94 & 1.02 \\
\hline Stores with SSB marketing & 0.74 & 0.91 \\
\hline SSB at check out & 0.51 & 0.69 \\
\hline SSB visible from main & 0.43 & 0.70 \\
\hline Number of SSB displays & 0.52 & 0.90 \\
\hline Restaurants, any type & 1.24 & 1.50 \\
\hline Restaurants, fast food & 0.58 & 0.87 \\
\hline Modified Retail Food Environment Index (mRFEI) & 10.45 & 16.02 \\
\hline \multicolumn{3}{|l|}{ Shopping frequency } \\
\hline \multicolumn{3}{|l|}{ Supermarkets, n (\%) } \\
\hline Never & 8 & 1.0 \\
\hline Occasionally & 90 & 11.0 \\
\hline Sometimes & 101 & 12.3 \\
\hline Often & 622 & 75.8 \\
\hline \multicolumn{3}{|l|}{ Convenience stores, n (\%) } \\
\hline Never & 391 & 47.6 \\
\hline Occasionally & 227 & 27.7 \\
\hline
\end{tabular}




\begin{tabular}{lrr} 
& Mean & SD \\
\hline \hline Sometimes & 144 & 17.5 \\
Often & 59 & 7.2 \\
Neighborhood stores, $\mathrm{n}(\%)$ & & \\
$\quad$ Never & 452 & 55.1 \\
Occasionally & 170 & 20.7 \\
Sometimes & 134 & 16.3 \\
Often & 65 & 7.9 \\
Fast food, $\mathrm{n}(\%)$ & & \\
$\quad$ Never & 191 & 23.3 \\
Less than once a week & 414 & 50.5 \\
1-2 times a week & 156 & 19.0 \\
3 or more times per week & 59 & 7.2 \\
\hline Characteristics of major store for food shopping & & \\
No. of SSB displays & 19.36 & 7.01 \\
Monthly exposure to SSB displays & 43.11 & 33.68 \\
Has SSB at check out, $\mathrm{n}$ (\%) & 712 & 95.3 \\
Has SSB visible from main, $\mathrm{n}$ (\%) & 433 & 58.0 \\
Full-service supermarket, $\mathrm{n}$ (\%) & 599 & 80.2 \\
High price index, $\mathrm{n}$ (\%) & 475 & 68.1 \\
\hline
\end{tabular}

† chain convenience or neighborhood store

mRFEI = $100 \times$ (\# of supermarkets, supercenters, wholesale, and farmstand retailers) / (\# of supermarkets, supercenters, wholesale, farmstand, convenience, and fast food retailers)

High price index = store sells basket of common items at a price above the median for all stores

\section{Food environment and SSB consumption}

Results from the regression analyses testing associations between each food environment variables and SSB consumption (in ounces) are shown in Table 3-4 and Table 3-5. The average marginal effects of food environment characteristics on daily SSB consumption in 2011 are reported in Table 3-4.

More than 25 relationships were tested, but only frequency of visiting fast food restaurants was significantly associated with SSB consumption after adjusting for multiple comparisons. As fast food frequency increased, SSB consumption increased. Participants who reported going to fast food once or twice a week consumed almost 5oz more than those who "never" went to fast food restaurants. Those who went the most (three or more times a week) consumed $7 \mathrm{oz}$ more than the "never" group.

We investigated whether the food environment variables predicted fast food frequency, to see if fast food frequency mediated the effects of the food environment on SSB consumption, but found no significant associations (see Appendix A).

Sensitivity analyses using negative binomial models showed no differences from the generalized linear models. 
Table 3-4. Average marginal effects of food environment on SSB intake (oz), PHRESH 2011

\begin{tabular}{|c|c|c|c|}
\hline & $\begin{array}{l}\text { Predictor variabl } \\
\text { Average } \\
\text { marginal effect } \\
\text { (AME) } \\
\end{array}$ & $\begin{array}{l}\text { one at a ti } \\
\text { p-value }\end{array}$ & \\
\hline \multicolumn{4}{|l|}{ Distance (miles) to closest } \\
\hline Food store & -1.22 & 0.6707 & \\
\hline Supermarket & -2.01 & 0.2701 & \\
\hline Corner store $†$ & -1.23 & 0.6696 & \\
\hline Store with SSB marketing & -1.36 & 0.6297 & \\
\hline SSB at check out & -1.42 & 0.5998 & \\
\hline SSB visible from main & -1.68 & 0.4951 & \\
\hline Any SSB displays & -1.15 & 0.5000 & \\
\hline Restaurant, any type & -0.17 & 0.9319 & \\
\hline Restaurant, fast food & -0.85 & 0.6813 & \\
\hline \multicolumn{4}{|l|}{ Density (counts within 0.25 miles) } \\
\hline Stores & 0.07 & 0.8181 & \\
\hline Supermarkets & $\mathrm{n} / \mathrm{a}$ & & \\
\hline Corner stores† & 0.43 & 0.4137 & \\
\hline Stores with SSB marketing & 0.58 & 0.3347 & \\
\hline SSB at check out & 1.24 & 0.0959 & \\
\hline SSB visible from main & 1.11 & 0.1557 & \\
\hline Number of SSB displays & 0.32 & 0.5841 & \\
\hline Restaurants, any type & 0.02 & 0.9608 & \\
\hline Restaurants, fast food & 0.21 & 0.7266 & \\
\hline Modified Retail Food Environment Index (mRFEI) & -0.03 & 0.4396 & \\
\hline \multicolumn{4}{|l|}{ Shopping frequency } \\
\hline Supermarkets ( $1=$ Never, $4=$ Often) & 0.60 & 0.3732 & \\
\hline Convenience stores ( $1=$ Never, $4=$ Often) & 0.26 & 0.6075 & \\
\hline \multicolumn{4}{|l|}{ Neighborhood stores (Ref=Never) } \\
\hline Occasionally & 1.02 & 0.3675 & \\
\hline Sometimes & 1.12 & 0.3489 & \\
\hline Often & 4.36 & 0.0176 & \\
\hline \multicolumn{4}{|l|}{ Fast food (Ref $=$ Never) } \\
\hline Less than once a week & 3.18 & 0.0050 & \\
\hline 1-2 times a week & 4.68 & 0.0008 & * \\
\hline 3 or more times per week & 7.04 & 0.0017 & * \\
\hline \multicolumn{4}{|l|}{ Characteristics of major store for food shopping } \\
\hline Not full-service supermarket & 2.32 & 0.0669 & \\
\hline No. of SSB displays & -0.05 & 0.5223 & \\
\hline Monthly exposure to SSB displays & -0.03 & 0.0802 & \\
\hline Has SSB at check out & -3.68 & 0.1637 & \\
\hline Has SSB visible from main & 0.43 & 0.6866 & \\
\hline High price index & -4.42 & 0.6434 & \\
\hline
\end{tabular}


$\mathrm{AME}=$ average marginal effect obtained from generalized linear model

* indicates statistically significant from zero for AME after Bonferroni correction for multiple comparisons $\dagger$ chain convenience or neighborhood store

mRFEI = $100 \times$ (\# of supermarkets, supercenters, wholesale, and farmstand retailers) / (\# of supermarkets, supercenters, wholesale, farmstand, convenience, and fast food retailers)

High price index = store sells basket of common items at a price above the median for all stores

Note: All analyses control for sex, black/African American, children in household, highest education, marital status, age, and adjusted income. Analyses including preferred store characteristics also control for the preferred store not being a full-service supermarket.

Table 3-5 reports the odds ratios of being a moderate SSB consumer (12 oz or more a day, based on 24-hr recall) for each food environment variable. Distance, density, and characteristics of the major food store did not predict moderate SSB consumption.

Participants who went to fast food restaurants had 1.3-2.3 times the odds of being a moderate SSB consumer than those who never visited fast food restaurants. After adjusting for multiple comparisons, none of these associations remained significant.

Table 3-5. Odds ratios of food environment variables and moderate SSB consumption (12 oz or more), PHRESH 2011

\begin{tabular}{lll} 
& \multicolumn{2}{c}{$\begin{array}{c}\text { Predictor variable, } \\
\text { one at a time }\end{array}$} \\
& OR & p-value \\
\hline \hline Distance (miles) to closest & & \\
Store & 0.63 & 0.2944 \\
Supermarket & 0.71 & 0.2458 \\
Corner store $†$ & 0.61 & 0.2699 \\
Store with SSB marketing & 0.60 & 0.2479 \\
$\quad$ SSB at check out & 0.66 & 0.3289 \\
$\quad$ SSB visible from main & 0.70 & 0.3420 \\
$\quad$ Any SSB displays & 1.08 & 0.7730 \\
Restaurant, any type & 0.98 & 0.9499 \\
Restaurant, fast food & 0.86 & 0.6424 \\
\hline Density (counts within $\mathbf{0 . 2 5}$ miles) & & \\
Stores & 1.00 & 0.9430 \\
Supermarkets & $\mathrm{n} / \mathrm{a}$ & \\
Corner stores $\dagger$ & 1.02 & 0.8197 \\
Stores with SSB marketing & 1.02 & 0.8485 \\
$\quad$ SSB at check out & 1.06 & 0.5821 \\
$\quad$ SSB visible from main & 1.08 & 0.4862 \\
$\quad$ Number of SSB displays & 0.95 & 0.5389 \\
Restaurants, any type & 0.97 & 0.5550 \\
Restaurants, fast food & 1.00 & 0.9560 \\
Modified Retail Food Environment Index (mRFEI) & 0.99 & 0.2354 \\
\hline Frequency & & \\
Supermarkets (1=Never, 4=Often) & 1.17 & 0.1352
\end{tabular}




\begin{tabular}{lcc} 
& \multicolumn{2}{c}{$\begin{array}{c}\text { Predictor variable, } \\
\text { one at a time }\end{array}$} \\
& OR & p-value \\
\hline \hline $\begin{array}{l}\text { Convenience stores (1=Never, 4=Often) } \\
\text { Neighborhood stores (Ref=Never) }\end{array}$ & 1.00 & 0.9971 \\
$\quad$ Occasionally & 1.28 & \\
$\quad$ Sometimes & 1.65 & 0.2101 \\
$\quad$ Often & 1.84 & 0.0175 \\
Fast food (Ref = Never) & & \\
$\quad$ Less than once a week & 1.28 & \\
1-2 times a week & 1.61 & 0.2057 \\
$\quad$ or more times per week & 2.30 & 0.0500 \\
\hline Characteristics of major store for food shopping & & \\
Not full-service supermarket & 1.31 & 0.0105 \\
No. of SSB displays & 0.99 & 0.5477 \\
Monthly exposure to SSB displays & 1.00 & 0.0669 \\
Has SSB at check out & 0.73 & 0.4298 \\
Has SSB visible from main & 0.97 & 0.8353 \\
High price index & 1.25 & 0.8767 \\
\hline
\end{tabular}

$\mathrm{OR}=$ odds ratio obtained from logistic regression

* indicates statistically significant from zero for AME or one for OR after Bonferroni correction for multiple comparisons

$\dagger$ chain convenience or neighborhood store

$\mathrm{mRFEI}=100 \times$ (\# of supermarkets, supercenters, wholesale, and farmstand retailers) / (\# of supermarkets, supercenters, wholesale, farmstand, convenience, and fast food retailers)

High price index = store sells basket of common items at a price above the median for all stores

Note: All analyses control for sex, black/African American, children in household, highest education, marital status, age, and adjusted income. Analyses including preferred store characteristics also control for the preferred store not being a full-service supermarket.

\section{Change-change model}

Table 3-6 shows the results from modeling the change in SSB consumption (in ounces) between 2011 and 2014 on changes in the food environment during the same period. Changes were calculated as the Post (2014) value minus the Baseline (2011) value. After applying attrition weights, the mean change in SSB consumption was -1.1 (11.03 oz in 2014, down from $12.17 \mathrm{oz}$ in 2011).

\section{Distance}

A negative change in distance variables indicates a participant is closer to a store now than at baseline, and a negative change in SSB consumption indicates that the participant is consuming less SSBs now than previously, therefore a positive coefficient in the first set of coefficients in Table 3-6 indicates that SSB consumption improved as participants became closer to stores. 
None of the changes in distance variables had a significant association with changes in SSB intake.

\section{Density}

A positive change in density variables indicates that more stores are within walking distance now than at baseline, and a positive change in SSB consumption indicates that the participant is consuming more SSBs now than previously, therefore a positive coefficient in the second set of coefficients in Table 3-6 indicates diet gets worse as participants have more stores within walking distance of them.

Because the mRFEI is a 100-point scale where 0 indicates no food outlets are healthy and 100 indicates all food outlets are healthy, the change coefficient must be interpreted differently. A positive change in $\mathrm{MRFEI}$ indicates the participant is living in a more healthful environment and a negative change in SSB consumption indicates that the participant is consuming less SSBs now than previously. However, there was no significant association between changes in MRFEI and changes in SSB consumption.

\section{Frequency}

A positive change in frequency variables indicates that participants are visiting an outlet more frequently than at baseline, and a positive change in SSB consumption indicates that the participant is consuming more SSBs now than previously, therefore a positive coefficient in the third set of coefficients in Table 3-6 indicates diet got worse when participants increased their shopping/patronage. Changes in frequency were calculated as the number of category changes for an ordinal scale variable between Post (2014) and Baseline (2011), therefore someone who "Often (4)" went to supermarkets in 2014 and "Never (1)" went in 2011 had a value of 3 for change in supermarket frequency. There were no significant associations between changes in shopping frequency and changes in SSB consumption.

\section{Characteristics of store for major food shopping}

The fourth and final set of variables in Table 6 looks at changes in the characteristics of the store where participants do their major food shopping. A positive change in the number of SSB displays indicates the participant now shops at a store with more advertisements and a negative change in SSB consumption indicates the participant is consuming less SSBs now than previously, therefore a negative coefficient indicates a relationship between more advertising and better diet. However this relationship was not significant.

The coefficient on monthly exposure (the frequency of shopping X number of SSB displays) indicates more exposure was negative and significant, indicating that the participant has more exposure to SSB displays now than previously and less SSB consumption. However, the magnitude of this effect was very small and not significant after adjusting for multiple comparisons. 
For the dichotomous variables (whether the store had SSBs at checkout, whether SSBs were visible from the main entrance, and whether the store was a full-service grocery store), there were no significant relationships. Participants who switched to a store with SSBs at checkout consumed $7.5 \mathrm{oz}$ less SSBs in 2014 than in 2011, compared to participants who shopped at a store with the same characteristics in each year, although this was not significant after adjusting or multiple comparisons. The 19 participants included in this group all switched their preferred store for major food shopping (4 from discount grocers, 8 from meat/seafood markets, 6 from wholesale retailers, and 1 from a specialty market to full-service supermarkets $(n=15)$, discount grocers $(n=3)$ or a supercenter $(n=1))$.

There were no differences when demographic covariates were excluded from the analyses.

Table 3-6. Change-change model of food environment and SSB consumption (oz), 2011-2014

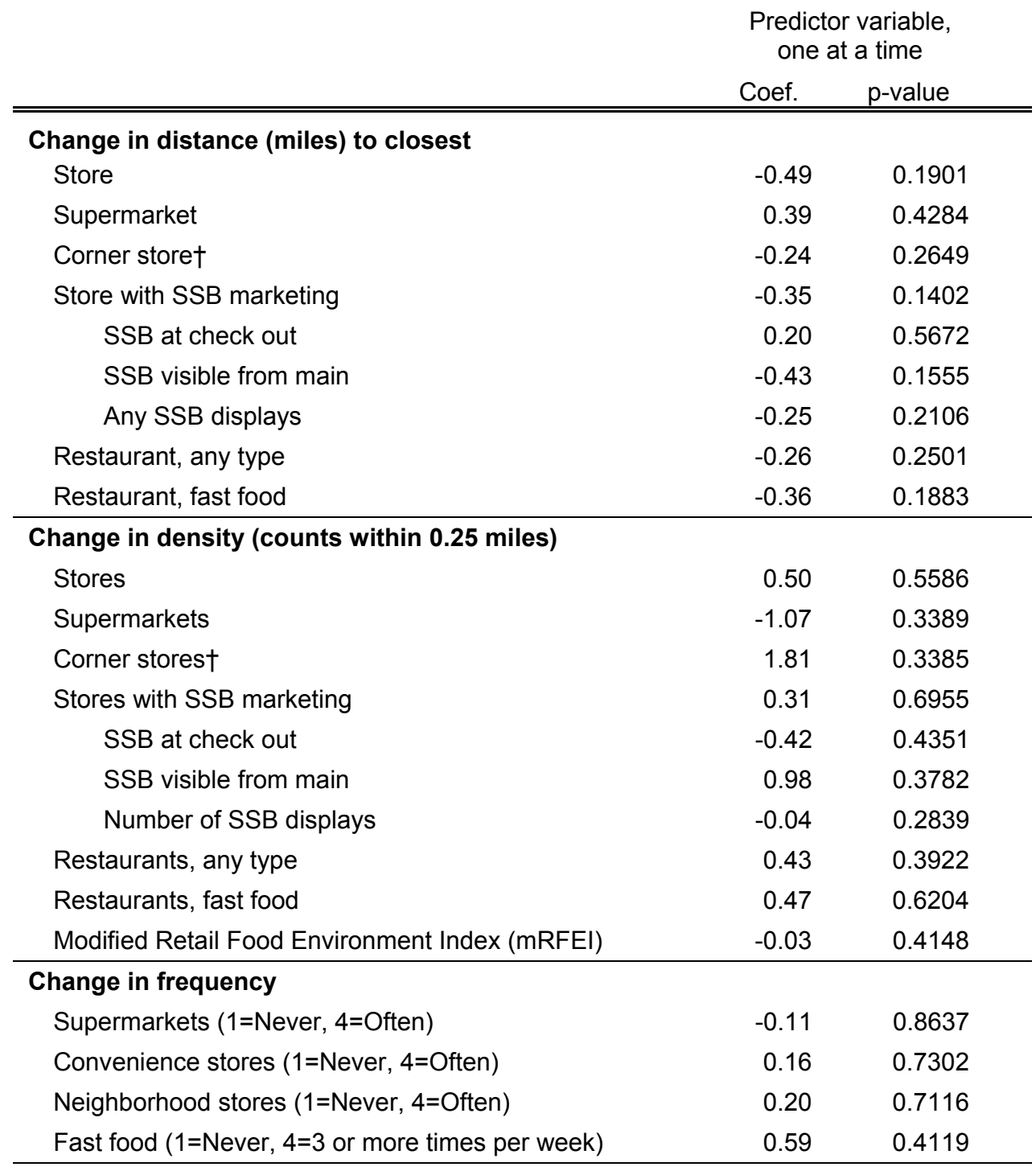

Change in characteristics of store for major food shopping 


\begin{tabular}{lcc} 
& \multicolumn{2}{c}{$\begin{array}{c}\text { Predictor variable, } \\
\text { one at a time }\end{array}$} \\
& Coef. & p-value \\
\hline \hline No. of SSB displays & -0.07 & 0.1752 \\
Monthly exposure to SSB displays & -0.03 & 0.0171 \\
SSB at check out & & \\
$\quad$ Current store does not have (previously did) & 0.97 & 0.7132 \\
$\quad$ Current store has (previously did not) & -7.49 & 0.0014 \\
SSB visible from main & & \\
$\quad$ Current store does not have (previously did) & 1.29 & 0.4004 \\
$\quad$ Current store has (previously did not) & -0.52 & 0.7591 \\
$\quad$ Full-service supermarket & & \\
$\quad$ No longer shops at supermarket (previously did) & -1.48 & 0.4159 \\
$\quad$ Currently shops at supermarket (previously did not) & 3.23 & 0.1414 \\
\hline
\end{tabular}

* indicates result is statistically significant after Bonferroni's correction $\dagger$ chain convenience or neighborhood store

$\mathrm{mRFEI}=100 \times$ (\# of supermarkets, supercenters, wholesale, and farmstand retailers) / (\# of supermarkets, supercenters, wholesale, farmstand, convenience, and fast food retailers)

Note: OLS regression, controlling for baseline sex, black/African American, children in household, highest education, marital status, age, and adjusted income.

\section{Discussion}

There was little evidence of a relationship between the food environment, as defined by several definitions including distance, density, shopping frequency, and characteristics of store for major food shopping, and SSB consumption in this sample of two predominantly black lowincome neighborhoods. At the beginning of the study, participants from this sample of mostly older black women were consuming about $12 \mathrm{oz}$ of SSBs daily, which seems in line with other research that has found higher SSB consumption in blacks than whites, and lower SSB consumption among older adults compared to younger adults. ${ }^{16,90}$ We looked at several domains related to the food environment - distance, density, shopping frequency, and store characteristics - and found only one primary cross-sectional association between greater frequency of going to a fast food restaurant and higher SSB consumption.

\section{Distance}

Participants lived about a quarter mile from the nearest corner store and more than 1.5 miles to a supermarket, representing a six-fold difference in food store access. Despite these participants living in food deserts, we saw no evidence of any relationships between distance and SSB consumption. In the cross-sectional analyses, the distance to various types of stores (supermarkets, corner stores, stores with marketing, and restaurants) did not appear related to SSB consumption. In the change-change model, a positive coefficient for supermarket would have supported the "supermarket solution," that improving geographic access to supermarkets improves diet. A negative coefficient for supermarket would validate a worry that supermarkets 
make cheap junk foods more available, a concern mostly voiced in countries outside the US. ${ }^{69}$ However, this study did not support either notion.

\section{Density}

On average, participants were within walking distance $(0.25 \mathrm{mi})$ of at least one food store. The Modified Retail Environment Index (mRFEI) score of 10.45 (out of a possible 100) indicates a low proportion of healthy food outlets within walking distance. Conventional wisdom suggests that increases in density of more healthy outlets would result in better diet, while increases in density of more unhealthy outlets, such as convenience stores and fast food restaurants, would result in worse diet. Yet, we found no evidence of any relationships in this analysis.

A recent analysis of the Coronary Artery Risk Development in Young Adults (CARDIA) study matched dietary data to food outlet data and found no associations between the proportion of convenience stores within $3 \mathrm{~km}$ (1.9mi) of the participant's home address and SSB consumption. $^{91}$

\section{Shopping frequency}

The strongest and most consistent finding in this study was that people who went to fast food restaurants were more likely to be SSB drinkers and drank more SSBs that people who didn't go to fast food restaurants. These findings are in line with previous research in African Americans

as well as, more generally, US adults, adolescents, and children. ${ }^{92-95}$ A person who eats fast food 1-2 times/week consumes almost 5 more ounces of SSBs in a day than someone who never goes. An extra $5 \mathrm{oz}$ each day over the course of a week would be $35 \mathrm{oz}$, or about the amount from two drinks included in the typical chain fast food combination meal (medium size $=20 \mathrm{oz}$ ). Policies that reduce the size of the default drink or that change the default to a zero- or low-calorie drink could reduce the number of calories consumed at these food venues. However, our changechange model showed no effect that reducing fast food frequency also reduced SSB consumption, so it may be that people who like SSBs will consume them, regardless of where they buy them.

Similarly, we would expect to see diet improve as participants increased their patronage of "more healthy" outlets like supermarkets and "less healthy" outlets like convenience stores, however we saw no evidence of changes in store frequency with changes in SSB consumption.

\section{Store for major food shopping}

We saw a large reduction in SSB consumption of almost 8oz among participants who shopped at a store with SSBs at checkout in 2014 and at a store without SSBs at checkout in 2011. This finding is in the opposite direction of what we might expect. There were few participants in this category $(n=19,<3 \%)$ since stores with SSBs at checkout were so popular at baseline. Almost all of these participants switched to a full-service supermarket (15 of 19), but 
there was no overall effect of switching to a full-service supermarket in the larger sample. These participants also had greater SSB consumption at baseline, therefore had more room to change their SSB consumption.

Previous studies have found that price is a more important factor than distance. ${ }^{86,96} \mathrm{We}$ did not find a strong association with SSB consumption and price when measured with the high price index based on staple goods. This may be because the price index is based upon a variety of products including produce and cereal in addition to SSBs. The lack of association may also be due to SSBs being cheap with little variation. A recent review of price effects for SSBs estimated that the overall mean price elasticity of demand for SSBs was -1.21 (demand would decrease by $12 \%$ with a $10 \%$ increase in price), which suggests an important role of price in SSB consumption. $^{97}$

\section{Limitations}

This study did not attempt to quantify the total exposure of in-store marketing of SSBs, however other audit studies have noted that junk foods such as SSBs are ubiquitous in the supermarket setting. ${ }^{98}$ It may be that we did not see direct effects of the store marketing characteristics that were measured because the overall exposure within the store had surpassed some marketing threshold such that the individual indicators are meaningless. It is also worthwhile to note that store characteristics were based on an assessment at one point in time under the assumption that this assessment was representative of the environment the participants shopped in, but it's likely that these characteristics change with time. Specifically, the number and distribution of displays are likely to change in conjunction with weekly sales and seasonal promotions. In order to more rigorously test the association between in-store characteristics and the SSB consumption, one would need to conduct the supermarket observational audit and the dietary recall on a day where the participant was shopping.

This study did not examine whether the results differed by type of SSB, for example soft drinks versus juice drinks. Reports on the prevalence of SSB consumption among adults similarly group all SSB consumption together, ${ }^{62,99}$ however there may be regional differences in the type of SSBs consumed. ${ }^{100}$ Studies of children and adolescents have found that African Americans have soda consumption similar to that of whites, but have greater consumption of fruit drinks and sports drinks, ${ }^{101,102}$ so it's possible that combining the SSBs together may mask important differences in the mechanisms that factor into SSB consumption. Unfortunately, the food store observation audit also did not distinguish between the different types of SSBs when capturing in-store marketing characteristics (i.e., whether SSBs were at checkout, whether SSBs were visible from the main entrance, and the number and type of SSB displays). Additionally, although we saw an association between fast food frequency and SSB consumption, the dietary recall did not require participants to indicate where they consumed their meals and snacks (e.g., at home, at a restaurant). 
It's also worthwhile noting that although more than 800 people participated in both years of the study, they only shopped at 16-20 stores where observational information was available, decreasing the effective sample size and amount of variation. Multiple participants shop at the same stores and therefore have the same store-level characteristics. Although this clustering creates an analytic limitation, from a policy perspective, changes to a small set of stores can potentially have an impact on a large number of people.

To calculate the distance between the participant and a food store, we used the difference in geospatial coordinates based on known addresses. As such, the addresses are used a proxy for physical location, however this may not always be the case. Using a hypothetical example, say a store address of 123 Pine Ave corresponds to a certain coordinate on a map, however, the actual store may be set back from the store address by a large parking lot, thus the actual physical distance to the store would be different than that calculated using the store address. Similarly, for the density measures, a 0.25 mile radius is drawn around a participant's residence and all outlets meeting the criteria within the radius are counted. This could potentially underestimate or overestimate the number of outlets, depending on the biasedness of the geolocation of addresses. This limitation is something all researchers in this field must contend with, but is potentially more problematic for small effects where an effect size of 400 feet could be due to an imprecise location.

Finally, the findings from this study may have limited generalizability beyond low-income African American communities. It has previously been documented that residents in disadvantaged neighborhoods shop outside of their neighborhood, ${ }^{103}$ thus the lack of associations between the distance and density measures and SSB consumption in this sample is not too surprising. Social aspects such as safety and relationships with food store retailers may affect how and where African Americans shop and define their food environment. ${ }^{104}$ Although we were able to look at the stores where participants did their major food shopping, we don't know why they choose those stores and therefore can't assess whether those reasons would impact interpreting this findings to a larger population.

\section{Next steps}

Additional research, specifically with longitudinal or experimental designs, is needed to further identify the causes of different dietary patterns. SSBs have become ubiquitous in many settings, such as vending machines in parks, but this study focused only on food outlets. Studies that encompass all of the many opportunities to eat or buy foods that individuals are exposed to would be better suited to describe what relationships between the environment and SSB consumption exist. The results from this study also suggest that individual characteristics, such as food preferences, may matter more than environmental characteristics such as access to food stores.

Successful advocacy for changes in the food landscape has created several opportunities for policy evaluation. At least eight large fast food chains have pledged to remove fountain drinks 
from children's meal combinations. ${ }^{105}$ Such voluntary programs could dramatically reduce opportunities to consume SSBs. In addition, a number of food stores are promoting healthier checkouts. Discount grocer chain Aldi recently announced it would be overhauling checkout lanes in its locations nationwide (approximately 1000 stores) by removing candy and chocolate and replacing them with trail mix and other healthier snacks. ${ }^{106}$ Meanwhile, big box retailer Target had earlier announced a pilot study to eliminate candy bars and reduce soda and chips at registers in 30 locations. ${ }^{107}$ Results from this pilot are not available; however, evidence from another chain in the UK demonstrated positive results - customer volume in healthier checkout lanes was $20 \%$ higher than traditional checkouts and $70 \%$ of surveyed customers preferred a healthier checkout lane. ${ }^{108}$ Studies of these policies using purchase data would provide valuable information about the potential effect of the food environment on SSBs.

\section{Conclusion}

We used several different measures of the food environment to test relationships between the food environment and SSB consumption. Frequency of going to fast food restaurants was the only variable that was significantly associated with SSB consumption in the cross-sectional analyses. None of the relationships tested appeared causal in nature; however, further research is needed. 


\section{Chapter 4 In-store Marketing Practices and Children's Diet}

\section{Summary}

Introduction. Marketing practices in food retail stores may affect children's diet through children's "pestering", parent purchases that increase home availability of unhealthy foods, and ultimately, children's SSB consumption.

Methods. This study examines a potential pathway to SSB consumption in 129 low-income households with a child between 5 and 13 years who are participating in the Pittsburgh Hill/Homewood Research on Eating, Shopping \& Health (PHRESH) study. In-store marketing characteristics were documented through an audit tool completed by trained data collectors. Parents were asked about the frequency of their child's pestering (how often the child requested a snack or sweet, placed unnecessary items in the cart, or got upset if the parent didn't buy the desired item). To measure purchases, parents were asked about their frequency of purchasing their child's requested items as well as availability of unhealthy foods (regular soda, snack chips, and candy/cookies) in the home during the past week. Frequency of children's SSB consumption was based on parent report.

Results. Most parents (74\%) reported their child "often" or "always" requested snacks and sweets, but only $22 \%$ of parents "often" or "always" purchased requested items. Most households had candy/cookies (78\%) and snack chips (89\%), and about half had regular soda (57\%). On average, children consumed a sugar sweetened beverage (SSB) 37 times a month, or more than once a day. Regular soda consumption, but not non-soda SSB consumption, was associated with home availability of regular soda and whether SSBs were visible from the main entrance of the store where the parent reported doing their main food shopping.

Conclusion. There was limited evidence in this study that in-store marketing characteristics were associated with children's SSB consumption, however the other behaviors in the pathway (pestering, purchase, and consumption) were linked.

\section{Introduction}

Poor diet among children is a growing public health problem in the United States. Evidence from longitudinal studies suggests that dietary intake during childhood, adolescence, and young adulthood may have long-reaching consequences later in life. ${ }^{109-111}$ However, most children do not meet dietary guidelines for fruits, vegetables, dairy, and whole grains and consume added sugars and saturated fats higher than recommended allowances. ${ }^{12,112-114}$

Food marketing to children is one of several potential drivers of children's poor diet. Systematic reviews show a strong body of evidence that unhealthy food marketing exposure has a negative impact on diet, weight, and related behaviors such as preferences and requests. ${ }^{115,116}$ 
Brand loyalty has been demonstrated in children as young as preschool age, creating a large incentive for companies to attract young customers. ${ }^{117}$ Such marketing strategies may take several forms including television commercials and special product packaging - often with the use of cartoon characters, mascots, or celebrity endorsement. Experimental studies have shown high rates of recognition for popular characters and a greater likelihood of choosing foods presented with familiar characters. ${ }^{118}$

Marketing to children has become ubiquitous in the United States, as well as other developed nations with increased consumer spending power. Products marketed toward children in supermarkets are often high in sugar, salt, and/or fat. ${ }^{119}$ In addition, commercials for food during children's television programming are often for unhealthy food items. ${ }^{120}$ One large multi-country study documented more than 12,000 television advertisements for food on popular children's channels and found the most common advertisements consisted of fast food and candy. ${ }^{120}$ School settings may also contain marketing to children in the form of sponsorships, in-school media, and incentive programs (e.g., pizza vouchers for attaining reading goals). ${ }^{121}$

Kelly and colleagues recently proposed a framework for how food marketing at the point-ofsale may affect awareness, preferences, purchase intent, purchases, consumption, and ultimately energy imbalance that results in weight gain and diet-related diseases. ${ }^{122}$ In their model (see Figure 4-1), marketing features at the point of sale play an important role in the chain of behaviors linked to poor diet and weight gain. ${ }^{122}$

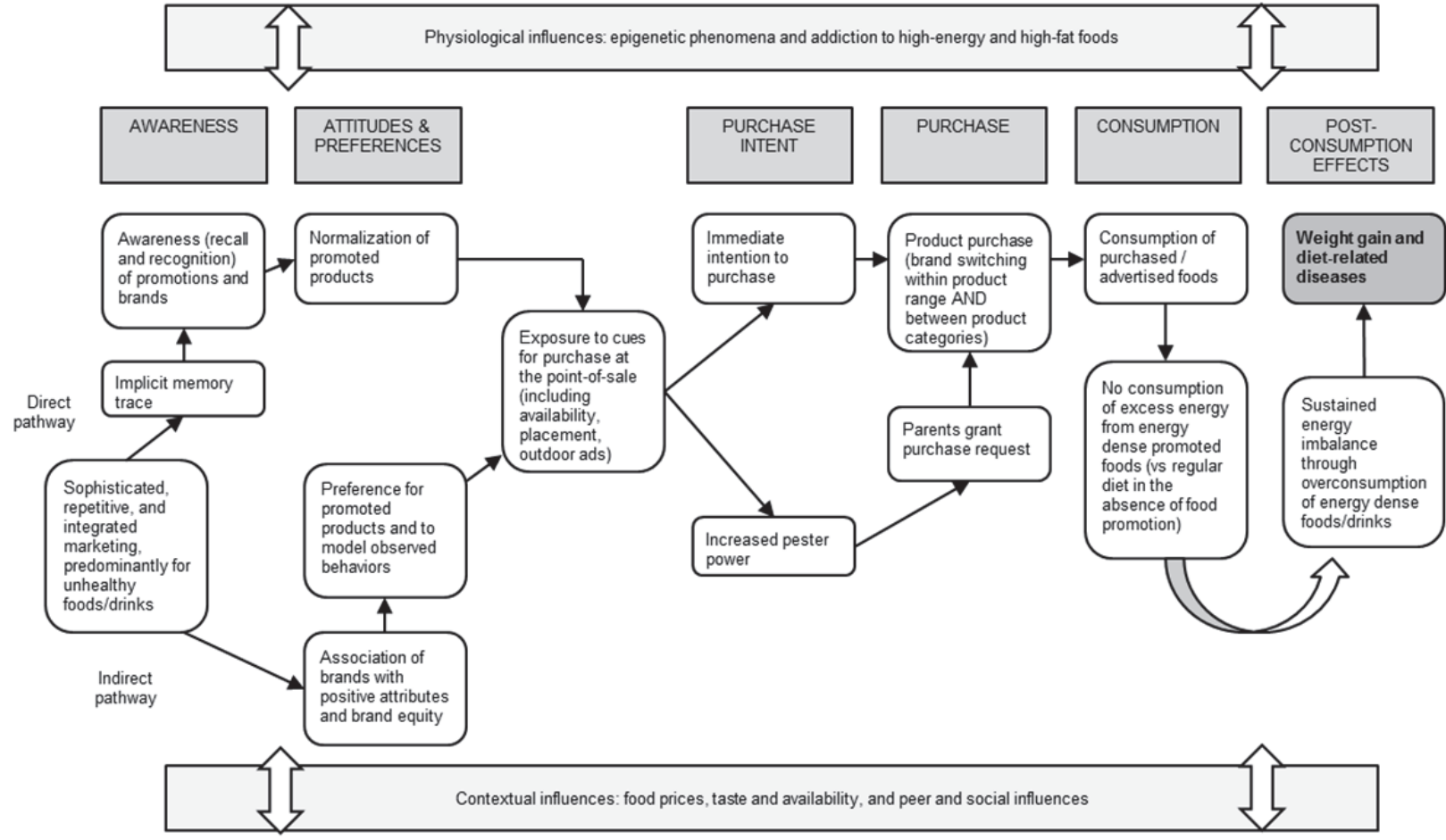




\section{Figure 4-1 Logic model of unhealthy food promotion effects from Kelly B, King L, Chapman K, Boyland E, Bauman AE, and Baur LA (2015)}

In terms of "purchase intent," marketing may affect children through their influence over adults' spending, often achieved through persistent pestering or nagging by children. The "ability children have to badger their parents into purchasing items they would otherwise not buy" is known as pester power. ${ }^{115}$ As noted above, children's products in supermarkets are often high in sugar, salt, and/or fat ${ }^{119}$ - these are the same items for which children often pester. In one of the original studies to examine pester power, researchers observed children ages 3-11 years old during a grocery store trip and recorded an average of 15 purchase requests. ${ }^{123}$ In a survey of British parents, 59\% agreed that their children tried to influence their in-store purchases and this was strongest among requests for sweets, snack foods, and cereals. ${ }^{124}$ When asked in surveys and interviews, mothers often attribute their children's pestering for new items to advertisements, including product packaging, character sponsorship, and television commercials. ${ }^{125,126}$ One review examined pestering in twelve studies, mostly within the context of the United States. ${ }^{127}$ Among these studies, eleven demonstrated an association between advertising and children's purchase requests, although the measurements of advertising and pestering varied across settings. None of the reviewed studies looked at marketing in food stores as a mechanism for children's requests. However, a later mixed-method study in Austria found a positive association between the number of products placed at a child's eye level and the number of requests made. ${ }^{128}$

Whether a parent makes the purchase is the next important step in the chain of effects. One report estimates that nagging results in one-third (34\%) of children's food sales. ${ }^{129}$ Previous observational research of parents and children in food store settings has found that parents typically purchase one-quarter to one-half of children's requests. ${ }^{123,128,130}$ The exact proportion tends to depend on the child's age (children who were in late elementary were granted their requests the most). ${ }^{130}$ Availabilities of certain foods in the home have also been used as measures of purchasing behavior. ${ }^{131}$

Previous studies have described the popularity of marketing strategies in food retail stores specifically targeting children, however none have linked specific characteristics to intermediate child diet outcomes such as consumption. One study examined checkouts at 13 supermarkets and found that $89 \%$ of products displayed at or below children's eye level were classified as "unhealthy" according to the UK Food Standards Agency's Nutrient Profiling score. ${ }^{132}$ The exception was one store located in an affluent neighborhood that displayed all healthy products at checkout. ${ }^{132}$ Another study asked mothers of young children in Illinois to identify the stores where they did their food shopping and then recorded the prevalence of marketing claims at a subsample of 24 stores. ${ }^{133}$ Marketing claims, including claims about nutrition, taste, fun, suggested use, and convenience, were most present for soda, salty snacks, and candy ( $>75 \%$ of stores) and least present for fruits and vegetables (33\% of stores), however the researchers did not have information on children's diets. ${ }^{133}$ One study audited restaurants and food stores within 
the census tracts of where children lived, but data collectors only recorded the availability of fruits and vegetables, and not any marketing features. ${ }^{52}$ In addition, it's unknown whether these families actually visited the observed food outlets. ${ }^{52}$

Restricting marketing to children of foods high in saturated fat, trans fat, added sugar, and/or salt has been recommended by the World Health Organization (WHO) since 2010, with other organizations such as the Institute of Medicine and Robert Wood Johnson Foundation also recommending standards for marketing to children. ${ }^{15,134,135}$ However, because of the lack of studies that measure both diet and marketing in food stores, it's unclear to what extent in-store marketing practices may impact children's health. This study explores the potential pathway introduced by Kelly and colleagues ${ }^{122}$ and looks at the relationship between in-store food promotion, children's pestering and parents' responses, and children's diet in households from two low-income neighborhoods in Pittsburgh, PA.

\section{Methods}

\section{Data Sources}

The data come from a larger study, the RAND Pittsburgh Hill/Homewood Research on Eating, Shopping \& Health (PHRESH). PHRESH is a five-year study funded by the National Institutes for Health and the National Cancer Institute (R01CA149105 NIH/NCI; PI: Tamara Dubowitz) to longitudinally examine the impact of a new full-service supermarket on diet and obesity in a predominantly low-income, African American, urban neighborhood in Pittsburgh. The study capitalizes on a natural experiment whereby the Hill neighborhood, an area comprised of six census tracts located 100-250 ft. above the bordering neighborhoods, received a new $\$ 8.5 \mathrm{M}$ supermarket through a large, public-private collaboration partially financed by the Healthy Food Financing Initiative. The Homewood neighborhood, comparable in demographic and geographic isolation, did not, thereby serving as a comparison neighborhood. Households with children between the ages of 5-13 years were identified from the PHRESH baseline data collection and were asked to participate in an additional study funded through the Robert Wood Johnson Foundation (RWJF HER Grant 71502; PI: Karen Flórez).

Data for these analyses consist of three parts from these two studies: 1) household surveys with the primary food shopper that included two administrations of 24 hour individual dietary recalls and questions about neighborhood perceptions, social support, and health beliefs, 2) supplemental questionnaires about family eating and food habits for households with children, and 3) observational measures of food stores and restaurants. Although the household surveys and observational measures were collected before and after the introduction of the new supermarket, the supplemental survey of children was not conducted until after the introduction of the new supermarket. The data presented in these analyses are cross-sectional and were 
collected in 2014, approximately nine to fourteen months after the opening of the new supermarket.

\section{Household surveys}

Households from the two neighborhoods were randomly selected based on geographic location within the neighborhood, and data collectors enrolled households through in-person door-to-door recruitment. The primary food shopper in the household was invited to complete an in-person questionnaire and dietary recall for the larger PHRESH study. Participants could receive up to $\$ 40$ in incentives for completing the household survey and dietary recall during each wave of data collection. A total of 1,373 households participated in the baseline data collection in 2011 and 912 households in the follow-up data collection in 2014. The questionnaire covered six domains (neighborhood, food availability and purchasing, food security, demographics, sociocultural and psychosocial factors, and health status). The analyses in this chapter use sociodemographic characteristics and information about sources for food shopping, collected in 2014, after the construction of the new supermarket. Sociodemographic characteristics in this analysis include age, race (whether the participant identifies as black/African American), highest level or education (less than high school, high school graduate, some college, or college graduate), marital status (never married, married or living with a partner, or widowed or divorced), whether there are any children (under 18 years) living in the household, and total household income adjusted for the number of people living in the household. Parents also completed two 24-hour dietary recalls, administered between 7 - 10 days apart. Dietary recall data was averaged and total SSB intake (in ounces) for each individual was calculated based on the sum of reported portion sizes for drinks matching the Food and Nutrient Database for Dietary Studies (FNDDS) food codes for regular soft drinks, fruit drinks, and presweetened teas.

\section{Supplemental survey of households with children}

Households with children between the ages of 5-13 years were asked to complete an additional survey about their family's nutrition and physical activity behaviors in 2014 . The parent or legal guardian (the adult participant is referred to as the "parent" from this point) completed a 30-minute in-person questionnaire designed to capture information about psychosocial factors in the home environment and parent-child interactions, such as whether the family ate meals together or the adult used food for restriction or reward. Each household received a \$15 gift card incentive for completing the questionnaire. Parents with more than one child between 5 and 13 years were asked to answer the questions based on the child with the closest birthday to the interview date. To capture parent-child shopping behaviors, the parents were asked how often 1) the parent takes the child along for food shopping, 2) the child helps plan and shop for groceries, 3) the child places unnecessary items in the shopping card, 4) the child requests a sweet or snack, and 5) the child becomes upset if the parent doesn't buy 
requested sweets or snacks. Responses were from a five-point frequency scale (1= "Never", 2="Rarely", 3="Sometimes", 4="Often", or 5="Always"). Adjacent response categories, such as "never" and "rarely" or "often" and "always", were collapsed into one category when the counts were low. Parent purchase was measured in two ways. First, parents were asked how often the parent buys the requested sweets or snacks, using the five-point frequency scale from above. Second, parents reported whether candy or cookies, snack chips, or regular soda were available in the home during the past week. If home availability data was unknown, it was assumed unavailable for that household ( $<3 \%$ of observations). The child's SSB consumption included frequency of soda and other SSB consumption in the past month based on wording from the 2009-2010 NHANES questionnaire. ${ }^{136}$ Parents were asked "How often does your child drink regular soda, not including diet soda?" and "How often does your child drink other sweetened beverages such as sweet teas, Kool-Aid, Vitamin Water?" Response options for each question were "Never or rarely", "1 time per month", "2-3 times per month", "1-2 times per week," "3-4 times per week", "1 time per day", "2 times per day" or "3 or more times per day". Responses were converted from ordinal categories into a variable representing monthly consumption using the lower bound of the categories (e.g., "3-4 times per week" became 12 times per month). A frequent SSB drinker was defined based on endorsement of a general question about beverage choices ("Our child frequently drinks soda pop or other sweetened drinks, and rarely drinks low fat milk with meals or at snacks" or "Our child frequently drinks soda pop or other sweetened drinks, but frequently drinks low fat milk with meals or at snacks”).

\section{Observational measures of food outlets.}

Data were collected on every food store in the two neighborhoods using an adapted version of the Bridging the Gap (BTG) observation form. ${ }^{81}$ Data were also collected from the most common food stores where residents reported major food shopping, which were typically outside of the neighborhood of residence. The BTG Food Store Observation Form assessed availability, pricing, and in-store marketing of common foods at food stores such as supermarkets, convenience stores, and warehouses/supercenters. For this study, aspects of the food environment that were analyzed included whether candy, salty snacks, or sugar-sweetened beverages (SSBs) were available at checkout; whether candy, salty snacks or SSBs were visible from the main entrance; and the number of end-aisle displays, special floor displays, price reductions/promotions, and cash register displays promoting SSBs or salty snacks, candy, or sweetened baked goods (“junk foods”).

\section{Analyses}

Following Kelly's logic model of unhealthy food promotion effects, ${ }^{122}$ we examined the linkages between exposure to cues for purchase, increased pester power, purchase outcomes, and consumption of requested/advertised foods. Exposure to cues for purchase was measured by marketing characteristics of the store for main food shopping. Due to low variability in checkout 
characteristics at the stores (e.g., more than $80 \%$ of participants shopped at a store where all three were available), checkout characteristics are presented in the descriptive tables, but were excluded from subsequent analyses. Previous studies have found that pestering may take several different forms depending on the age, gender, and affect of the child. ${ }^{137-139}$ Pester power was measured in three ways: 1) frequency of child requests, 2) frequency of putting items in the cart, and 3) frequency of getting upset when requested items are not purchased. The three variables represent verbal, physical, and emotional manifestations of pestering, respectively. Purchase outcome was measured in two ways, as mentioned previously. Parental report of how often they give in to their children's requests may underestimate the true frequency due to social desirability bias (e.g., parents may underreport how often they buy requested sweet or snacks because they don't want to be perceived as being too permissive). If a food is available in the home, this indicates a purchase was made, although may be affected by another social desirability bias (e.g., parents may not want to admit to having unhealthy products). However, anecdotally, the data collectors (who were hired from the community), indicated participants were comfortable answering questions about sensitive topics and frequency counts of response categories demonstrate variation across and within these purchase questions. Consumption was measured in four ways - frequency of soda, frequency of other SSBs, frequency of SSBs, and "frequent SSB drinker" based on parent report.

We tested immediate bivariate linkages between steps of the logic model (e.g., increased pester power and parents grant purchase request) as well as any associations between exposure to cues to subsequent steps in the pathway. Analyses were limited to those parent-child pairs where the parent "sometimes", "often", or "always" took the child shopping. Missing values for parental age, and household income were imputed with the software IVEWare in SAS macros (version 0.2, 2009, Software Survey Methodology Program at the University of Michigan's Survey Research Center, Institute for Social Research, Ann Arbor). All analyses were conducted in Stata (Statacorp v11) and controlled for the child's sex, age, parent's sex, parent's age, and per capita household income. Clustered standard errors accounted for parents shopping at the same supermarkets. We used Bonferroni's correction to account for multiple hypothesis testing. Analyses controlling for the number of times the parent went shopping were conducted, but were not presented as there were no qualitative differences. We used OLS analyses and negative binomial regression analyses for SSB intake (regular soda, other SSBs and total SSBs) because SSB consumption was positively skewed, but present the OLS model for ease of interpretation except in instances where the results differed.

Based on the exploratory findings, we constructed multivariate models that focused on the potential pathway of SSB-specific marketing to children's SSB consumption. In the multivariate models, to avoid collinearity, we used one variable to represent the construct at each stage of the logic model. For example, whether regular soda was available in the home was entered as the "purchase" variable. Although there were three variables related to pestering, we used frequency of making requests based on the five-point response category for the statement, "Your child will 
request a sweet or a snack." This variable was identified as the most important of the five items related to parent-child shopping behaviors in a factor analysis (see Appendix B). Multivariate models also included the parents' own SSB consumption (in ounces), based on the 24-hour recall data.

\section{Results}

\section{Sample characteristics}

A total of 214 households from the original PHRESH study had a child between 5 and 13 years of age in 2014 and were invited to participate in the supplemental survey. Of those, 162 household completed the additional interview for a response rate of $76 \%$. Characteristics of the stores used for major food shopping were not available for 11 households and 22 parents did not regularly bring their child food shopping, reducing the analytic sample size to 129 . As seen in Table 4-1, more than half of the children were female (60\%) and almost all (93\%) of the respondent parents were female. Almost all households had snack chips $(87 \%)$, or candy/cookies $(78 \%)$ in the home in the past week, and more than half (57\%) had regular soda. Thirty-eight percent of parents reported their child "frequently drinks soda pop and other sweetened beverages." On average, the children drank soda 10 times a month and other SSBs about 28 times a month, or almost daily.

Pestering was fairly common. Three-quarters of children (74\%) who went shopping with their parent requested sweets or snacks "often" or "always" and half (55\%) "often" or "always" placed items in the shopping cart. Most commonly, parents "sometimes" granted their child's request $(57 \%)$.

Table 4-1. Characteristics of the study sample

\begin{tabular}{lr} 
& $\begin{array}{c}\text { Total Sample } \\
(\mathbf{n = 1 2 9 )}\end{array}$ \\
\hline \hline Demographics & \\
Child - female & $59.7 \%$ \\
Child age in years, mean(SD) & $9.4(2.7)$ \\
Parent - female & $93.0 \%$ \\
Parent age in years, mean(SD) & $41.2(13)$ \\
Parent education & $7.8 \%$ \\
Less than HS & $44.2 \%$ \\
High school & $43.4 \%$ \\
Some college/technical & $4.7 \%$ \\
College/Graduate degree & \\
Household income per person in \$US, mean(SD) & $6526.6(6166.1)$ \\
Pestering & \\
Requests a sweet or snack &
\end{tabular}




\begin{tabular}{|c|c|}
\hline & $\begin{array}{c}\text { Total Sample } \\
(n=129)\end{array}$ \\
\hline Never & $2.3 \%$ \\
\hline Rarely & $2.3 \%$ \\
\hline Sometimes & $20.2 \%$ \\
\hline Often & $27.1 \%$ \\
\hline Always & $45.0 \%$ \\
\hline \multicolumn{2}{|l|}{ Places item in the cart } \\
\hline Never & $9.3 \%$ \\
\hline Rarely & $7.8 \%$ \\
\hline Sometimes & $27.9 \%$ \\
\hline Often & $17.1 \%$ \\
\hline Always & $37.2 \%$ \\
\hline \multicolumn{2}{|l|}{ Becomes upset } \\
\hline Never & $36.4 \%$ \\
\hline Rarely & $19.4 \%$ \\
\hline Sometimes & $23.3 \%$ \\
\hline Often & $7.0 \%$ \\
\hline Always & $14.0 \%$ \\
\hline \multicolumn{2}{|l|}{ Purchases } \\
\hline \multicolumn{2}{|l|}{ Parent grants requests } \\
\hline Never & $10.9 \%$ \\
\hline Rarely & $9.3 \%$ \\
\hline Sometimes & $57.4 \%$ \\
\hline Often & $14.7 \%$ \\
\hline Always & $7.8 \%$ \\
\hline \multicolumn{2}{|l|}{ Foods available in home in past week } \\
\hline Candy/cookies & $78.3 \%$ \\
\hline Snack chips & $86.8 \%$ \\
\hline Regular soda & $56.6 \%$ \\
\hline \multicolumn{2}{|l|}{ Child diet } \\
\hline Regular soda intake in times/month, mean(SD) & $9.7(21.1)$ \\
\hline Other SSB intake in times/month, mean(SD) & $28(32.6)$ \\
\hline Total SSB intake in times/month, mean(SD) & $37.2(45)$ \\
\hline Frequent SSB consumption & $37.2 \%$ \\
\hline \multicolumn{2}{|l|}{ Parent diet } \\
\hline Total SSB intake in oz/day, mean(SD) & $13.1(14.2)$ \\
\hline
\end{tabular}

The households reported doing their major food shopping at 17 unique stores in the Pittsburgh area where observational measures were available. Characteristics of the stores are presented in two ways - by stores and by participants - in Table 4-2. In the first column, stores are the units of analysis. In the second column, participants are the units of analysis, thereby showing how the store characteristics are weighted by popularity among the participants. The 
Herfindahl-Hirschman Index (HHI) of 1169 indicates a moderately concentrated marketplace for food shopping among participants and is demonstrated by the differences between the store distribution and the distribution of stores among participants. Although only one-third of the stores $(35 \%)$ were full-service supermarkets, more than half of participants $(56 \%)$ shopped at these stores. All three junk foods - candy, chips, and SSBs - were available at checkout for fourfifths of the participants (81\%). Most participants (88\%) shopped at stores where at least one junk food was visible from the main entrance. On average, participants could face up to 50 snack displays (for items such as candy or chips) and 29 SSB displays when doing their shopping. Junk food displays accounted for approximately $65 \%$ of all the marketing displays.

Table 4-2. Description of stores where participants did major food shopping and in-store marketing strategies

\begin{tabular}{|c|c|c|}
\hline & $\begin{array}{l}\text { Stores } \\
(n=17)\end{array}$ & $\begin{array}{c}\text { Participants } \\
(n=129)\end{array}$ \\
\hline Herfindahl-Hirschman Index (HHI) & $7.59(7.77)$ & \\
\hline \multicolumn{3}{|l|}{ Type of store } \\
\hline Discount grocery & $24 \%$ & $15 \%$ \\
\hline Supercenter or wholesale & $18 \%$ & $24 \%$ \\
\hline Specialty or meat market & $24 \%$ & $5 \%$ \\
\hline Full-service supermarket & $35 \%$ & $56 \%$ \\
\hline \multicolumn{3}{|l|}{ Checkout } \\
\hline Candy available & $94 \%$ & $99 \%$ \\
\hline Chips available & $71 \%$ & $84 \%$ \\
\hline Sweetened beverages available & $71 \%$ & $88 \%$ \\
\hline \multicolumn{3}{|l|}{ Types of junk foods available (0-3) } \\
\hline 1 & $24 \%$ & $11 \%$ \\
\hline 2 & $18 \%$ & $8 \%$ \\
\hline 3 & $59 \%$ & $81 \%$ \\
\hline \multicolumn{3}{|l|}{ Seen from main entrance } \\
\hline Candy & $47 \%$ & $30 \%$ \\
\hline Salty snacks & $53 \%$ & $48 \%$ \\
\hline Sweetened beverages & $35 \%$ & $52 \%$ \\
\hline \multicolumn{3}{|l|}{ Types of junk foods visible $(0-3)$} \\
\hline 0 & $24 \%$ & $12 \%$ \\
\hline 1 & $41 \%$ & $61 \%$ \\
\hline 2 & $12 \%$ & $15 \%$ \\
\hline 3 & $24 \%$ & $13 \%$ \\
\hline Number of junk food displays, mean(SD) & $61.9(37.8)$ & $78.9(29.6)$ \\
\hline \multicolumn{3}{|l|}{ Display strategy } \\
\hline Aisle displays & $10.8(6.3)$ & $12.1(5.8)$ \\
\hline Floor displays & $17.9(12.7)$ & $22.5(9.7)$ \\
\hline Price displays & $17.8(16.4)$ & $24.8(15.3)$ \\
\hline Register displays & $15.4(14.3)$ & $19.5(12.8)$ \\
\hline \multicolumn{3}{|l|}{ Type of display } \\
\hline Snack displays & $41.2(22.5)$ & $50.4(17.1)$ \\
\hline SSB displays & $20.7(16.8)$ & $28.5(13.8)$ \\
\hline $\begin{array}{l}\text { Proportion of displays for junk food, } \\
\text { mean(SD) }\end{array}$ & $0.65(0.27)$ & $0.65(0.26)$ \\
\hline
\end{tabular}


Characteristics of the store are represented in two ways. In the first column, stores are the units of analysis. In the second column, participants are the units of analysis. The second column shows how the store characteristics are weighted by popularity among the participants.

Herfindahl-Hirschman Index (HHI) is a measure of market concentration (from 0 to 10,000 ) where values closer to zero indicate nearly perfect competition and a value of 10,000 indicates a monopoly.

\section{Store characteristics and pestering}

We first tested the association between exposure to cues (store characteristics) to the purchase intent step (increased pester power). Each marketing characteristic was included separately in a model predicting pestering for each of the three pestering variables. Each column represents the results for a different pestering outcome, starting with 1) the child "always" requests a sweet or snack, 2) the child "always" puts an unnecessary item in the cart, and 3) the child is "often" or "always" upset if the requested item is not bought. None of the in-store marketing characteristics were significantly associated with any of the three pestering variables (Table 4-3).

Table 4-3. Associations between in-store marketing characteristics and pestering

\begin{tabular}{|c|c|c|c|c|c|c|}
\hline \multirow[b]{2}{*}{ STORE CHARACTERISTICS } & \multicolumn{2}{|c|}{ Always request } & \multicolumn{2}{|c|}{ Always puts in cart } & \multicolumn{2}{|c|}{$\begin{array}{c}\text { Often/Always } \\
\text { upset }\end{array}$} \\
\hline & OR & $\mathrm{p}$-value & OR & $\mathrm{p}$-value & OR & $\mathrm{p}$-value \\
\hline Main entrance - candy visible & 0.98 & 0.953 & 1.16 & 0.625 & 0.77 & 0.378 \\
\hline Main entrance - chips visible & 0.61 & 0.110 & 0.73 & 0.238 & 1.26 & 0.405 \\
\hline Main entrance - SSBs visible & 0.74 & 0.245 & 0.58 & 0.014 & 0.84 & 0.505 \\
\hline Main entrance - no. of types of junk foods & 0.75 & 0.122 & 0.76 & 0.094 & 0.94 & 0.784 \\
\hline Displays - no. of junk food displays & 1.00 & 0.641 & 1.00 & 0.762 & 1.01 & 0.242 \\
\hline Displays - no. of junk food aisle displays & 1.03 & 0.304 & 1.01 & 0.555 & 1.04 & 0.013 \\
\hline Displays - no. of junk food floor displays & 1.01 & 0.295 & 1.00 & 0.929 & 1.01 & 0.347 \\
\hline Displays - no. of junk food price displays & 1.01 & 0.319 & 1.00 & 0.936 & 1.01 & 0.392 \\
\hline Displays - no. of junk food register displays & 0.98 & 0.105 & 0.99 & 0.175 & 1.00 & 0.685 \\
\hline Displays - no. of snack displays & 1.01 & 0.434 & 1.00 & 0.924 & 1.02 & 0.080 \\
\hline Displays - no. of SSB displays & 1.00 & 0.931 & 0.99 & 0.439 & 1.01 & 0.677 \\
\hline Displays - \% junk food displays & 1.77 & 0.252 & 1.78 & 0.196 & 1.74 & 0.173 \\
\hline
\end{tabular}

* indicates OR is significantly different from 1.0 after applying Bonferroni's adjustment for multiple comparisons. Responses that the child was "often" upset $(n=9)$ or "always" upset $(n=18)$ were combined into one category due to low counts.

Each store characteristic was analyzed in a separate model, delineated by a dark line. Each column shows results for a different dichotomous pestering outcome. Logistic regression analyses controlled for child age, child sex, parent age, parent sex, and adjusted household income. Standard errors were clustered by store for major food shopping.

Including the number of shopping trips in the past month in the models did not affect the results (data not shown). 


\section{Store characteristics and purchase behavior}

We also tested the association between exposure to cues (store characteristics) to the purchase step (parents grant purchase requests). Each in-store marketing characteristic was included separately in a model predicting parent purchase and home availability. Each column represents a different outcome. The first outcome is the parent "often" or "always" buys the requested item. The next outcome is whether candy is available in the home, followed by home availability of chips, and then home availability of regular soda. None of the in-store marketing characteristics were significantly associated with purchase behavior - either based on parent report or home availability.

Table 4-4. Associations between in-store marketing characteristics and purchases (parent purchases and home availability)

\begin{tabular}{|c|c|c|c|c|c|c|c|c|}
\hline \multirow[b]{3}{*}{ STORE CHARACTERISTICS } & \multirow{2}{*}{\multicolumn{2}{|c|}{$\begin{array}{l}\text { Parent Purchase } \\
\text { Often/Always buys }\end{array}$}} & \multicolumn{6}{|c|}{ Home Availability } \\
\hline & & & \multicolumn{2}{|c|}{ Candy } & \multicolumn{2}{|c|}{ Chips } & \multicolumn{2}{|c|}{ Regular soda } \\
\hline & OR & $\mathrm{p}$-value & OR & $\mathrm{p}$-value & OR & $\mathrm{p}$-value & $\mathrm{OR}$ & p-value \\
\hline Main entrance - candy visible & 0.59 & 0.313 & 0.26 & 0.002 & 0.60 & 0.401 & 0.48 & 0.013 \\
\hline Main entrance - chips visible & 0.72 & 0.342 & 0.56 & 0.314 & 0.96 & 0.931 & 0.75 & 0.356 \\
\hline Main entrance - SSBs visible & 0.69 & 0.205 & 1.30 & 0.668 & 1.27 & 0.674 & 1.00 & 0.996 \\
\hline Main entrance - no. of types of junk foods & 0.68 & 0.082 & 0.60 & 0.058 & 0.90 & 0.733 & 0.72 & 0.052 \\
\hline Displays - no. of junk food displays & 1.00 & 0.776 & 1.01 & 0.354 & 1.00 & 0.986 & 1.00 & 0.979 \\
\hline Displays - no. of junk food aisle displays & 1.03 & 0.279 & 0.94 & 0.179 & 1.04 & 0.469 & 1.00 & 0.970 \\
\hline Displays - no. of junk food floor displays & 1.00 & 0.985 & 1.03 & 0.244 & 1.01 & 0.744 & 0.99 & 0.705 \\
\hline Displays - no. of junk food price displays & 1.00 & 0.778 & 1.04 & 0.025 & 0.99 & 0.603 & 1.00 & 0.633 \\
\hline Displays - no. of junk food register displays & 1.00 & 0.881 & 0.99 & 0.702 & 1.00 & 0.998 & 1.00 & 0.889 \\
\hline Displays - no. of snack displays & 1.00 & 0.838 & 1.01 & 0.444 & 1.00 & 0.899 & 1.00 & 0.849 \\
\hline Displays - no. of SSB displays & 1.01 & 0.700 & 1.02 & 0.276 & 1.00 & 0.870 & 1.00 & 0.844 \\
\hline Displays - \% junk food displays & 1.49 & 0.481 & 0.12 & 0.062 & 1.12 & 0.885 & 0.83 & 0.808 \\
\hline
\end{tabular}

* indicates OR is significantly different from 1.0 after applying Bonferroni's adjustment for multiple comparisons. Responses that the parent "often" gives in $(n=19)$ or "always" gives in $(n=10)$ were combined into one category due to low counts.

Each store characteristic was analyzed in a separate model, delineated by a dark line. Each column shows results for a different dichotomous outcome. Logistic regression analyses controlled for child age, child sex, parent age, parent sex, and adjusted household income. Standard errors were clustered by store for major food shopping.

\section{Store characteristics and SSB consumption}

There were also no significant association between exposure to cues (store characteristics) and consumption (see Table 4-5). Each in-store marketing characteristic was included separately in a model predicting parent purchase and home availability. Each column represents a different outcome. The first column shows results of logistic regressions for whether the child is a frequent SSB drinker (based on parent report). The second, third, and fourth columns show 
results of OLS regression for the child's frequency of regular soda consumption, other SSB consumption (non-soda), and total SSB consumption, respectively.

\section{Table 4-5. Associations between in-store marketing characteristics and children's SSB consumption}

\begin{tabular}{lcccccccc} 
& \multicolumn{2}{c}{$\begin{array}{c}\text { Frequent SSB } \\
\text { drinker }\end{array}$} & \multicolumn{2}{c}{$\begin{array}{c}\text { Regular soda } \\
\text { consumption }\end{array}$} & \multicolumn{2}{c}{$\begin{array}{c}\text { Other SSB } \\
\text { consumption }\end{array}$} & \multicolumn{2}{c}{$\begin{array}{c}\text { Total SSB } \\
\text { consumption }\end{array}$} \\
STORE CHARACTERISTICS & OR & p-value & b & p-value & b & p-value & b & p-value \\
\hline \hline Main entrance - candy visible & 0.33 & 0.006 & -6.05 & 0.040 & -3.37 & 0.434 & -8.63 & 0.106 \\
\hline Main entrance - chips visible & 1.12 & 0.809 & 2.10 & 0.549 & 1.78 & 0.660 & 2.91 & 0.601 \\
\hline Main entrance - SSBs visible & 1.66 & 0.181 & 4.36 & 0.136 & 3.58 & 0.439 & 7.29 & 0.203 \\
\hline Main entrance - no. of types of junk foods & 0.92 & 0.717 & 0.46 & 0.795 & 0.88 & 0.753 & 0.99 & 0.762 \\
\hline Displays - no. of junk food displays & 1.00 & 0.595 & 0.08 & 0.052 & 0.14 & 0.081 & 0.21 & 0.011 \\
\hline Displays - no. of junk food aisle displays & 0.99 & 0.796 & 0.25 & 0.454 & 0.62 & 0.048 & 0.86 & 0.067 \\
\hline Displays - no. of junk food floor displays & 1.02 & 0.271 & 0.20 & 0.177 & 0.48 & 0.052 & 0.64 & 0.010 \\
\hline Displays - no. of junk food price displays & 0.99 & 0.723 & 0.08 & 0.426 & 0.17 & 0.252 & 0.27 & 0.154 \\
\hline Displays - no. of junk food register displays & 1.02 & 0.443 & 0.16 & 0.114 & 0.10 & 0.622 & 0.21 & 0.390 \\
\hline Displays - no. of snack displays & 1.00 & 0.805 & 0.17 & 0.030 & 0.20 & 0.154 & 0.36 & 0.024 \\
\hline Displays - no. of SSB displays & 1.01 & 0.434 & 0.12 & 0.224 & 0.33 & 0.048 & 0.42 & 0.023 \\
\hline Displays - \% junk food displays & 0.95 & 0.946 & 2.77 & 0.728 & 9.94 & 0.160 & 13.05 & 0.268 \\
\hline
\end{tabular}

* indicates OR is significantly different from 1.0 or b is significantly different from zero after applying Bonferroni's adjustment for multiple comparisons.

Each store characteristic was analyzed in a separate model, delineated by a dark line. Each column shows results for a different outcome. The first outcome is dichotomous and the odds ratio (OR) is presented. The second through fourth outcomes are continuous and the beta coefficient (b) is presented. Regression analyses controlled for child age, child sex, parent age, parent sex, and adjusted household income. Standard errors were clustered by store for major food shopping.

\section{Pestering and purchases}

In-store marketing characteristics did not appear to bear any significant relationships with factors in the hierarchy of unhealthy food promotion effects, however this may be due to breakdowns in key relationships at other steps, which are investigated in the following sections.

Pestering had some associations with purchase behavior (see Table 4-6). In the first column, children who "always" requested sweets/snacks were 4.6 times more likely to have parents who "often" or "always" purchased requested items, compared to children who only pestered "sometimes" or less frequently. In the second column, the proportional odds ratio from an ordered logistic regression (from "never" to "always") shows that for a child who "always" verbally pesters by making requests, the odds of a parent who "always" purchases versus a parent of the other categories combined ("never" to "often") is 3.8 times greater than of a child who only pestered "sometimes" or less frequently. Looking at a second measure of pestering whether the child places unnecessary items in the cart - in the ordered logistic regression (from 
"never" to "always"), children who "often" and "always" physically pester by putting items in the cart have 3.6 and 5.0 times the odds of the parents being in a higher frequency purchase group compared to a child who pestered "rarely" or less. Emotional pestering - where the child gets upset if denied requested items - was not associated with frequency of parental purchase.

Table 4-6. Associations between children's pestering and frequency of parent purchases

\begin{tabular}{|c|c|c|c|c|}
\hline \multirow[b]{3}{*}{ PESTERING } & \multicolumn{4}{|c|}{ Parent Purchase } \\
\hline & \multicolumn{2}{|c|}{ Often/Always Purchase } & \multicolumn{2}{|c|}{ Purchase Frequency } \\
\hline & $\mathrm{OR}$ & $\mathrm{p}$-value & $\mathrm{pOR}$ & $p$-value \\
\hline \multicolumn{5}{|c|}{ Request (Never/Rarely/Sometimes $=$ ref) } \\
\hline Often & 2.47 & 0.131 & 2.17 & 0.163 \\
\hline Always & $4.59^{*}$ & 0.009 & $3.80^{*}$ & 0.006 \\
\hline \multicolumn{5}{|c|}{ Places item in cart (Never/Rarely = ref) } \\
\hline Sometimes & 1.53 & 0.540 & 2.38 & 0.024 \\
\hline Often & 2.72 & 0.167 & $3.63^{*}$ & 0.004 \\
\hline Always & 2.56 & 0.248 & $5.07^{*}$ & 0.001 \\
\hline \multicolumn{5}{|c|}{ Gets upset (Never = ref) } \\
\hline Rarely & 0.21 & 0.029 & 0.75 & 0.546 \\
\hline Sometimes & 0.45 & 0.171 & 0.99 & 0.988 \\
\hline Often & 0.89 & 0.872 & 1.28 & 0.714 \\
\hline Always & 1.37 & 0.718 & 1.65 & 0.580 \\
\hline
\end{tabular}

$\mathrm{pOR}=$ proportional odds ratio. For a one unit change in the predictor variable, the odds of a group of a certain level versus the lower levels combined is the proportional odds times larger.

* OR or pOR is significantly different from 1.0 after applying Bonferroni's adjustment for multiple comparisons. Responses that the child "never" $(n=3)$, "rarely" $(n=3)$, or "sometimes" $(n=26)$ requests were combined into one category due to low counts. Responses that the child "never" $(n=12)$ or "rarely" $(n=10)$ places item in the cart were combined into one category due to low counts. Responses that the parent "often" gives in $(n=19)$ or "always" gives in $(n=10)$ were combined into one category due to low counts.

Each pester variable was included as a categorical predictor in a separate model, delineated by a dark line. Each column shows results for a different outcome. The first outcome is dichotomous for whether the parent "often" or "always" purchase the requested item and the odds ratio $(\mathrm{OR})$ is presented. The second column shows the results from an ordered logit model and presented the proportional odds ratio (pOR) for parent purchases where "never" is the low end and "always" is the high end. Regression analyses controlled for child age, child sex, parent age, parent sex, and adjusted household income. Standard errors were clustered by store for major food shopping.

When using another indicator of purchases - whether certain junk foods were available in the home - no significant relationships emerged with any of the three pestering variables (see Table 4-7). 
Table 4-7. Associations between children's pestering and home availability of foods

\begin{tabular}{|c|c|c|c|c|c|c|}
\hline & \multicolumn{6}{|c|}{ Home Availability } \\
\hline & \multicolumn{2}{|c|}{ Candy/ cookies } & \multicolumn{2}{|c|}{ Salty snacks } & \multicolumn{2}{|c|}{ Regular soda } \\
\hline & OR & $\mathrm{p}$-value & OR & $\mathrm{p}$-value & $\mathrm{OR}$ & $\mathrm{p}$-value \\
\hline \multicolumn{7}{|c|}{ Request (Never/Rarely/Sometimes $=$ ref) } \\
\hline Often & 1.01 & 0.992 & 8.46 & 0.083 & 2.45 & 0.058 \\
\hline Always & 1.17 & 0.828 & 1.51 & 0.530 & 1.44 & 0.476 \\
\hline \multicolumn{7}{|c|}{ Places item in cart (Never/Rarely $=$ ref) } \\
\hline Sometimes & 0.69 & 0.36 & 0.71 & 0.679 & 1.10 & 0.883 \\
\hline Often & 0.59 & 0.359 & 0.55 & 0.410 & 4.37 & 0.103 \\
\hline Always & 1.03 & 0.966 & 0.46 & 0.236 & 1.19 & 0.752 \\
\hline \multicolumn{7}{|c|}{ Gets upset (Never $=$ ref) } \\
\hline Rarely & 1.8 & 0.275 & 2.56 & 0.142 & 1.53 & 0.506 \\
\hline Sometimes & 1.29 & 0.685 & 1.39 & 0.664 & 1.60 & 0.44 \\
\hline Often & 0.98 & 0.981 & 0.88 & 0.906 & 2.56 & 0.328 \\
\hline Always & 0.80 & 0.772 & 0.46 & 0.293 & 1.34 & 0.597 \\
\hline
\end{tabular}

* OR is significantly different from 1.0 after applying Bonferroni's adjustment for multiple comparisons.

Each pester variable was included as a categorical predictor in a separate model, delineated by a dark line. Each column shows results for a different outcome. Logistic regression analyses controlled for child age, child sex, parent age, parent sex, and adjusted household income. Standard errors were clustered by store for major food shopping.

\section{Purchases and children's SSB consumption}

We tested whether parent purchases of requested items were related to children's frequency of SSB consumption (see Table 4-8). Frequency of parent purchases appeared positively associated with frequency of regular soda consumption, however only the "sometimes" purchase category, the largest category (57\%), was statistically significant after adjusting for multiple comparisons. Availability of regular soda in the home was associated with almost 12 more occasions of regular soda consumption in a month, on average. Availability of other junk foods (candy and chips), was not associated with consumption of regular soda. Neither purchasing nor home availability were associated with frequency of other SSB consumption or total SSB consumption. 
Table 4-8. Associations between purchases and children's SSB consumption

\begin{tabular}{|c|c|c|c|c|c|c|c|c|}
\hline & \multicolumn{8}{|c|}{ SSB consumption } \\
\hline & \multicolumn{2}{|c|}{$\begin{array}{l}\text { Frequent SSB } \\
\text { drinker }\end{array}$} & \multicolumn{2}{|c|}{ Regular soda intake } & \multicolumn{2}{|c|}{ Other SSB intake } & \multicolumn{2}{|c|}{ Total SSB intake } \\
\hline & OR & $p$-value & $b$ & $\mathrm{p}$-value & $\mathrm{b}$ & $\mathrm{p}$-value & $\mathrm{b}$ & $\mathrm{p}$-value \\
\hline \multicolumn{9}{|c|}{ Purchase $($ Never $=$ ref) } \\
\hline Rarely & 3.5 & 0.205 & 2.82 & 0.076 & -3.05 & 0.774 & 0.08 & 0.994 \\
\hline Sometimes & 2.78 & 0.194 & $8.93^{*}$ & $<0.001$ & -2.11 & 0.787 & 6.93 & 0.376 \\
\hline Often & 3.71 & 0.123 & 15.72 & 0.097 & 7.97 & 0.447 & 21.28 & 0.079 \\
\hline Always & 5.26 & 0.090 & 17.24 & 0.118 & -6.13 & 0.641 & 11.44 & 0.603 \\
\hline \multicolumn{9}{|c|}{ Home availability } \\
\hline Candy & 1.70 & 0.300 & 5.73 & 0.192 & -3.59 & 0.670 & 1.63 & 0.876 \\
\hline Chips & 3.97 & 0.065 & 3.02 & 0.469 & 9.17 & 0.156 & 11.94 & 0.134 \\
\hline Regular soda & 2.09 & 0.024 & $11.53^{*}$ & 0.001 & -4.24 & 0.493 & 8.25 & 0.289 \\
\hline
\end{tabular}

* OR is significantly different from 1.0 or b is significantly different from zero after applying Bonferroni's adjustment for multiple comparisons.

Each purchase variable was analyzed in a separate model, delineated by a dark line. The first purchase variable, parent report of purchasing frequency, is a categorical variable. The second through fourth purchase variables are home availability indicators for candy, chips, and regular soda, respectively. Each column shows results for a different outcome. The first outcome is dichotomous and the odds ratio (OR) is presented. The second through fourth outcomes are continuous and the beta coefficient (b) is presented. Regression analyses controlled for child age, child sex, parent age, parent sex, and adjusted household income. Standard errors were clustered by store for major food shopping.

\section{Multivariate analysis of children's SSB consumption}

Results from the multivariate models are presented in Table 4-9. Only one variable was associated with being a frequent soda consumer. Having regular soda available in the home was associated with two times greater odds of being a frequent soda consumer.

There were a few significant associations with the number of times children drank soda in a month. Children whose households shopped at a store with SSBs visible from the main entrance drank regular soda approximately six times more than those from households where the store didn't have those characteristics. Children who "always" requested sweets or snacks drank regular soda approximately 11 more times than their counterparts who only "sometimes" or less frequently requested these items. Home availability of regular soda continued to be a significant predictor of more frequent soda intake - approximately 10 more times in a month, or 2 to 3 times a week, on average.

Parent's daily SSB consumption was positively associated with their child's consumption of other SSBs. Parent's consumption of a 12-oz can of soda a day was associated with approximately 6 more occasions of other SSB consumption. No other variable predicted child consumption of other SSBs.

None of the predictors were significantly associated with all SSB consumption, except for parent SSB consumption in the negative binomial model (see Appendix C). 
Table 4-9. Predictors of children's SSB consumption

\begin{tabular}{lcccccccc} 
& \multicolumn{2}{c}{$\begin{array}{c}\text { Frequent soda } \\
\text { drinker }\end{array}$} & \multicolumn{2}{c}{ Regular soda } & \multicolumn{2}{c}{ Other SSBs } & \multicolumn{2}{c}{ Total SSBs } \\
& OR & p-value & b & p-value & b & p-value & b & p-value \\
\hline \hline Parent SSB consumption, daily (oz) & 1.02 & 0.255 & 0.29 & 0.189 & $0.52^{*}$ & 0.020 & 0.82 & 0.051 \\
$\quad$ & 1.91 & 0.116 & $5.73^{*}$ & 0.037 & 4.90 & 0.326 & 9.83 & 0.121 \\
SSBs visible at main & & & & & & & & \\
Request & (ref) & & (ref) & & (ref) & & (ref) & \\
$\quad$ Never/Rarely/Sometimes & 2.05 & 0.255 & 2.94 & 0.488 & 4.70 & 0.560 & 5.84 & 0.557 \\
$\quad$ Often & 2.84 & 0.079 & $11.19^{*}$ & 0.004 & 8.89 & 0.270 & 19.82 & 0.056 \\
$\quad$ Always & $2.07^{*}$ & 0.009 & $10.16^{*}$ & 0.007 & -6.12 & 0.369 & 5.24 & 0.548 \\
\hline
\end{tabular}

* OR is significantly different from 1.0 or b is significantly different from zero.

Results from multivariate regressions where each column shows results for a different outcome. The first outcome is dichotomous and the odds ratio (OR) is presented. The second through fourth outcomes are continuous and the beta coefficient (b) is presented. Regression analyses controlled for child age, child sex, parent age, parent sex, and adjusted household income. Standard errors were clustered by store for major food shopping.

\section{Discussion}

There was some evidence of a feasible pathway of unhealthy food promotion effects on children's consumption of SSBs in this cross-sectional sample from two low-income neighborhoods in Pittsburgh. In-store marketing, measured by availability of sweet and salty snacks and SSBs at the checkout, visible from the main entrance, and on display promotions, was not independently associated with children's pestering, parents' purchases, or children's SSB consumption. However, shopping at a store where SSBs were visible from the main entrance was associated with frequency of regular soda consumption in the multivariate model. In addition, several of the logical mechanisms for how marketing may impact children's consumption held up - namely "always" requesting snacks or sweets was associated with more frequent parent purchasing of requested items, and home availability (another indicator of purchase behavior) of soda was associated with more frequent soda consumption.

\section{Children's SSB consumption}

Average frequency of total SSB intake among children was 37 times per month, or more than once a day. SSBs other than soda accounted for most of that total - 28 times per month - with regular soda accounting for approximately one-fourth of the total. Both the WHO and USDA suggest that calories from added sugars (from all sources) should comprise less than $5-10 \%$ of total calories for children. ${ }^{12,140}$ Just one cup of lemonade (8oz; 140 calories from sugar) for a moderately active 5-year old girl would start to exceed these recommendations. Consumption of juice drinks and caloric soft drinks decreased between 2003 and 2012, ${ }^{141}$ however, these trends mask differences by age and race/ethnicity. African American children of similar age (6-11 
years) to this study consumed the same amount of SSBs between 2003 and $2010 .{ }^{142}$ Furthermore, although nationwide trends indicate that consumption of soda and other SSBs are declining among 2-18 year olds, low-income families have not demonstrated the same decline in SSB consumption. ${ }^{141,143,144}$

Previous research has found that children prefer and request high-fat and high-sugar items, ${ }^{123}$ thus we would expect that children who pester would consume sodas and other SSBs more often than children who didn't. "Always" requesting items was associated with an additional 11 occasions of regular soda consumption in the multivariate model, but there was no relationship between requesting and other, non-soda SSBs. The different findings for regular soda versus non-soda SSBs may highlight differences in perceptions of the varying types of SSBs. The negative consequences of children drinking regular soda have been discussed for years, however non-soda sugar beverages have only recently garnered attention for their association with similar health risks. In fact, some fruit juices contain even more sugar than soda. ${ }^{145}$ In a 2011 survey of parents with children between 2-17 years of age, more than half of parents indicated concern about high fructose corn syrup and sugar (58\% and 55\%, respectively), yet the majority of parents $(77 \%)$ provided fruit drinks for their child, indicating a level of disconnect regarding which beverages contain sugar. ${ }^{146}$ Similarly, in a telephone survey of parents in Philadelphia, higher perceived healthfulness of SSBs (soda, sweetened tea, fruit drinks, and sports drinks) was associated with children consuming more of that $\mathrm{SSB},{ }^{147}$ suggesting parent education may be a key component for reducing SSB consumption in children.

\section{In-store marketing characteristics}

Only one in-store marketing characteristic - whether SSBs were visible from the main entrance - had a significant association in the multivariate model. There are several reasons that might explain why we didn't find direct effects of the in-store marketing characteristics on children's SSB consumption. This study did not attempt to quantify the total exposure of in-store marketing of junk foods, although other audit studies have noted that junk foods are ubiquitous

in the supermarket setting. ${ }^{98}$ It may be that we didn't see significant associations with the in-store marketing characteristics that were measured because the overall exposure within the store had surpassed some threshold such that the individual indicators are meaningless. It is also worthwhile to note that store characteristics were based on an assessment at one point in time under the assumption that this assessment was representative of the environment the participants shopped in, but it's likely that these characteristics change with time. Specifically, the number and distribution of displays are likely to change in conjunction with weekly sales and seasonal promotions. In order to more rigorously test the association between in-store characteristics and the various antecedents of children's consumption, one would need to conduct an observational study where in-store marketing characteristics are documented and parent-child pairs are followed throughout the store on the same day to record pestering and purchase behaviors, and then subsequently contacted to ask about consumption. Although parent-child pairs have been 
observed in supermarket settings before, observational studies of this kind can be resourceintensive. $^{128,148,149}$

Contrary to prior evidence on the role of in-store marketing on children's preferences, the shopping environment was not associated with child pestering in this sample. ${ }^{128}$ Previous research has demonstrated strong relationships between advertising and children's food choices, however it may be that in-store marketing is only a small piece of the larger landscape of food advertisements, particularly that in TV and other media. ${ }^{115,116}$ Researchers across eleven countries coded television advertisements on popular children's television channels and estimated that a child who watches 2 hours of TV programming per day would be exposed to approximately 56 to 126 food advertisements per week. ${ }^{120}$ Using those estimates, advertisements on TV would far outnumber the number of times a child was exposed to SSBs and junk foods while waiting in the checkout in a week. Other studies have found positive correlations between children's media exposure and the number of requests they made. ${ }^{123,150}$ These effects are especially concerning given reports that African American children consume more SSBs than their white counterparts ${ }^{151,152}$ and are exposed to more television food promotion through television. ${ }^{153}$ In a preliminary analysis of the PHRESH population, screen time (categorized as $<2$ hours/day, 2-4 hours /day, and $>4$ hours/day) was not associated with greater likelihood of requests, however, more precise measurement of screen time, specifically with and without commercial advertisements would be necessary to draw stronger conclusions. It's especially important to fully capture the changing landscape of media. For example, recent experimental work using "advergames" - computer games that integrate advertisements into the playing experience using strategies such as product placement or brand sponsorship - has found that exposure to foods while playing advergames increased children's consumption of energy-dense snacks compared to children exposed to non-food cues. ${ }^{154,155}$

\section{Pestering}

Three types of pestering were examined - verbal, physical, and emotional. The majority (75\%) of children "often" or "always" pestered, which is similar to the $80 \%$ of UK mothers who have been asked by their children to buy an advertised food product and the $78 \%$ of children from a multi-country European sample who ask for items seen on the television. ${ }^{125,156}$ The pestering-purchase link was established in parent purchases, but not home availability. Both verbal and physical pestering were associated with greater frequency of parent purchases, however the causality of these relationships remains unknown. It could be that because parents often purchase their child's requests, a child will pester more, knowing the parent will grant the request. We were surprised to see that emotional pestering - where the child gets upset - was not related to parent purchases. However, only one-fifth of children in this study "often" or "always" emotionally pestered, and the small sample size may have limited our ability to see a significant association. 


\section{Purchasing}

Parent purchases were measured in two ways - frequency of parents buying requested sweets or snacks and availability of junk foods in the home. We saw a trend of more frequent purchasing with more frequent regular soda intake, although only one comparison ("sometimes" buying compared to "never" buying) was statistically significant. The association between home availability of regular soda and children's regular soda consumption had a strong effect size equivalent to the child drinking soda three more times each week in the bivariate analysis and 10 more times a month in the multivariate analysis. In an exploratory study in New Zealand, children reported being influenced by ads for high fat, high sugar, and high salt foods, however their actual consumption typically depended on what foods parents made available in the home and what parents had permitted them to eat. ${ }^{157}$

\section{Parent modeling}

In our sample, a typical can of SSBs (12 oz) consumed by the parent was associated with six more instances of SSB consumption in the child. Previous studies have looked at the role of the parent's dietary behaviors in relation to their children's and found similar results. Parental SSB consumption was positively associated with children's soft drink consumption in a European sample, although the magnitude of the effect was small. ${ }^{158}$ Soda availability and parent consumption of soda were both associated with greater odds of children consuming soft drinks five or more times per week in a national mail-in survey. ${ }^{159}$ One study looked specifically at African American father-child pairs and found that the father's SSB consumption and home

availability significantly predicted the child's SSB consumption. ${ }^{160}$ In the only one of these studies that also looked at marketing characteristics (exposure to commercial TV), researchers found that exposure to commercial TV was significantly associated with children's SSB consumption even after controlling for whether parents consumed sugar sweetened beverages and whether they approved of their child's sugar sweetened beverages. ${ }^{161}$ This suggests the need for further research on whether addressing the parent side of the equation can meaningfully improve children's diets, and ultimately weight status.

\section{Limitations}

The lack of consistent relationships in the logic model was surprising, but may be due to limitations in the study design.

Due to the cross-sectional nature of this analysis, we cannot attribute causality. For example, it may be that frequent consumption of SSBs increases pestering, or that because children (or their parents) regularly drink SSBs, parents chose to shop at stores where SSBs are very prominent or easily accessible. To establish the causality of these associations, we'd need a longitudinal study or experimental supermarket where these factors could change and we could see the resulting effects. 
Having regular soda in the home was consistently associated with children's soda consumption, however the measure of home availability is subject to several limitations. Home availability is a reflection of the entire household's preferences and is thus a noisy measure. For example, a child in our sample might not pester the parent for junk foods, however, regular soda may be in the home anyway because a teenager requests the item. These household preferences might also alter the child's pestering behavior. If the household is always stocked with cookies, the child might not need to specifically request it because it will be bought regardless. It's also possible that there was not enough variation in household availability of the other junk foods salty snacks and sweets - to identify additional effects. For example, almost all of the households $(87 \%)$ had snack chips in the home. Little variation and a small sample size may have resulted in underpowered analyses.

The child diet outcomes were based on parent report and it's possible that parents may not fully account for their child's diet outside of the home and the reported intake may be an underestimate of children's true consumption, particularly for empty calories. In fact, an examination of 2009-2010 NHANES data found that one-third of empty calories came from school. ${ }^{162}$ In addition, older children who have their own spending money may be buying foods and drinks their parents don't know about. In this sample, $60 \%$ of children received allowance or spending money, thus their SSB consumption may be higher than reported by parents. In addition, the parent questionnaire asked about the frequency of SSB consumption, not the amount, and no reference serving size was provided. This means that a child who drinks one 8ounce soda would analytically be the same as a child who drinks one 20 -ounce soda. One of the outcomes examined - frequent SSB drinker - was based on whether the parent affirmed a statement that "our child frequently drinks soda pop or other sweetened drinks", which relied on the parent's definition of "frequent."

Reliance on parent report versus objective or observed measures posed additional problems. For example, parents might be reluctant to answer honestly about how often they give in to their child's requests. To minimize social desirability bias, parents were assured of confidentiality of all their responses, but this is unlikely to fully eliminate this type of biased reporting. There is always a possibility that this type of misreporting can distort the true association. Furthermore, although the parent was asked about their child's behaviors in the context of food shopping, it's possible that parents recalled their child's overall request behaviors across numerous settings, for example asking for dessert when eating out. In addition, when parents were asked how frequently their child requested "a sweet or a snack", parents who did not consider a sugarsweetened beverage a "sweet" would have underreported their child's pestering, biasing results towards a smaller effect size.

This study did not attempt to quantify the total exposure of in-store marketing of junk foods, however other audit studies have noted that junk foods are ubiquitous in the supermarket setting. ${ }^{98}$ It may be that we did not see direct effects of the store marketing characteristics that were measured because the overall exposure within the store had surpassed some marketing 
threshold such that the individual indicators are meaningless. It is also worthwhile to note that store characteristics were based on an assessment at one point in time under the assumption that this assessment was representative of the environment the participants shopped in, but it's likely that these characteristics change with time. Specifically, the number and distribution of displays are likely to change in conjunction with weekly sales and seasonal promotions. In order to more rigorously test the association between in-store characteristics and parent and child behaviors, one would need to conduct the supermarket observational audit and the parent questionnaire on the same day of shopping. Although we saw differences in regular soda as an outcome and other SSBs as an outcome, the food store observation audit did not distinguish between the different types of SSBs when capturing in-store marketing characteristics (e.g., number and type of SSB displays).

\section{Conclusion}

There is a large pool of prior evidence that speaks to the effect of marketing exposure on children's preferences, and although we did not see a strong association between in-store marketing characteristics and child and parent behaviors, our lack of evidence could be related to the study design and small sample size. We did find an association between pestering and parent purchases, and although this association was not driven by in-store marketing, it does support policy efforts to reduce influences on children's requests, such as media advertisements and product sponsorship. We also found a link between home availability of soda and soda consumption, which may not be surprising, but further identifies the home environment as an important predictor of soda consumption and potential setting for intervention. Moreover, the

difference between our findings for soda and for other SSBs indicates a need to increase parental awareness of the high sugar content in common sugary beverages other than soda, such as juice drinks and sports drinks. 


\section{Chapter 5 Public opinions on the food environment}

\section{"Stay out of my kitchen": A case study of word usage and how the public talks about nutrition policy}

\section{Summary}

Introduction. Public policies may improve nutrition; however not every strategy will be palatable to all audiences. This analysis looks at how changing access to certain foods by 1) decreasing access to unhealthy foods and 2) increasing access to healthy foods, is perceived by the public.

Methods. A total of 1824 reader comments were collected from two online New York Times articles about a ban on large size sugar-sweetened beverages (SSBs) and the role of supermarkets in food deserts. Text analysis software were used to conduct a content analysis to inform what readers said about these policies and a rhetorical analysis to examine language use related to culturally meaningful categories such as emotions, social relationships, and cultural values.

Results. There were very different public comments and perceptions to each of these strategies and their perceived ability to improve diet. The so-called "soda ban" induced reactive comments about social/political freedoms, rights, and choice, while words such as science, research, evidence, and knowledge were underrepresented. An exploratory factor analysis revealed a dominant "Us vs. Them" mentality characterized by negative emotions and subjective perceptions of government overreach, with comments about "Big Brother" and "slippery slopes." In contrast, the discussion around increasing access to supermarkets was descriptive and narrative, and overall readers rallied around a common goal to achieve health, although they differed in whether supermarkets could achieve this.

Discussion. Decreasing access to unhealthy foods motivates emotional and ideological, rather than empirical, discussions. Understanding the public mindset towards various strategies to improve diet is important for effective communication and can inform policy formulation and decision making.

\section{Introduction}

Chronic disease is a serious public health issue in the United States. One out of every two adults (ages 18+) has a chronic disease, such as heart disease, hypertension, stroke, diabetes, or cancer. ${ }^{1}$ Diet is a key modifiable risk factor for chronic diseases, however few Americans eat a diet high in nutrient-dense foods such as fruits, vegetables, whole grains, fat-free or low-fat dairy, and lean proteins and limited intake of sodium, saturated fats, added sugars, and refined grains, as recommended by the USDA's Dietary Guidelines for America. ${ }^{163}$ 
Policymakers could impact diet through regulation, such as directing tax dollars to nutrition education, banning food marketing to children, and restricting development of fast food businesses. Between 2001 and 2015, over 4,000 nutrition policies have been introduced at the state level. ${ }^{164}$ However, of those where a decision has been reached, about half have been enacted and half have failed to be enacted, demonstrating that regulatory actions are not always politically popular.

Public opinion can be crucial to the success of population health policies. Dodson et al. (2009) conducted interviews with 16 legislators and staffers who were leaders in obesity policy and identified barriers and facilitators to state policies to prevent childhood obesity. ${ }^{165}$ They found that public opinion can serve as a facilitator or barrier - support from stakeholders was helpful, while misinformed constituents posed a challenge.

How issues are framed to the public can be a critical determinant of public opinions. For example, reading and agreeing with the idea of a "toxic" food environment as a cause of obesity was significantly associated with more support for redistributive policies (e.g., funding for greater access to healthy foods in public schools), compensatory policies (e.g., warning labels), and price-raising policies (e.g., taxes and surcharges). ${ }^{166}$ Two recent studies on news media coverage of soda tax proposals found that proponents of these taxes used frames highlighting the health concerns related to SSBs while opponents focused on concerns about economics and Big Government. ${ }^{167,168}$

Both researchers and policymakers have likened America's nutrition crisis to the smoking epidemic that caused the public health battle against Big Tobacco. ${ }^{167,169-171}$ Policymakers have encountered difficulties in passing regulations and furthering the public discourse due to strong industry lobbying. In some cases, the food and beverage industries have created groups, such as the Americans Against Food Taxes (AAFT), whose members include community-based groups who lend grassroots credibility to industry groups but are sponsored by or otherwise affiliated with the food and beverage industries. ${ }^{172}$ Such strategies are part of sophisticated public relations campaigns and attacks on health policy that are reminiscent of Big Tobacco's playbook. ${ }^{170}$ Other tactics include emphasizing personal responsibility, making large political contributions, disputing science, and inundating consumers with product marketing. ${ }^{170,173}$ Reducing smoking required a multi-pronged approach and some strategies were more successful than others. Similarly, improving the nation's diet requires understanding which policies are deemed more controversial and how to frame issues for maximum acceptability.

A key issue for improving diet has to do with food access, or a person's ability to obtain foods. Two ways to address diet through food access are to 1) decrease access to unhealthy foods and 2) increase access to healthy foods. Decreasing access to unhealthy may take the form of making unhealthy foods less affordable (e.g., price-raising strategies) or less available. Increasing access to healthy foods might involve making foods more affordable (e.g., subsidies) or more available. For this analysis I looked at the two contrasting policy levers for improving nutrition using two policies that could be implemented by local jurisdictions as examples - 
portion size restrictions (decreasing access) and food store growth (increasing access). These two policies were selected because they both received significant media attention around the same time (Spring 2012), thus public opinion would be shaped by similar political and cultural climates at the time.

Portion size restrictions. In 2012, Mayor Michael Bloomberg of New York City proposed a new measure to restrict the sale of sugars sweetened beverages (SSBs) such as soda, sports drinks, and energy drinks larger than 16 oz. ${ }^{174}$ A typical $20 \mathrm{oz}$. soda contains $15-18$ teaspoons of sugar and children and adolescents consume more than 200 calories on average from SSBs each day - more than $10 \%$ of their daily caloric intake. ${ }^{144}$ SSBs increase the risk of obesity, diabetes and heart disease. ${ }^{60,175}$ The proposed regulation would have affected NYC's food service establishments, including delis, fast food, restaurants, movie theaters, and corner stores that are inspected by the health department. This was the first proposal in the nation to limit SSB sales to a specific portion size. The regulation was deemed unconstitutional by an appellate court in 2013 and was never implemented.

Food store growth. In 2011, the U.S. Departments of Agriculture (USDA), Treasury, and Health and Human Services (HHS) established the Healthy Food Financing Initiative (HHFI) to increase healthy, affordable food in communities that lack such options. ${ }^{25}$ These communities are often referred to as "food deserts" and a growing body of research has studied the relationship between living in a food desert and negative health outcomes such as obesity and poor diet. ${ }^{49,50,72}$ The HHFI encourages the growth of food venues by supporting the construction of new food outlets (e.g., supermarkets and farmer's markets) as well as the renovation/expansion of existing food stores to include more healthy foods through grants, zoning changes, and monetary incentives (e.g., tax breaks, matching funds).

Previous research has explored media coverage of SSB taxes, ${ }^{168,176,177}$ however, little is known about the public opinion of alternative strategies to improve nutrition, namely soda bans and supermarket growth. The purpose of this research is to examine public opinion about nutrition policy. Understanding the underlying arguments for and against these strategies can inform policymakers and advocates about how to frame nutrition policy.

\section{Methods}

\section{Data sources}

The data used were two specialized texts curated from online comments from related $\mathrm{New}$ York Times articles. New York Times is a well-read and well-regarded newspaper. It is ranked \#1 for digital editions ${ }^{\dagger}$ with an average daily circulation close to 2 million. New York Times

\footnotetext{
${ }^{\dagger}$ Alliance for Audited Media. Available at http://auditedmedia.com/news/blog/top-25-us-newspapers-for-march2013.aspx (last accessed December 5, 2014).
} 
advertises an online audience that is $58 \%$ male, $77 \%$ age 35 or older, and $71 \%$ college graduates. Comments are limited to the first few days after online publication and thus represent initial reactions.

The portion size restriction (decreasing access) text contained 1426 online comments on an article published May $30^{\text {th }}, 2012$ when the proposal was first announced. ${ }^{178}$ The article, entitled "New York Plans to Ban Sale of Big Sizes of Sugary Drinks," provided an overview of the city's proposal, including the rationale, affected establishments, examples of covered and exempt drinks, and timeline. ${ }^{178}$

The food store growth (increasing access) text contained 416 online comments from an article published on April 17 ${ }^{\text {th }}$, 2012. ${ }^{179}$ The article, entitled "Studies Question the Pairing of Food Deserts and Obesity," was motivated by two research studies ${ }^{180,181}$ that had just been published whose results undermined First Lady Michelle Obama's approach to eliminating food deserts by encouraging more retail food stores in low-resource neighborhoods. ${ }^{179}$

The comments were copied from the website in reverse chronological order (i.e., most recent comments first) into a single text file for each topic. Information about the comment (i.e., commenter name, geographic location, time/date) was removed to facilitate processing of the text. All text was converted into Unicode- 8 format to ensure consistent recognition of words and punctuation.

Online comments represent the opinions of people who feel strongly enough about the issue to engage in the discussion, and may overrepresent the most passionate individuals (i.e., the squeaky wheel gets the grease). However, these people are also more likely to be involved in advocacy and voting around the issue, thus their opinions are very important. At the same time, the texts could also potentially underrepresent people with controversial views who fear retribution for an unpopular stance, however people could choose to post anonymously if they did not wish to have their name associated with their viewpoint.

Online comments can be incredibly diverse in their formality and be characterized as anywhere between spontaneous speech and planned speech. Spontaneous speech is distinguished by its inclusion of interruptions, overlaps, false starts, hesitations, fillers, omission, repetition, and feedback while planned speech is more scripted and lacks such characteristics. Because of the way these online comments were created (a commenter must submit their comment to be published $^{\S}$ ), an online comment may contain all, some, or none of the characteristics of spontaneous speech. A comment may be proof-read and edited before submission, thereby resembling planned speech, or can be a commenter's stream of consciousness thoughts with hesitations (“...”) and fillers ("you know”) which are more reminiscent of spontaneous speech.

\footnotetext{
$\$$ Percentages for a key advertising target of affluent adults, according to The New York Times Media Kit . Available at http://nytmediakit.com/online (last accessed February 26, 2016)

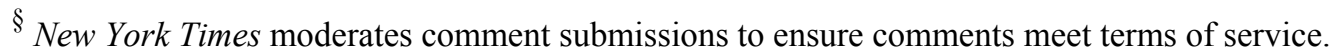




\section{Analyses}

\section{Content Analysis}

To understand what people think about the policies, content analysis was used to systematically identify recurrent themes in the comments. This was done using three techniques - word frequency, word collocation, and n-grams - using AntConc (Laurence Anthony, Version 3.4.3 Tokyo, Japan).

Word frequency can capture the words and ideas that are associated with the topic. Frequencies were calculated as raw counts and relative frequencies. Raw counts highlight the most salient words within a text while relative frequencies are useful for putting raw counts into context and looking across texts. Using relative frequencies can help separate the signal from noise. For example, the word "good" might appear 50 times in a text and seem important, however since it is one of the most common words in the English language, 50 times might be expected, or even comparatively low. In this analysis, relative frequencies identified keywords that occurred more frequently or less frequently when compared to frequencies in a standard American English text (the Freiburg-Brown corpus of American English, or FROWN) using loglikelihood calculations.

The word collocation function detects pairs of words that were commonly used together in close proximity (within five words of each other). Many words have multiple definitions with the meaning of the word depending on how it is used. Looking at words in close proximity (i.e., words that are collocated together) helps determine which definition the word takes on during a specific instance. For example, the word vessel can indicate a container or a boat, but if vessel was collocated with the word captain, the latter definition could be inferred. For this analysis, collocates of keywords identified by word frequency were examined.

The n-gram function, finds common consecutive words and phrases of $n$ length. It is similar to the collocate function and helps characterize the meaning of words based on their context but is more restrictive than collocation because words must be consecutive to be identified as a cluster. For example, the phrase breed of dog would be a different n-gram than dog breed, however, dog and breed would be considered collocates. In other words, all n-grams are collocates, but not all collocates will be n-grams. N-grams of three or more words that appeared three or more times were identified through the software and then investigated. N-grams with thematic similarities were categorized together.

Both word collocation and n-grams can help refine the interpretations that are based solely on word frequency. For example, the word good may be disproportionately frequent in a text and since the word good is often used to connote positivity, we may think that the writer or speaker is in favor of something. However if good is preceded with not, this may reverse the previously drawn conclusion from the word frequency. For this analysis, the word frequency, word collocation, and word n-grams were all reviewed iteratively to facilitate interpretation of the content. The software was primarily used to create initial working knowledge of the discussions 
and highlight places in the text that could contribute to the construction of themes, which was then reviewed in context for meaning.

\section{Rhetorical analysis}

To understand how people think about the policies, a rhetorical analysis was conducted using DocuScope ( Kaufer, Ishizaki, \& Ishizaki, Version 3.4 Carnegie Mellon University), a lexicogrammatical software designed to analyze text. A pre-loaded dictionary of patterns developed by David Kaufer uses a taxonomy to classify language features (i.e., words and phrases) by culturally meaningful categories such as emotions, social relationships, and cultural values. ${ }^{182}$ This software has previously been used to classify and compare language patterns to predict consumer sentiment with high accuracy. ${ }^{183}$ The 1426 comments in the portion size restriction text comprised 99,119 words, of which 7959 were unique. The 416 online comments in the food store growth text comprised 41,717 words, of which 5010 were unique. The text was split into smaller word files ("chunks") containing the same number of words (1000 each) for statistical comparability across texts. Chunks with less than 1000 words were not included in the analyses. Frequencies of language features were calculated for each text chunk.

The software codes all of the language features into classes, dimensions, and clusters (the full list includes 118 classes nested within 43 dimensions and 15 larger clusters). Classes represent the smallest unit of analysis and include categories such as Uncertainty, Negativity, and Curiosity. For example, use of hedging words such as maybe and perhaps would be classified as Uncertainty language. Dimensions are larger groupings of classes, for example, the Sadness and Fear classes belong to the Negative Emotion dimension. Clusters encompass dimensions and their classes and are useful for broad characterizations of language, such as whether language is Emotional, as when it contains the Negative Emotion and Positive Emotion dimensions, or Academic, due to preponderance of Abstract Thought or Citing Others. The frequencies were standardized to represent the percent of words in the text belonging to that set of patterns (e.g., 54 occurrences of words defined as relaying the Confidence class in a 1000-word chunk would have a frequency of 5.4).

ANOVA tests were used to identify differences between the two policies in the average frequencies. Kolmogorov-Smirnov tests were used to identify differences in class frequency distributions between the policy text and a Standard English text (FROWN corpus). Exploratory factor analysis (EFA) was used to identify latent constructs comprised of language classes that strongly correlate with each other. ${ }^{184}$ Stata version 11.2 (StataCorp) was used for ANOVA and

Kolmogorov-Smirnov and R version 3.2.2 (R Foundation for Statistical Computing) was used for EFA. 


\section{Results}

\section{Content analysis}

Comments in both texts reflected people's thoughts and opinions, although commenters focused on different aspects about the policies. In the Decrease_Access text, restrictive and negative words (e.g., too much, too far) were common and people talked about freedom and rights more than science and research. There was an overall popular view that this was a liberal or Socialist policy and that government had overstepped its boundaries. In the Increase_Access text, people appeared split over whether poor geographic access to foods was a problem, and whether adding more stores would improve nutrition. The discussion included descriptions of people's own experiences as food and transportation (e.g., bus, car, drive, walk) words were common.

\section{Decrease_Access text}

\section{Frequency}

Table 5-1 shows keywords organized by four common topics (general understanding, population, political ideology, values) that emerged and offered implications about the policy's potential for success. The first row presents keywords that describe the general understanding of what the proposed policy is about. The commenters understood this is a policy about drink size and brought up words like sugar, calories, and obesity. They also primarily talked about the policy as a ban. People also brought up related topics not discussed in the original article, such as diabetes, healthcare, and corn syrup, indicating prior knowledge about obesity and nutritionrelated topics. In the second row, keywords that emerged about different populations emerged. Commenters talked about broad groups - people, adults, citizens, Americans. Kids and children also came up, mostly as a vulnerable population that people were more willing to accept restrictions for. A fraction of references to children were in the context of feeling infantilized. Other age-specific groups - babies, teens, and elders - were neither more nor less frequent. Gender did not appear to matter - commenters discussed people in general, not specifically men or women. The third row shows how political ideology comes into play. Commenters bring up more left-leaning language - Democrat, liberal, socialist. Finally, in the fourth row, I present different values that can be associated with attitudes about policies. Overwhelmingly, people brought up words like freedom, rights, liberty, and choice; these words were relatively more frequent indicating that these values were most important. On the other end of the spectrum, science words like research, evidence, and information were less frequently used indicating that research-based arguments were less likely to be persuasive. 
Table 5-1 Word frequency for Decrease_Access text

\begin{tabular}{|c|c|c|c|}
\hline Topic & More frequent & As frequent & Less frequent \\
\hline General understanding & $\begin{array}{l}\text { soda, size, portion, sugar, } \\
\text { calories, ban, obesity }\end{array}$ & & standard(s), guidelines \\
\hline Population & $\begin{array}{l}\text { people, adults, citizens, } \\
\text { Americans, kids, children }\end{array}$ & babies, teens, elders & women, men \\
\hline Political ideology & $\begin{array}{l}\text { Democrat, liberal, socialist, } \\
\text { Libertarian }\end{array}$ & $\begin{array}{l}\text { Republican, Independent, } \\
\text { progressive, communist }\end{array}$ & $\begin{array}{l}\text { conservative, party, } \\
\text { political }\end{array}$ \\
\hline Values & $\begin{array}{l}\text { freedom, rights, liberty, } \\
\text { choice }\end{array}$ & $\begin{array}{l}\text { privacy, proof, studies, } \\
\text { correlation }\end{array}$ & $\begin{array}{l}\text { science, research, logic, } \\
\text { evidence, knowledge, } \\
\text { information }\end{array}$ \\
\hline
\end{tabular}

${ }^{*}$ Frequency is relative to FROWN corpus of American English

\section{Collocation}

The collocation function identified words that commonly occurred together. In this first example, Table 5-2, all three words, large, big, and too are related to excess, however we can see differences in their usages. The word large is often associated with measurements and physical size. In this text, the word big takes on a different negative connotation. In addition to a reference to physical size, big is also associated with the derisive pronouns Big Brother and Big Government. The word too also takes on a negative connotation - collocates include (too) much and (too) far.

Table 5-2 Collocated words in the Decrease_Access text related to words conveying excess

\begin{tabular}{lll}
\multicolumn{1}{c}{ LARGE } & \multicolumn{1}{c}{ BIG } & \multicolumn{1}{c}{ TOO } \\
\hline - drinks & $\bullet$ brother & $\bullet$ government \\
- soda & $\bullet$ gulp & $\bullet$ bad \\
- size & $\bullet$ government & $\bullet$ stupid \\
- small & $\bullet$ drinks & $\bullet$ far \\
- extra & $\bullet$ soda & $\bullet$ much \\
- portion & $\bullet$ size & \\
& $\bullet$ super & \\
\hline
\end{tabular}

Notes:

bold type indicates common words between large and big

underlined type indicates common words between big and too

I also examined freedom, choice, and right. There was overlap in collocates across the three words, including people, government, have, and make. Choice and right both had collocates relating to the content (food and healthy) of the policy while freedom had neither of those words as collocates, thus was used only ideologically.

n-grams

The n-gram function identified common phrases, mostly manifestations of disagreement with the policy. Four main themes emerged from the n-grams - Personal responsibility, Personal freedom, Government overreach, and Negativity/skepticism. Example phrases of each theme are displayed in Table 5-3. 
Table 5-3. Themes from Decrease_Access n-gram analysis

\begin{tabular}{|c|c|}
\hline Theme & Examples \\
\hline Personal responsibility & $\begin{array}{l}\text { - } \text { Make their own choices... } \\
\text { - Responsible for their own... }\end{array}$ \\
\hline Personal freedom & $\begin{array}{l}\text { - Have the right to... have a right to... } \\
\text { - If you want to... if you really want... if people want to... should be able } \\
\text { to... should be allowed to } \\
\text { - Land of the free }\end{array}$ \\
\hline Government overreach & $\begin{array}{l}\text { - } \quad \text { Government has no business...Stay out of my... } \\
\text { - Nanny state...Big brother... } \\
\text { - } \quad \text { Can and cannot...Tell them what to... tell us what to... } \\
\text { - } \quad \text { Out of control... }\end{array}$ \\
\hline Negativity/skepticism & $\begin{array}{l}\text { - } \quad \text { There is no way... } \\
\text { - } \quad \text { Give me a break... Not going to... }\end{array}$ \\
\hline
\end{tabular}

Increase_Access text

Frequency

Table 5-4 shows keywords organized by five common topics that emerged from the comments. There was some overlap in topics between the two policies (general understanding, population, political ideology) as well as novel topics that were apparent only in the Increase_Access text (access and causation). The Increase_Access text about grocery stores demonstrated general understanding of the policy and related health concerns. In terms of population, commenters of the grocery store policy referenced minorities more than Standard English and seemed more focused on local levels, based on the frequency of words such as communities and neighborhoods. Political ideology also emerged, although less so than in the Decrease_Access text. Additional common themes in the Increase_Access text were dimensions of access and causation. Commenters discussed various ways to think about access using words like availability, affordability, and quality. Language related to transportation and modes of transportations, such as walking and riding the bus, was also common. Despite the discussion describing access, many commenters still felt as though people should be able to overcome such barriers - poor diet was attributed to bad choices, inadequate skills or knowledge, and lack of motivation. 
Table 5-4. Word frequency for Increase_Access text

\begin{tabular}{|c|c|c|c|}
\hline Topic & More frequent & As frequent & Less frequent \\
\hline General understanding & $\begin{array}{l}\text { food, healthy, obesity, } \\
\text { grocery, nutrition }\end{array}$ & & death \\
\hline Population & $\begin{array}{l}\text { people, citizens, kids, } \\
\text { children, communities, } \\
\text { neighborhoods, minorities }\end{array}$ & $\begin{array}{l}\text { constituents, Americans, } \\
\text { society, individuals }\end{array}$ & $\begin{array}{l}\text { women, men, national, } \\
\text { federal, world }\end{array}$ \\
\hline Political ideology & $\begin{array}{l}\text { liberal, socialist, } \\
\text { progressive }\end{array}$ & propaganda, government & political, democrat \\
\hline Dimensions of access & $\begin{array}{l}\text { availability, affordability, } \\
\text { prices, time, options, poor, } \\
\text { quality, transportation }\end{array}$ & $\begin{array}{l}\text { infrastructure, } \\
\text { environment }\end{array}$ & \\
\hline Causation & $\begin{array}{l}\text { blame, ignorance, } \\
\text { laziness, excuses, } \\
\text { knowledge, education, } \\
\text { motivation, choice(s) }\end{array}$ & decisions, information & industry, company \\
\hline
\end{tabular}

${ }^{*}$ Frequency is relative to FROWN corpus of American English

\section{Collocation}

In the collocate analysis for the Increase_Access text, I examined three words - poor, bad, and unhealthy - and listed in Table 5-5 words that commonly occurred, grouped by similarity (e.g., people and children both describe types of populations). In the first example, the word poor was used to denote a population or population characteristics - the poor, poor minorities. Poor and $\mathrm{bad}$ were both used to describe lower quality when coupled with words such as choices, judgment, and decisions. Bad was often associated with broad types of foods such as fast food, while unhealthy was more nutritionally specific, including words like sugar and fats. The population group of children was only strongly associated with unhealthy.

Table 5-5. Collocated words in the Increase_Access text

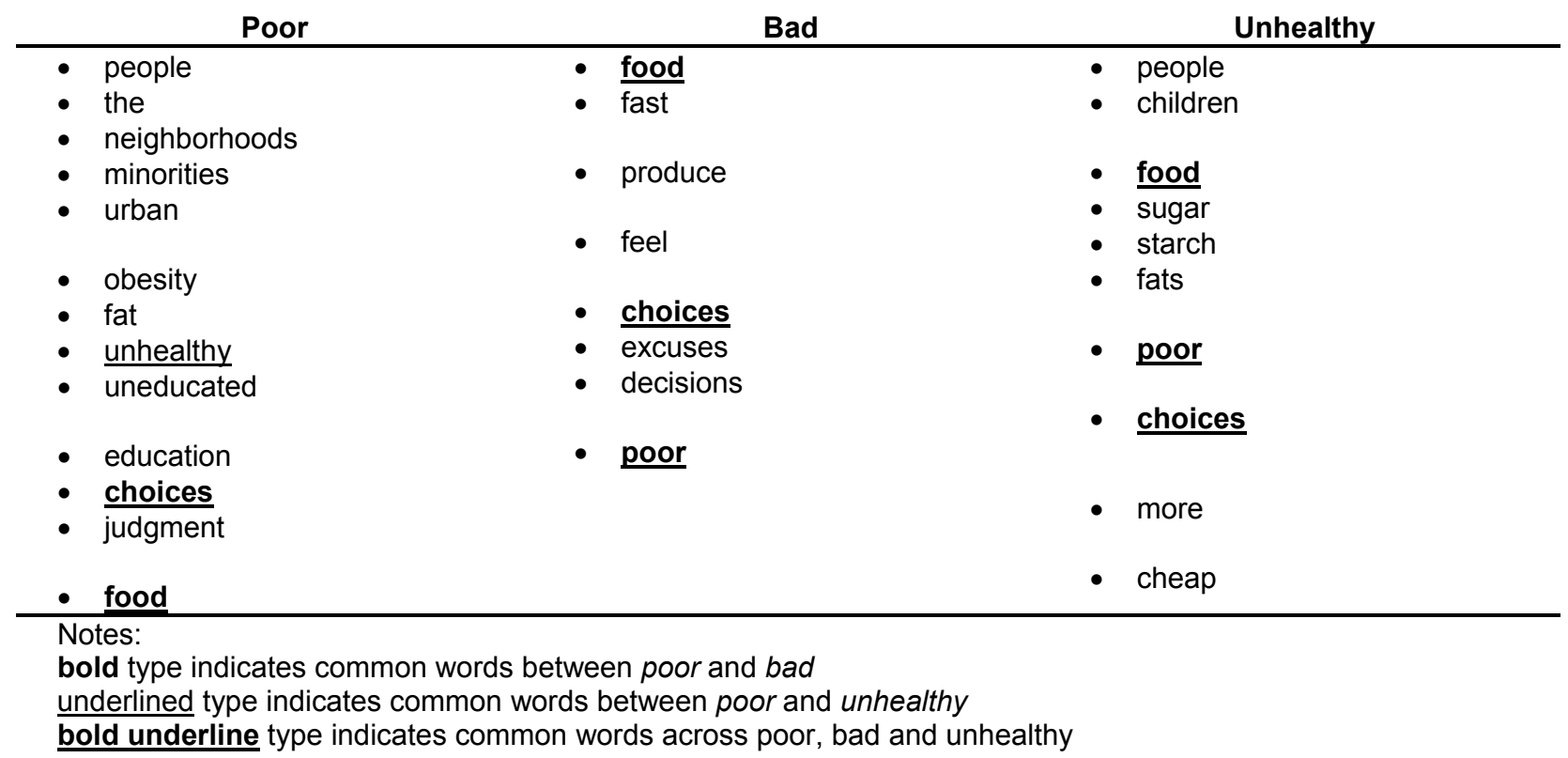


n-grams

Fewer common phrases emerged from the n-gram analysis of the Increase_Access text. The main themes were that of Personal responsibility and Barriers (Table 5-6. Themes from Increase_Access n-gram analysisTable 5-6). Commenters dismissed the role of grocery stores in health both because of individual choice and accountability, as well as the myriad of other causal factors that might have more impact, such as time constraints, skill deficiencies, and affordability issues.

Table 5-6. Themes from Increase_Access n-gram analysis

\begin{tabular}{|c|c|}
\hline Theme & Examples \\
\hline Personal responsibility & $\begin{array}{l}\text { - Stop making excuses for people... } \\
\text { - No one forces you to... } \\
\text { - Not the problem... } \\
\text { - It is simply choice... } \\
\text { - This is about personal accountability... bring personal accountability into } \\
\quad \text { the conversation }\end{array}$ \\
\hline Barriers (other causal factors) & $\begin{array}{l}\text { - Have no time to cook... Have no time to shop } \\
\text { - } \text { Don't know how to cook... } \\
\text { - } \text { Produce is more expensive than... if you have more money... } \\
\text { - } \text { More time and effort... } \\
\text { - It is very hard to stand on your feet... }\end{array}$ \\
\hline
\end{tabular}

\section{Rhetorical Analysis}

The two texts were analyzed together in the rhetorical analysis to enable direct comparisons between opinions on the two policies.

Frequency of language use

\section{Average frequency}

The Decrease_Access and Increase_Access texts differed in the average frequency of 12 of the 15 clusters pre-defined by the software, indicating many broad differences between the ways commenters talked about the two policies (See Table 5-7). A cluster is considered "active" if it is present in the text. 
Table 5-7. Average percent frequencies for clusters in Increase_Access and Decrease_Access texts

\begin{tabular}{|c|c|c|c|c|}
\hline Clusters & Definition $^{a}$ & $\begin{array}{l}\text { Decrease_Access } \\
\text { (portion size } \\
\text { restriction) }\end{array}$ & $\begin{array}{l}\text { Increase_Access } \\
\text { (food store } \\
\text { growth) }\end{array}$ & Difference \\
\hline $\begin{array}{l}\text { Subjective } \\
\text { Register }\end{array}$ & $\begin{array}{l}\text { This cluster is active when the text contains } \\
\text { subjective observation. }\end{array}$ & 6.536 & 5.756 & $0.780^{* * *}$ \\
\hline Emotion & $\begin{array}{l}\text { This cluster is active when the writing includes } \\
\text { emotion. }\end{array}$ & 3.104 & 2.776 & $0.328^{*}$ \\
\hline Description & $\begin{array}{l}\text { This cluster is relevant when your writing needs } \\
\text { to appeal to a feast of sights and sounds and } \\
\text { maybe even smells, touches ("the warm } \\
\text { embrace") and tastes ("the salty crunch of } \\
\text { bacon"). Description conjures in the reader's } \\
\text { mind concrete spaces, scenes, objects with } \\
\text { lively and colorful properties, human speech } \\
\text { and dialog. }\end{array}$ & 7.945 & 10.174 & $-2.230^{\star \star *}$ \\
\hline $\begin{array}{l}\text { Institutional } \\
\text { Register }\end{array}$ & $\begin{array}{l}\text { The Institutional Cluster includes writing that } \\
\text { invokes public registers and values. }\end{array}$ & 4.150 & 3.569 & $0.581^{* * *}$ \\
\hline $\begin{array}{l}\text { Academic } \\
\text { Register }\end{array}$ & $\begin{array}{l}\text { This cluster is active when the text uses an } \\
\text { academic register. }\end{array}$ & 5.424 & 5.881 & $-0.457^{*}$ \\
\hline Future & This cluster is active when the future is invoked. & 1.252 & 0.887 & $0.366^{* * *}$ \\
\hline Past & $\begin{array}{l}\text { This cluster is active when the text invokes the } \\
\text { past. }\end{array}$ & 0.466 & 0.691 & $-0.225^{\star * *}$ \\
\hline $\begin{array}{l}\text { Personal } \\
\text { Relations }\end{array}$ & $\begin{array}{l}\text { This cluster is active when the text contains } \\
\text { personal relations. }\end{array}$ & 0.824 & 0.460 & $0.364^{* * *}$ \\
\hline Reasoning & $\begin{array}{l}\text { This cluster is active when the text contains } \\
\text { reasoning. }\end{array}$ & 4.500 & 4.274 & 0.226 \\
\hline Interactive & $\begin{array}{l}\text { This cluster is active when there is interaction } \\
\text { between author and reader. }\end{array}$ & 3.032 & 2.461 & $0.571^{* * *}$ \\
\hline Elaboration & $\begin{array}{l}\text { This cluster is active when the writer elaborates } \\
\text { ideas. }\end{array}$ & 3.745 & 3.814 & -0.07 \\
\hline Reporting & $\begin{array}{l}\text { This cluster is active when the text contains } \\
\text { verbs of reporting. Contrasts with verbs of } \\
\text { narration or story-telling. }\end{array}$ & 7.541 & 7.773 & -0.232 \\
\hline Directing & $\begin{array}{l}\text { This cluster is active when the text directs the } \\
\text { reader or characters direct other characters. }\end{array}$ & 0.817 & 0.545 & $0.272^{* * *}$ \\
\hline Narrative & $\begin{array}{l}\text { This cluster is active when the text contains } \\
\text { narrative. }\end{array}$ & 0.803 & 1.038 & $-0.236^{* * *}$ \\
\hline Character & $\begin{array}{l}\text { This cluster is active when a reference is made } \\
\text { of a man or woman, a human pronoun (he, she) } \\
\text { or a generic character (butcher, baker, candle- } \\
\text { stick maker). The reference may involve a } \\
\text { positive, negative or neutral attribution about } \\
\text { the character. Typically supports narrative. }\end{array}$ & 2.7 & 2.364 & $0.335^{*}$ \\
\hline
\end{tabular}

a Source: DocuScope 3.4 Dictionary

${ }^{*} p<0.05 ;{ }^{* *} p<0.01 ;{ }^{* * *} p<0.001$

The Decrease_Access text contained more language patterns related to the Subjective Register, Emotion, Institutional Register, Future, Personal Relations, Interactive, Directing, and Character clusters. 
Overall, this indicates that people are deeply affected by this topic as they talk about personal opinions (Subjective Register) and feelings (Emotion) with others (Personal Relations) in attempts to tell them what to do or think (Directing and Interactive). This was evident in antiregulation sentiments, characterized by personal outrage and intensity, as in the examples below:

We do many harmful things. Let's just have Big Brother step in an[sic] regulate every breath we take, to make sure it is healthy. But we will have put a leash around our necks in so doing. Apparently that does not bother some of us. I do not myself drink "sugar drinks" as defined in the article. I simply don't care for them. But regulating the size of drink an adult can purchase is ridiculous.

It is different with smoking. By smoking you can not only effect my wallet by increasing healthcare costs but you can also negatively impact my health, and I have no choice in the matter; I can't choose not to breath the air you are exhaling into. This is why smoking is banned and cigarettes should be banned. 9 On the other hand, with beverages, I can choose water and you can choose a Big Gulp. My health is intact, but I probably have to pay more in healthcare. Tax the soft drinks, don't ban them.

Even when commenters were for the policy, their language was similarly emotion-laden as they tried to implore others to view another perspective:

Corporations are amoral entities soley[sic] focused on profits, hacking relentlessly at human weaknesses and paying nothing for the "externality" of their customers' welfare. I know - like many of us, I work for one. They spend millions of dollars tempting and distracting us to benefit their bottom line. Example: do you really think a coupon is for your benefit? Regulations are a check on this amoral power. It's not about whether they're perfect or not. It is, as Bloomberg says, about doing something! About governing!

The larger Institutional Register, Future, and Character clusters in the Decrease_Access text suggest that people have a strong reaction to the portion restriction policy, specifically expressed through their talk about public institutions and values such as the role of the government (Institutional Register), the mayor and affected populations (Character), and consequences of the proposed policy (Future). Again, this was true of both anti-regulation and pro-regulation stances:

Dear Mayor, As you know we are just too darn stupid to make our own food choices so we were hoping that you, as our wise leader, will make them for us. In addition please make any other choices for us that you deem fit. It is common knowledge that you, having been elected mayor, must in fact be all wise and all knowing and an expert on nutrition and many other things. We your humble citizens await your further guidance on any other matter you choose . After all that is what we want you to do! You're our leader and we're just dying to be lead[sic].

And for all those who cry of personal freedom, well, you are welcome to buy more than one drink, nobody is stopping you from that. This initiative's main 
purpose is to suggest that a $12 \mathrm{oz}$ or $16 \mathrm{oz}$ drink is standard. Perhaps kids will then not grow up thinking a $48 \mathrm{oz}$ drink is "normal" and expected...

In contrast, the Increase_Access text contained more language patterns related to Description, Academic Register, Past, and Narrative. While both texts engaged in abstract thought (Academic Register), the Increase_Access evoked more story-telling (Narrative and Past) about concrete objects, places, and events (Description).

\begin{abstract}
Alas -- we once had Home Ec classes in our schools. I was among the last generation lucky enough to get this (roughly, 1967-1970) in Junior High. I We actually had real miniature kitchens -- with aqua appliances! -- and learned to make all kinds of foods, from basic dishes to baking. We had nutrition and meal planning classes.
\end{abstract}

Is it possible that the current approach is not working due to lack of understanding of how Childhood Obesity starts. And school food is not the cause! Gosh at least in most schools of Today children are given more food choices (yogurt, salad on side of tray, etc.) yet we never had those choice s and didn't grow up obese! ๆ Thus just maybe the time has come address the habits and choices of the parents and help guide them (not tell but guide) toward making better choices, culinary and behavioral, within the home where Obesity begins!

I am a former resident of one of these "non-existent" food deserts. In New Orleans, I lived a stones throw away from a housing project and about a mile from 2 different grocery stores. There were also 2 corner stores and a small grocery within 3 blocks of my house. These stores sold snacks, processed and preserved foods (cannned foods, pasta), some frozen foods, milk,eggs and processed cheese, and some processed meats. You could probably pick up some inedible tomatoes, potatoes, onions and bell peppers as well. Everything was sold at outrageously jacked-up prices. These corner stores were a far cry from those in NYC, which offer up fresh vegetables, fruits, organic and specialty fare. I I didn't own a car. One of the grocery stores, located in an industrial zone and closer to the housing projects, was an appalling large version of a corner store, and I never went there. The other, located down further on Magazine St, catered to wealthier Garden District residents and was my go to. But I had to take a bus to get there, which ran only every half-hour to hour. So a trip to a grocery store a mile away became a 2 hour ordeal. Not to mention when using public transportation you can only carry/struggle with 2-4 bags worth of groceries anyways. But I did it because I was (1) alone and (2) am well-educated and extremely health conscious. Most of my minority, N.O. public school neighbors were not. I Without factoring in the costs of time and travel, the research is meaningless.

A more specific examination helped identify more examples of the language use patterns, or classes, driving these larger differences in clusters. I examined word class frequencies greater 
than 1 (10 occurrences per 1,000 words) to focus on the most commonly occurring classes which reduced the number of classes to 18 , or approximately $15 \%$ of the 118 classes. Table $5-8$ lists the average percent frequencies for the selected classes.

Table 5-8. Average percent frequencies of word classes in Decrease_Access and Increase_Access texts for classes greater than 1 (10 occurrences per 1,000 words)

\begin{tabular}{|c|c|c|c|c|}
\hline Word classes & Cluster & $\begin{array}{c}\text { Decrease_Access } \\
\text { (portion size } \\
\text { restriction) }\end{array}$ & $\begin{array}{l}\text { Increase_Access } \\
\text { (food store } \\
\text { growth) }\end{array}$ & Difference \\
\hline Intensity & Subjective Register & 1.339 & 1.298 & 0.042 \\
\hline Subjective perception & Subjective Register & 1.285 & 1.100 & $0.185^{\star *}$ \\
\hline Negativity & Emotion & 2.014 & 1.838 & 0.177 \\
\hline Sense Property & Descriptive & 1.123 & 1.165 & -0.042 \\
\hline Sense Object & Descriptive & 4.266 & 5.873 & $-1.607^{* * *}$ \\
\hline Space Relation & Descriptive & 0.894 & 1.811 & $-0.917^{\star * *}$ \\
\hline Motions & Descriptive & 1.089 & 0.729 & $0.360^{* * *}$ \\
\hline Common Authorities & Institutional Register & 1.542 & 0.680 & $0.862^{* * *}$ \\
\hline Standards Positive & Institutional Register & 1.770 & 2.076 & $-0.306^{\star *}$ \\
\hline Abstract Concepts & Academic Register & 4.525 & 4.863 & $-0.338^{\star}$ \\
\hline Contingency & Reasoning & 1.434 & 1.262 & $0.172^{*}$ \\
\hline Deny Disclaim & Reasoning & 1.125 & 1.408 & $-0.283^{* * *}$ \\
\hline Question & Interactivity & 1.301 & 0.808 & $0.493^{* * *}$ \\
\hline Comparison & Elaboration & 1.113 & 1.311 & $-0.198^{\star}$ \\
\hline Specifiers & Elaboration & 1.072 & 1.091 & -0.019 \\
\hline Reporting States & Reporting & 2.058 & 2.023 & 0.035 \\
\hline Reporting Events & Reporting & 2.939 & 3.215 & $-0.276^{\star *}$ \\
\hline Person Property & Character & 2.185 & 2.040 & 0.145 \\
\hline
\end{tabular}

${ }^{*} p<0.05 ;{ }^{* *} p<0.01 ;{ }^{* * *} p<0.001$

Both texts had approximately $2 \%$ of words related to the Negativity class, the use of words such as mistreatment, criminal, and despised. Although the Emotion cluster was more common in the Decrease_Access text overall, this difference was due to higher use of Anger, Fear, and Sadness words (data not shown).

Within the Institutional Register cluster (language related to public values and public sources), which was higher in the Decrease_Access text, there were differences in two classes Common Authorities and Standards Positive. The Common Authorities class refers to familiar public or institutional authorities such as the government, and this was evident in the 
Decrease_Access text. When people discussed the proposal to restrict portion sizes for soda, they brought up the proposing entity (the mayor, government), the implementing entity (government), and their opinions on appropriate scope (the role of the government).

The government should not treat us as incapable of making such choices by limiting them. Even the obese among us have the capability to decide what to buy, what to consume and what package size we desire. No legislation will limit the amount of bad choices we make. We are and should be free to make our own (good or bad) choices...

The Increase_Access text, however, contained more Standards Positive language, which is related to cohesion around positive standards such as justice and fairness. Use of the words

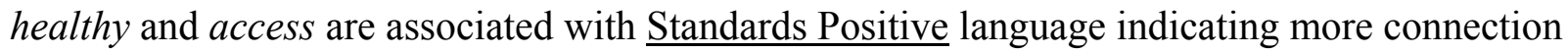
of the Increase_Access commenters to the goal of the food store growth policy than Decrease_Access people to the goal of the portion size restriction policy.

I don't know of any public health officials who have said that food deserts are the only reason for obesity, or even the most important reason. But where they exist they are still an obvious barrier to good health, so they SHOULD be eliminated, by whatever means will be practical and work best in each specific community.

\begin{abstract}
Almost ALL people love sweets, snacks and salty foods. And they are not even that bad, eaten in moderation. The problems start when we eat those foods instead of real, healthy meals. But as discussed here, the poorest people have the least time and the fewest tools to eat healthy -- even if they know the information about healthy eating, or have the DESIRE to eat healthy stuff.
\end{abstract}

The subject of nutrition should be of paramount importance to all of us. Nutrition is not just understanding the food pyramide[sic], it is understanding the elements that comprise food, and the relationship to the human body as a system.

Although there had been no differences in the larger Reasoning cluster, when examined at the more granular level of classes, differences emerged. When people discussed the portion size restriction policy, they used more Contingency language indicating conditionality (e.g., if, possibly). These types of words were often coupled with Question words. For example, commenters would set up a situation (Contingency) and then pose a question (Question):

I hate sugary drinks, I've always thought I'd rather eat my calories if I am going to have calories, especially if I am going to indulge in any way. BUT why do people think it's a good thing for the "gooberment" to always intervene? Why do you want to be controlled? I Like smoking and everything else they've heaped regulations on, whether you are for it or against it, eventually they are going to 
chip away more and more until you have no rights at all and they are telling you what to do with your entire life.

Yes, there is an obesity problem in the United States but really, do we want our "government" here in NYC taking it upon itself to tell us what to drink now or how much? W What's next? Having too much red meat in your diet? Hmmmm, maybe we can get back to ration cards - so much per person per month, etc., etc. I What are we children? What is Mayor Bloomberg our caring, loving father?

In contrast, the Increase_Access text used more Deny Disclaim language from the Reasoning cluster. Deny Disclaim language is more oppositional and tries to undermine a prior belief:

We had no money for junk food, juice, soda. It wasn't a "health" thing it was a money thing. It is not cheaper to eat Macdonalds [sic]. It's cheaper to buy a bag of rice and a bag of vegetables, dried beans, potatoes. Tap water was and is free,

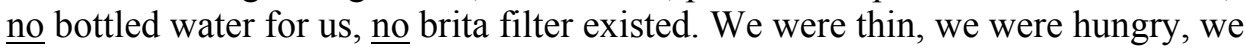
were poor.

Healthier foods are more costly, such as leaner cuts of meat, and fresh fruit and vegetables. Even with drinks, juices are higher than cheaper drinks that contain more sugar and fructose.

[response] This is not true. The healthiest foods are the cheapest. The best example is whole oatmeal. Eggs, brown rice, onions, and frozen veggies are cheap and delicious. Water is practically free - why drink juice or soda at all?

Finally, the Kolmogorov-Smirnov revealed significant differences in the distributions of a number of classes (see Table 5-9). Differences in a distribution indicate unexpected variation or segmentation of language usage across the text. For example, the difference in Fear indicates that fearful language was not even distributed across all comments, but was bunched within a few responses. These results are not discussed in detail because the class frequency was low (greater likelihood of identifying a disturbance as signal rather than noise) or the difference was already discussed as a difference in average frequency (e.g., Sense Properties, Sense Objects, Spatial Relations, and Scene Shifts all belong to the Descriptive cluster). 


\section{Table 5-9. Differences in frequency distributions of word classes in Decrease_Access and Increase_Access texts}

\begin{tabular}{|c|c|c|}
\hline Word Class & Description $^{a}$ & Example \\
\hline \multicolumn{3}{|c|}{ Decrease_Access (portion size restriction) } \\
\hline Private Thinking & $\begin{array}{l}\text { The use of words indicating the } \\
\text { unshared contents of an individual mind } \\
\text { (e.g., believe, feel, conjecture, } \\
\text { speculate, pray for, hallucinate). A front } \\
\text { row seat into someone else's mind. }\end{array}$ & $\begin{array}{l}\text { Please, allow me to make my own decisions and } \\
\text { allow me to also accept full responsibility for those } \\
\text { actions. }\end{array}$ \\
\hline Fear & The use of words referencing fear. & $\begin{array}{l}\text { Personally, I believe there are another group of } \\
\text { people who I fear more than the "evil-doers". It's } \\
\text { the "do-gooders", these are the people who } \\
\text { believe it is their responsibility to put in laws and } \\
\text { take actions that take away individual rights and } \\
\text { choices. }\end{array}$ \\
\hline Sad & The use of words referencing sadness. & $\begin{array}{l}\text { I'm saddened to see adults place themselves in } \\
\text { the role of children, and government as their } \\
\text { parents. }\end{array}$ \\
\hline $\begin{array}{l}\text { Common } \\
\text { Authorities }\end{array}$ & $\begin{array}{l}\text { The use of words making direct } \\
\text { reference to public or institutional } \\
\text { authorities, already familiar and } \\
\text { respected in the culture (e.g., founding } \\
\text { fathers, Emirs, parliamentary course of } \\
\text { action, duly authorized). }\end{array}$ & $\begin{array}{l}\text { This law is just one more example of the slow } \\
\text { creep of government regulation into our lives. }\end{array}$ \\
\hline Responsibilities & $\begin{array}{l}\text { The use of words where public } \\
\text { responsibility is referenced (e.g., } \\
\text { responsible). Assigning } \\
\text { responsibility in the second person (e.g. } \\
\text { you are responsible) overlaps with } \\
\text { confrontation. }\end{array}$ & $\begin{array}{l}\text { Every day when I read about the stupid things this } \\
\text { idiot mayor takes on I thank the lord he is not } \\
\text { mayor of my city. }\end{array}$ \\
\hline Prior Knowledge & $\begin{array}{l}\text { The use of words indicating that the } \\
\text { ideas under discussion are already } \\
\text { public and familiar to the audience } \\
\text { hearing or reading them (e.g., as you } \\
\text { know). }\end{array}$ & $\begin{array}{l}\text { The resulting obesity epidemic is no surprise. } \\
\text { Government Ag policy *could* have supported the } \\
\text { economical production of healthy foods. }\end{array}$ \\
\hline Resemblances & $\begin{array}{l}\text { The use of words indicating perceptual } \\
\text { similarity. Resemblances indicate } \\
\text { positive comparisons based on visual, } \\
\text { auditory, or other sensory similarities } \\
\text { (e.g., resembles, looks like). }\end{array}$ & $\begin{array}{l}\text { Geez, NYC is sounding like San Francisco. It is } \\
\text { wonderful, however, to see progressives } \\
\text { squirming a bit around the issue, and some } \\
\text { outraged enough to sound like tea-partiers - be } \\
\text { careful though, make that a diet tea, less than } 16 \\
\text { oz please. }\end{array}$ \\
\hline Person Property & $\begin{array}{l}\text { The use of words referencing a } \\
\text { person's formal (e.g. someone) or } \\
\text { occupational and identity roles (e.g., } \\
\text { butcher, baker, catholics). }\end{array}$ & $\begin{array}{l}\text { Bloomberg ... is imposing dictatorial power, the } \\
\text { natural proclivity of all liberals / progressive elitists } \\
\text { to decide what is best for their minions. I hope that } \\
\text { the companies and NYC citizens sue Bloomberg } \\
\text { personally for relief and the courts slap his hand } \\
\text { really hard! }\end{array}$ \\
\hline \multicolumn{3}{|c|}{ Increase_Access (food store growth) } \\
\hline $\begin{array}{l}\text { Sense } \\
\text { Properties }\end{array}$ & $\begin{array}{l}\text { The use of words indicating concrete } \\
\text { properties (e.g., pink, velvety). The five } \\
\text { senses related to properties. }\end{array}$ & $\begin{array}{l}\text { Bottled water is as expensive as soda! It is } \\
\text { different drinking clean, filtered ice cold water than } \\
\text { it is drinking warm rusty water with an aftertaste. }\end{array}$ \\
\hline
\end{tabular}




\begin{tabular}{|c|c|c|}
\hline Word Class & Description $^{a}$ & Example \\
\hline Spatial Relations & $\begin{array}{l}\text { The use of words indicating relations in } \\
\text { space (e.g., sitting next to, abutting). }\end{array}$ & $\begin{array}{l}\text { There was another store that ... had a larger } \\
\text { selection of produce and cheaper meat, but it } \\
\text { meant paying for the jitney drivers, or lugging } \\
\text { bags home on a bus - generally, a 90-minute trip } \\
\text { for a store three miles away. And you couldn't } \\
\text { walk to it because it was only accessible along a } \\
\text { freeway. }\end{array}$ \\
\hline Scene Shifts & $\begin{array}{l}\text { The use of words indicating shifts in } \\
\text { spatial location, typically indicated by } \\
\text { entering or leaving human-made and } \\
\text { geographically defined enclosures (e.g., } \\
\text { left the room, went oudoors). }\end{array}$ & $\begin{array}{l}\text {... if transportation is so overwhelming a problem } \\
\text { then bring the healthy foods to the neighborhoods, } \\
\text { at the turn of the century all sorts of vendors } \\
\text { would travel a route to bring their products to the } \\
\text { communities. }\end{array}$ \\
\hline Generic Events & $\begin{array}{l}\text { The use of words reporting generic } \\
\text { events, events that repeat over time } \\
\text { through processes of biology, culture, } \\
\text { and convention (e.g., sleeping, playing, } \\
\text { working, relaxing). }\end{array}$ & $\begin{array}{l}\text { If NO ADULT in the house... is around to plan } \\
\text { meals -- shop for health foods - bring them home } \\
\text { and put them away properly -- prepare the food -- } \\
\text { serve the food -- and ... CLEAN UP } \\
\text { AFTERWARDS -- then what will happen is what } \\
\text { HAS happened... we will all end up eating takeout } \\
\text { foods, frozen dinners and haphazard ... }\end{array}$ \\
\hline
\end{tabular}

a Source: DocuScope 3.4 Dictionary

Note: Kolmogorov-Smirnov tests. Word classes listed have distributions that are statistically different from the other text and from a general English text (FROWN corpus)

\section{Latent constructs}

The exploratory factor analysis (EFA) revealed a total of seven factors with factor loading $\geq$ 0.4, a widely-used cut-off criteria in EFA. The primary factor identified included the word classes Negativity, Commonplace Authority, and Inclusiveness. This "Us against Them" construct represents a mindset where individuals from an in-group (inclusiveness) express negativity towards an established other-group (commonplace authority). The "Us against Them" mentality is clearly evident in the Decrease_Access text:

Obesity in children and adults is arguably our nation's most serious health crisis. We are eating our [sic] drinking ourselves into diabetes, heart disease, high blood pressure, kidney disease, avoidable amputations and premature death. But, it is not the role of government -- and this is a liberal Democrat talking -- to tell people what they can and cannot eat and drink. Government can and should be a visible and vocal advocate in articulating the grave dangers of obesity.

I guess they figure NY residents are too ignorant to make their own choices. That's typical of the current administration. Child proof the world because we're too stupid to make our own decisions.

Government should not be telling us what to eat or drink and in what proportions. At best, government (our government) might seek to guide and inform, banning the size of certain drinks is absurd. Or better yet, leave us alone (and get their own house in order first). 
Our system is based on regarding the consumer as intelligent and not needing Big Brother to run his life for him. Don't curtail my liberty. I am not the one choosing that food. Government has NO BUSINESS whatsoever stepping in to decide how large our fast-food portions should be, or whether or not we should be free to drink a huge amount of soft drinks.

Although the majority of comments demonstrating this construct identified the government as "Them," this was not always true. In some cases, the negativity was directed towards a corporate "Them" as in the following examples:

McDonalds, Coke and Marlboro should not be allowed to run our public health campaigns. Corporations seek to sell as much, as cheaply, as possible, damn the consequences to public health. As a city, and country, we have suffered immense public health harm; our children are programmed into disease.

We've been manipulated by corporations for too long. This is not a choice made by individuals, solely accountable to themselves. All of us pay the price.

All seven factors are listed in Table 5-10, however, the remaining factors are not described in detail in this section because they contained only one class or did not contribute any novel understanding.

Table 5-10. Factors identified through exploratory factor analysis

\begin{tabular}{cll}
\hline Factor & \multicolumn{1}{c}{ Word class } & \multicolumn{1}{c}{ Description $^{\text {a }}$} \\
\hline 1 & Negative emotion & $\begin{array}{l}\text { This class is active when the writing includes negativity (e.g. } \\
\text { mistreatment, criminal, despised) }\end{array}$ \\
\cline { 2 - 3 } & Commonplace authority & $\begin{array}{l}\text { The use of words making direct reference to public or } \\
\text { institutional authorities, already familiar and respected in the culture (e.g., } \\
\text { founding fathers, Emirs, parliamentary course of action, duly authorized). }\end{array}$ \\
\cline { 2 - 3 } & Inclusiveness & $\begin{array}{l}\text { The use of inclusive words (e.g., we all, all together). } \\
\text { Someone feels a sense of social belonging, fellow feeling, or like- } \\
\text { mindedness and is expressing it. }\end{array}$ \\
\hline 2 & Oral element & The use of words indicating the oral register (e.g., well, uh..um). \\
\cline { 2 - 4 } & Formal query & $\begin{array}{l}\text { The use of survey-type queries. One mind seeking information from what } \\
\text { seems like a population of other heads. }\end{array}$ \\
\hline 3 & Motion & The use of words indicating motion (e.g., run, skip, jump). \\
\hline 4 & Sadness & The use of words referencing sadness. \\
\cline { 2 - 4 } & Responsibilities & $\begin{array}{l}\text { Assigning responsibility in the second person (e.g. you are responsible) is } \\
\text { a confrontation. }\end{array}$ \\
\cline { 2 - 4 } & Request & The use of words that make requests (e.g., I request). \\
\hline 5 & First person & The use of words indicating self-reference (e.g., l, me, my, myself). \\
\hline
\end{tabular}




\begin{tabular}{cll}
\cline { 2 - 3 } & Self-disclosure & $\begin{array}{l}\text { The use of words indicating self-reference (e.g., First } \\
\text { Person; I, me, my) in combination with verbs indicating personal thought } \\
\text { or feeling (e.g., I think, I feel, I believe). }\end{array}$ \\
\hline 6 & Scene shifts & $\begin{array}{l}\text { The use of words indicating shifts in spatial location, typically indicated by } \\
\text { entering or leaving human-made and geographically defined enclosures } \\
\text { (e.g., left the room, went outdoors). }\end{array}$ \\
\hline 7 & Concessive & $\begin{array}{l}\text { The use of words indicating that another and overridable } \\
\text { point of view is available (e.g., although, even if, it must be } \\
\text { acknowledged). The public acknowledgement of the weaknesses in one's } \\
\text { own position or the strengths in the position of an opponent. }\end{array}$ \\
\hline
\end{tabular}

${ }^{a}$ Source: DocuScope 3.4 Dictionary 


\section{Discussion}

Increasing access to healthy foods and decreasing access to unhealthy foods can be viewed as two sides of the same equation. Both are removing barriers that prevent people from exercising a healthy choice. In this case study of two policies to encourage food store growth (increase access) and standardize portion sizes for soda (decrease access), they both share the same goal of improving diet at the population level but the public reactions to the two policies differed in important ways.

People were generally unsupportive of the measure to restrict portion sizes. Comments were reactive, characterized by negative emotions and subjective observations, with many thinking or feeling that the government had overstepped its boundaries. There was a clear "Us vs Them" mentality with "Them" (either government or industry) acting in ways "Us" didn't like. People discussed "what if" and "if-then" scenarios resulting in "slippery slope" fears that the government would soon be banning pizza or doling out rations. Even across several selfproclaimed progressives and public health professionals, people strongly supported preservation of choice.

On the flip side of the access equation, the public opinion about encouraging food store growth was descriptive and narrative, as people explained viewpoints through stories and examples. This was a topic that elicited dialogue as people presented evidence justifying their position and attempting to undermine another's. In addition, they engaged in discussion around the meaning of "access" - whether it was strictly geographical, economical, or relating to some other limited resource, such as time. Finally, people rallied around a common goal to achieve health, although they differed on whether food store growth could achieve this.

In these two texts, emotions and facts were often mutually exclusive. In the Decrease_Access text, people expressed displeasure at the policy and at "Them" but did not always support their statement with reasons why. Arguments were circular (e.g., "government should not do this because government should stay out of my house") or assumed common agreement on certain issues (e.g., "government should not be doing anything in this sphere"). By comparison, the people in the Increase_Access text presented stories, but no explicit feelings in the discussion (e.g., "The walk back from the store is all up hill and there are no trees or shade"). This may be because the description should elicit a universal understanding (e.g., few would find pleasure walking uphill with groceries without shade), whereas invoking the idea of "government boundaries" results in more varied definitions and responses. Emotion also had the potential to displace other reactions or thoughts. People discussing the "soda ban" focused their statements on their dissatisfaction and frequently failed to voice suggestions for other solutions, although a number did bring up the idea of taxation. In the Increase_Access text, education, price, and social norms were frequently identified as potential factors that could make healthy foods more accessible. 
The finding that people generally opposed the portion size restriction should not be entirely surprising. A New York Times poll of approximately 1000 New Yorkers ${ }^{* *}$ found that $60 \%$ of respondents thought the soda ban was a bad idea with $65 \%$ citing overreach and freedom of choice as the main reason. It should be noted that only $34 \%$ reported drinking soda more than once a week; although the cross-tabulations were not available, mathematically even infrequent consumers of soda, who would be least affected by the policy, felt it was a bad idea.

Policies to decrease access through restrictions typically face public outcry. An earlier public opinion poll regarding taxes on sugar-sweetened beverages found greater agreement with antitax arguments than pro-tax arguments and half (54\%) of respondents felt that such a tax would be an intrusion of government. ${ }^{185}$ Dorfman further comments that the current political climate is unfavorable for public health advocates and characterized by disdain for government. ${ }^{186}$

It should also be noted that people's fear about losing choices in the Decrease_Access text is a perception based on subjective understanding of the policy. A few people correctly noted that consumers still had the right to drink as much soda as they wanted - they could buy more than one soda at an affected establishment or buy their soda at an unaffected establishment, such as a supermarket, instead. And while many people appeared weary of losing options, some of them also admitted they did not regularly exercise those options - either because they didn't drink soda or they preferred smaller sizes. Much more loss aversion was demonstrated in the Decrease_Access text, although policies to encourage food store growth could potentially result in greater loss. For example, the HFFI, through the USDA, Treasury, and HHS, has "helped leverage more than $\$ 109$ million in grants and an estimated $\$ 1$ billion in additional financing" since 2011 for increased access to food stores. ${ }^{\dagger \dagger}$ Although this initiative was framed as adding resources to communities, there was little outrage regarding the opportunity cost of such policies, that is, the other alternatives this large pool of money could otherwise be spent on.

The results from this study suggest several implications for constructing and framing policies for improving nutrition. When constructing policies, policymakers should remember that people feel losses more than gains ("loss averse"). The policy to increase access was viewed more favorably than a policy to decrease access, suggesting that policies should emphasize what they are adding rather than taking away. For example, another way to frame portion size restrictions would be to focus on adding standardization for a substance with demonstrated health harms. Soda with sugar could be standardized in the same way beer, wine, and spirits are served in different sizes such that they don't exceed a certain amount of alcohol per serving.

The examination of the distributions of word classes (Kolmogorov-Smirnov tests) also reminds us that variation may present in different ways. What appears to be an average

\footnotetext{
** Available at http://www.nytimes.com/interactive/2012/08/22/nyregion/22nyc-poll.html. Last accessed 8/15/2015)

${ }^{\dagger}$ The Reinvestment Fund. "House and Senate fail to fund critical Healthy Food Financing Initiative." May 23, 2014. Available at http://www.trfund.com/house-and-senate-fail-to-fund-critical-healthy-food-financing-initiative/ (last accessed January 5, 2015)
} 
difference may be driven by an uneven distribution of opinions, e.g., a small but vocal group. Strategies to placate a distinct subgroup are going to differ from those hoping to shift public opinion a small amount but for a large group of individuals.

Concerns of unintended consequences from the portion restriction policy were not entirely unfounded. In an experimental study, Wilson and colleagues found that participants bought more ounces of soda when presented with smaller sizes bundled together (e.g., participants purchases more two $12 \mathrm{oz}$ drinks than $12 \mathrm{oz}$ drinks). ${ }^{187}$ This finding may in part be due to an unrealistic pricing scheme (one 16 oz soda cost $\$ 1.59$ while a bundle of two 16 oz sodas cost $\$ 1.99$ ), it nevertheless reminds us that if the regulation had been implemented, it would not be long before companies discovered new ways to sell their product while being compliant to the letter of the law while still contributing to the problem the policy was intended to address.

However, it may be even more important to know your audience and tailor messages for them. For example, the debate seen in the Increase_Access text demonstrated that people valued facts, and the disagreements were over whether certain assertions were true. If this policy had undeniable scientific proof that encouraging food store growth could improve nutrition, most people would agree it is the right thing to do, since they want to uphold a standard value to achieve health. However, a similar scientific message would be unlikely to address the concerns people have with the portion size restriction. In this policy, scientific evidence was secondary to ideological concerns related to government role and free choice.

It should be noted that framing through word choice alone will not be sufficient to change or opinions or disguise policy. There will always be a smart journalist or lobbyist who will see through such attempts. In fact, the soda portion size restriction regulation was officially named the "Portion Cap Rule" by New York City, however, was quickly dubbed a "soda ban" by opponents and the media. Framing the argument requires a holistic approach that includes understanding the opposition's values and appealing to their arguments.

\section{Limitations}

This study is subject to a few limitations. First, the analytical software used a general dictionary and is best-suited for clean text. Because the comments were preserved as written by the author, errors such as misspellings and improper punctuation may have resulted in imprecise tallies. In addition, the analysis was conducted using a standard dictionary, thus unassigned words that should convey a special meaning (e.g., Bloomberg, public health) are either ignored or miscategorized. For these reasons, I focused on the broad and large findings to ensure confidence over precision, but may consider spell-checking and customizing the dictionary for future analyses. Finally, although each text was generally representative of well-read people who feel strongly about these issues, it may not adequately represent less digitally-connected individuals. Still, text analysis of other online content, such as tweets, has demonstrated a high level of accuracy with traditional public opinion polls, indicating that online sentiment can be representative of a broad population. ${ }^{188}$ 
Differences in public opinion between the two policies may also be a reflection of specific characteristics of the news articles that go beyond the general issue of access. For example, the portion size restriction policy would be a citywide regulation and affect everyday establishments that citizens patronize, whereas a policy to encourage food store growth would likely have a very localized effect only on the residents of the neighborhood that receives funding for food stores. This may affect how invested and opinionated people feel about the two policies. In fact, the difference in the number of comments (1426 about portion restriction vs. 416 about food store growth) demonstrates that a larger population of readers saw the portion restriction news article and felt compelled to comment than the food store article. In addition, differences at the larger cluster level might be explained by the different writing styles of the reporters. The food store article referenced several scientific studies relating to food stores and health, which may have prompted readers to make more comments using language from an Academic Register.

Likewise, because of the portion size restriction article's emphasis on a specific policy proposed by the government to be voted on and enacted in the next year, the public opinion may have inevitably skewed towards Institutional Register and Future language. However, even if the reader comments are a reflection of the reporting, it is likely still indicative of how the broader public would feel since the media plays such a large role in shaping public discourse.

\section{Conclusion}

How policymakers approach nutrition policy matters because unpopular policies are unlikely to be passed or implemented successfully. Decreasing access to unhealthy foods, such as in the portion size restriction of soda in New York City, may induce negative emotions related to the perception of limited choice and government overstep. Meanwhile, increasing access to healthy foods, such as encouraging the growth of food stores, can evoke descriptive narratives that lend themselves to greater understanding of the issues. Public opinions may not always be evidencebased, thus it is important for policymakers to try to identify the values underlying the opinions and address concerns stemming from those values. Understanding the public mindset towards the various strategies to improve diet can help increase effective communication between policymakers and the communities they are trying to serve. 


\section{Chapter 6 Conclusion}

This dissertation examined the role of the food environment in improving diet in low-income communities. First, I looked at whether the food environment is associated with consumption of a common junk food (sugar-sweetened beverages, or SSBs) and whether this changes over time. Next, I examined the role of the environment on children's behaviors and outcomes, considering how marketing may influence both child and parent decisions about junk foods. Finally, I looked at public views on different policies to change the food environment. Taken together, this dissertation provides multiple perspectives on how to improve diet.

\section{The supermarket "solution"}

Little is known about how changes to the food environment, such as the opening of a new full-service supermarket in a food desert, can affect people's diets. On one hand, a new supermarket may increase access to healthy foods such as fresh fruits and vegetables and improve diet, but on the other hand, the same supermarket may increase accessibility to unhealthy foods such as SSBs, snacks, and sweets. Only a few studies have looked at the impact of a new supermarket longitudinally. All three studies that have collected such data found no effect on weight and weight status, although this may be due to the relatively short timeframe after the change. ${ }^{42,44,45}$ Dubowitz et al. found a positive change to dietary quality in a Pittsburgh neighborhood receiving a brand new supermarket compared to a similar "control" neighborhood, but this change could not be attributed to residents using the new supermarket. ${ }^{45}$ In Chapter 3, I analyzed the same Pittsburgh study population and found that changes to the food environment were not related to changes in SSB consumption. Distance to the closest supermarket and density of supermarkets with a walkable buffer $(0.25 \mathrm{mi})$ did not appear to increase or decrease SSB consumption, nor did the marketing characteristics at the store where people did their major food shopping. However, the strong association between fast food frequency and SSB consumption indicates that individual-level factors such as preference may be a stronger predictor than environmental-level factors such as store density and store characteristics.

Supermarkets are expensive endeavors. Building a new supermarket can cost upwards of $\$ 125$ per square foot, or $\$ 6.25 \mathrm{M}$ for a 50,000 square foot store ${ }^{189}$ and is more expensive per square foot than home centers, specialty apparel stores, "big box" retailers, and convenience stores. ${ }^{190}$ Supermarkets are low-margin businesses (1-3\%) that require high sales volume in order to succeed. ${ }^{191,192}$ Adding a supermarket alone to environments with poor access to healthy foods might not be enough to create enough demand. Supermarkets may increase the supply of food available and accessible to neighborhoods, but individual-level interventions, including multisector efforts (within and outside of grocery stores) are likely a necessary, complementary strategy to any supply-side approach. 


\section{Policy implications}

In this study, one individual-level factors - frequency of eating at fast food restaurants - was an important predictor of SSB consumption. A change in the food environment within the neighborhood may not result in a change in diet by itself. Policymakers may need to consider levers that more directly influence individual decision-making, such as taxes and subsidies.

Fast food restaurants could play an important role in curbing SSB consumption. Frequency of eating at fast food was the only significant predictor of SSB consumption in this analysis. Changing the default size or caloric content (e.g., switching from regular to diet beverages) of fast food drinks may be impactful strategies for SSB reduction. Although several fast food chains have pledged to remove fountain drinks from children's meal combinations, no similar measures have been proposed for adult combination meals. ${ }^{105}$

\section{In-store marketing influences}

A body of evidence suggests that food preferences start young, ${ }^{109-111}$ and children are important consumers insofar that they can influence household purchasing. Chapter 4 has important implications for understanding how the food environment and marketing may impact household purchasing through parent-child shopping behaviors. Although the association between pestering and parent purchases was not driven by in-store marketing, it still speaks to the importance of reducing cues to pester, through policies such as limiting media advertisements and product sponsorships. The link between home availability of soda and soda consumption, further emphasizes the importance of understanding what influences parent purchases and how to nudge it towards more healthful products.

Although this study did not find strong associations between in-store marketing and purchasing of unhealthy SSBs, prior literature suggests in-store marketing encourage purchasing of healthier foods. One study randomized four supermarkets to receive a 6-month in-store marketing intervention consisting of changes in placement, signage, and product availability to promote healthier products and found greater sales of skim and $1 \%$ milk and water compared to the four control supermarkets. ${ }^{193}$

Retailers appear to be responding to consumer concern over marketing strategies. Discount grocer chain Aldi recently announced it would be overhauling checkout lanes in its locations nationwide (approximately 1000 stores) by removing candy and chocolate and replacing them with trail mix and other healthier snacks. ${ }^{106}$ Big box retailer Target had earlier announced a pilot study to eliminate candy bars and reduce soda and chips at registers in 30 locations. ${ }^{107}$ Results from this pilot aren't available; however, evidence from another chain in the UK demonstrated positive results - customer volume in healthier checkout lanes was $20 \%$ higher than traditional checkouts and $70 \%$ of surveyed customers preferred a healthier checkout lane. ${ }^{108}$ Such reports are encouraging that changes in marketing practices are feasible and acceptable, but further research on purchasing patterns, and ultimately diet outcomes in needed. 


\section{Policy implications}

Pestering was associated with more frequent parent purchases and child soda consumption. Removing cues to pester, such as TV advertisements for foods with high sugar, fat, and/or salt, may be effective for improving diet. Alternately, policymakers could try to replace the traditional cues to pester with cues to pester for healthful items, such as promotions for fruits and vegetables.

Home availability of soda was a significant predictor of child soda consumption. Policies that reduce soda purchases, such as taxes on SSBs or SSB warning labels, could reduce access in the home.

\section{Framing public policy}

Given the small effect of the environment in the first two studies, and the ambiguous findings elsewhere, it's not clear why so many resources and so much attention is given to the food environment and expensive projects like supermarkets. However, when considering the rhetoric around some of these alternatives, it becomes clear why efforts focus on constructing new supermarkets. As discussed in Chapter 5, people don't object to something being added, but they do when something is taken away. Certain policies are more likely to be perceived as bans or restrictions and discussed in the public discourse negatively. This may tie in to prior research that finds punitive measures, including surcharges for obese individuals, are least popular. ${ }^{194}$ The flip side of an "add" policy - zoning an area for construction of a supermarket is also a restriction developers cannot build housing, or an office park, or a baseball field. Each implemented policy means countless policies that are not. However, people seldom think of such opportunity costs when decisions are framed with limited options.

Although commenters talked about scientific studies and evidence when discussing adding more food stores to neighborhoods, similar words rarely appeared in the discussion around the so-called "soda ban." Frequently there is a disconnect between science and policy that can make certain policies controversial and unpopular. Chaufan and colleagues, in a commentary on sugarsweetened beverage taxation, note:

Our task as public health professionals is not to assess whether public health policies are politically feasible but rather whether they make public health sense. ${ }^{195}$

Although they go on to say that they believe such a tax is feasible, this statement highlights the different goals of a researcher versus a policymaker. Furthermore, if researchers are not thinking about policy as they design their studies, then their studies will not be able to contribute to the evidence base that policymakers may require before proposing policies, especially those that are politically risky. 


\section{Policy implications}

Policies that intend to decrease access to unhealthy foods may be met with more resistance than policies to increase access to healthy foods. Focusing on the gains and not the losses may be an effective way to frame nutrition policies.

\section{Next steps}

Like many public health issues, there is no silver bullet solution to improve diet in lowincome communities. Complex problems require multi-faceted solutions. Rather than advocate for a singular policy, we need a combination of policies from multiple domains to adequately support people making healthy choices.

The CDC advocates for 24 community strategies to prevent obesity, of which several are designed to improve diet. ${ }^{196}$ These strategies include price subsidies for healthy foods, taxation of unhealthy foods ("sin taxes"), product restriction, farm-to-table programs, limits to advertising, and educational campaigns. In a more specific review of policies to reduce SSB consumption, Studdert and colleagues also propose labeling rules and government procurement and benefits standards in addition to taxes, limits to advertisements, and product restrictions. ${ }^{197} \mathrm{~A}$ few popular strategies are discussed below and how they might contribute to the policy implications from this dissertation.

\section{Pricing strategies - subsidies and taxes}

Price is one of the most essential factors when people make purchasing decisions, thus pricing strategies - decreasing prices through subsidies to encourage the purchase of healthy foods and increasing prices through taxes to discourage the purchase of unhealthy foods - is likely an important lever for improving diet. Cost-effectiveness reviews support using both taxes and subsidies of at least $20 \%$ and modeling studies indicate that taxes and subsidies of at least $10-15 \%$ could affect consumption; although the evidence from experimental studies is less conclusive and generalizable. ${ }^{198}$ However, an earlier systematic review of 20 field studies of subsidies found subsidies for healthy foods (ranging from discounts equivalent to $10-50 \%$ of prices) generally increased healthy food purchases and consumption. ${ }^{199}$ Another review of 24 experimental studies on price changes in various settings (laboratory, cafeteria/restaurant, vending machines, and food stores) found evidence that price changes affected the targeted foods in the expected direction, however noted these effects might be diluted by substitution of nontargeted foods, particularly over a longer time period than typically assessed in these studies. ${ }^{200}$

Early evidence from jurisdictions that have passed taxes on certain sugar sweetened beverages (SSBs) is encouraging. In the one year (January 2014 - December 2014) since Mexico implemented a 1 peso/L excise tax (approximately a 10\% price increase) on SSBs, household purchases of taxed beverages decreased by an average of $6 \%$, with larger decreases in noncarbonated SSBs and for those in the lowest socioeconomic group. ${ }^{67}$ In Berkeley (CA), where America's first SSB tax was implemented in March 2015, research on changes in overall sales 
and consumption are not yet available, however there have already been early examinations of price changes. ${ }^{201-203}$ One study of SSB prices before and after implementation in Berkeley and San Francisco found pass-through rates of approximately $22 \%$ across the two major soda brands and common sizes - that is, distributors or retailers absorbed the increased cost or spread the increased cost across other products such that consumers only saw $22 \%$ of the 1 cent/oz tax three months after implementation. ${ }^{201}$ Another study that also tracked prices through three months post-implementation, but at a smaller set of stores across Berkeley, Oakland, and San Francisco, found pass-through rates for soda, fruit-flavored drinks, and sweetened teas of $69 \%, 47 \%$, and $32 \%$, respectively. ${ }^{202}$ A third report, for which interim findings from two studies were presented, determined that SSB prices from a random selection of stores in Berkeley had increased by more than $1 \mathrm{cent} / \mathrm{oz}$ in large and small chain supermarkets and chain gas stations (but not independent small markets or independent gas stations) and by 0.4 cents/oz in pharmacies four months after implementation. ${ }^{203}$ These researchers also examined prices from retail scanner data for two large grocery chains operating in the Bay Area and found prices increased by more than 1 cent/oz in the fourth, fifth, and sixth months post-implementation. ${ }^{203}$ This finding was similar to another evaluation of Mexico's SSB tax which found that prices for soda increased immediately with implementation, but prices for other SSBs did not start to increase until the fourth month. ${ }^{204}$ These findings suggest that the lower pass-through rates seen in the earlier studies may be the result of an insufficiently short follow-up period and that no definite conclusions should be drawn until the taxes have been in place at least four months.

In addition, SSB taxes may alter not just the affordability, but the availability of SSBs. In Berkeley, for example, one dollar store chain (Dollar Tree) decided to stop carrying soda in their stores that would be affected by the tax. ${ }^{205}$ In Chapter 3, we found no association between different measures of the food environment and SSB consumption, however availability of SSBs was not something explicitly tested because it was available in almost all stores.

Now that SSB taxes have been enacted, future research can focus on longer term studies tracking sales data as well as linking these policies to population health outcomes. Exploiting the variation in pass-through rates and matching to a representative survey (including dietary recall) could be a good approach to measuring the effectiveness of such taxes.

\section{Labeling}

Provision of information, either on the product or on the shelf, such as warning labels, has gained some traction in the policy arena. In 2014, New York State introduced the "SugarSweetened Beverages Safety Warning Act" which would require a warning label on the front of the package with a statement about the connection between SSBs and health consequences, similar to those found on tobacco and alcohol products. ${ }^{164}$ Baltimore, California, and San Francisco have introduced similar policies, with varying degrees of success. ${ }^{206}$ Additional state jurisdictions including Washington and Hawaii are considering their own bills modeled after California's warning label. ${ }^{207}$ In additional to political support, labeling appears to be accepted 
by the public as well - a recent Field Poll of registered voters in California found 78\% supported health warning labels on SSBs that state the contribution of SSB consumption to diabetes, obesity, and tooth decay. ${ }^{208}$

Evidence on the effectiveness of warning labels shows promise. In an online experiment, parents of 6- to 11-year olds who saw health warning labels were less likely to report intent to purchase SSBs for their child than parents who saw a calorie label or no label. ${ }^{209}$ Two other experimental studies looked at the effect of labeling as well as taxes and subsidies. In a webbased experiment in The Netherlands, researchers varied discount amounts and introduced frontof-pack nutrition labels, but found no effect of labeling. ${ }^{210}$ Elbel and colleagues created a small corner store and sold items under a variety of potential policies and found that individuals were 11 percentage points more likely to purchase a healthier item under the tax conditions, and 6 percentage points more likely to purchase a healthier item under the labeling only (no tax) condition over the control condition. ${ }^{211}$ Labeling may not be as effective as a tax, but it may be more politically feasible to implement. As we saw in Chapter 5, the public can have strong negative reactions to nutrition policies, and labeling is easily framed as a policy that adds information rather than takes away choice.

Studies should continue to test the efficacy of different label designs (e.g., wording, graphics) in lab settings as policymakers will need to provide specific guidance on the warning labels in their policies. If labeling is passed, evaluations should compare sales data (either aggregate store level or customer level through the use of loyalty cards) before and after labeling in both affected jurisdictions and unaffected, but similar, jurisdictions.

\section{Media campaigns}

There is a long history of using mass media campaigns to try to inform the public about health behaviors and jurisdictions continue to use such campaigns to supplement other strategies. For example, large localities such as New York City, Los Angeles County, and Multnomah County (Portland) have launched media campaigns to raise awareness about SSBs and their associated health risks, in addition to other efforts to improve diet and weight outcomes. ${ }^{63,64,66}$

Mass media campaigns can have modest success in changing health behaviors, particularly when coupled with products that facilitate behavior change (e.g., free condom distribution with a campaign promoting safe sex). ${ }^{212}$ As we saw in Chapter 3, individual factors and preferences remain an important determinant of dietary behaviors, so educational campaigns may be helpful in addressing knowledge or beliefs. For example, in Chapter 4, the difference in children's soda consumption and other SSB consumption may be due to lack of awareness by parents that common fruit drinks may contain as much added sugar as soda, and media campaigns can shed light on such information.

In addition to changing individual behavior, media campaigns may also change the discourse around health issues. For example, the antismoking truth campaign focused on revealing the 
deceptions and manipulations by the tobacco industry. ${ }^{213,214}$ Similarly, researchers in Philadelphia found a shift in how local media (news stations, radio stations, and newspapers) portrayed obesity following a media intervention to reduce SSB consumption - stories after the campaign were more likely to mention food and beverage companies as contextual agents in obesity. $^{215}$ Media campaigns can be a useful way to drive the narrative behind a policy, which is particularly important for public opinion, as we saw in Chapter 5.

Future research on media campaigns need to measure both reach/saturation (implementation) as well as behavioral outcomes (effectiveness). As these campaigns are often conceived alongside other initiatives, it will be difficult to determine the effects of media alone, however, perhaps assessing a portfolio of strategies as a whole might support a more holistic approach necessary for improving diet.

\section{Final thoughts}

This dissertation examined several important aspects of the food environment in low-income communities and found few relationships between the food environment and SSB consumption. It could be that SSBs are so ubiquitous in the food environment that the lack of variability made it difficult to capture any effects. It's also possible that for this low-income population, the food environment was less important than other factors such as cultural norms. By using unique data capturing the consumer, community, realized, and potential characteristics of the food environment, this research was able to investigate the food environment using different definitions. Although the exploration of public opinion helped inform which types of policies might be more acceptable for improving diet, more research is needed to determine the right balance of effectiveness vs. feasibility and what mix of interventions and ecological influences will most improve diet outcomes. 


\section{References}

1. Ward BW, Schiller JS, Goodman RA. Multiple chronic conditions among US adults: a 2012 update. Prev Chronic Dis. 2014;11:E62.

2. Murphy SL, Xu JQ, Kochanek KD. Deaths: Final data for 2010. Vol 61. Hyattsville, MD: National Center for Health Statistics; 2013.

3. Robert Wood Johnson Foundation. Chronic Care: Making the Case for Ongoing Care. Robert Wood Johnson Foundation;2010.

4. Blackwell DL, Lucas JW, Clarke TC. Summary health statistics for U.S. adults: national health interview survey, 2012. Vital and health statistics. Series 10, Data from the National Health Survey. Feb 2014(260):1-161.

5. Kramer H, Han C, Post W, et al. Racial/ethnic differences in hypertension and hypertension treatment and control in the multi-ethnic study of atherosclerosis (MESA). American journal of hypertension. Oct 2004;17(10):963-970.

6. Winkleby MA, Kraemer HC, Ahn DK, Varady AN. Ethnic and socioeconomic differences in cardiovascular disease risk factors: findings for women from the Third National Health and Nutrition Examination Survey, 1988-1994. JAMA : the journal of the American Medical Association. Jul 22-29 1998;280(4):356-362.

7. Gillespie CD, Wigington C, Hong Y, Centers for Disease C, Prevention. Coronary heart disease and stroke deaths - United States, 2009. MMWR supplements. Nov 22 2013;62(3):157-160.

8. Institute of Medicine (US) Committee on Understanding and Eliminating Racial and Ethnic Disparities in Health Care. Unequal Treatment: Confronting Racial and Ethnic Disparities in Health Care. Washington (DC): National Academies Press; 2003.

9. Adler NE, Rehkopf DH. U.S. disparities in health: descriptions, causes, and mechanisms. Annual review of public health. 2008;29:235-252.

10. Kirk JK, Bell RA, Bertoni AG, et al. Ethnic disparities: control of glycemia, blood pressure, and LDL cholesterol among US adults with type 2 diabetes. The Annals of pharmacotherapy. Sep 2005;39(9):1489-1501.

11. Roger VL, Go AS, Lloyd-Jones DM, et al. Heart disease and stroke statistics--2011 update: a report from the American Heart Association. Circulation. Feb 1 2011;123(4):e18-e209.

12. U.S. Department of Agriculture, U.S. Department of Health and Human Services. Dietary Guidelines for Americans, 2015-2020. Washington, DC: U.S. Government Printing Office;2016.

13. Joshipura KJ, Hu FB, Manson JE, et al. The effect of fruit and vegetable intake on risk for coronary heart disease. Annals of internal medicine. Jun 19 2001;134(12):1106-1114.

14. Gil A, Ortega RM, Maldonado J. Wholegrain cereals and bread: a duet of the Mediterranean diet for the prevention of chronic diseases. Public Health Nutr. Dec 2011;14(12A):2316-2322.

15. Centers for Disease Control and Prevention. State Indicator Report on Fruits and Vegetables Atlanta, GA: Centers for Disease Control and Prevention; May 20132013.

16. Welsh JA, Sharma AJ, Grellinger L, Vos MB. Consumption of added sugars is decreasing in the United States. Am J Clin Nutr. Sep 2011;94(3):726-734. 
17. Vartanian LR, Schwartz MB, Brownell KD. Effects of soft drink consumption on nutrition and health: a systematic review and meta-analysis. Am J Public Health. Apr 2007;97(4):667-675.

18. Maersk M, Belza A, Stodkilde-Jorgensen H, et al. Sucrose-sweetened beverages increase fat storage in the liver, muscle, and visceral fat depot: a 6-mo randomized intervention study. Am J Clin Nutr. Feb 2012;95(2):283-289.

19. Chen L, Appel LJ, Loria C, et al. Reduction in consumption of sugar-sweetened beverages is associated with weight loss: the PREMIER trial. Am J Clin Nutr. May 2009;89(5):1299-1306.

20. Ebbeling CB, Feldman HA, Chomitz VR, et al. A randomized trial of sugar-sweetened beverages and adolescent body weight. The New England journal of medicine. Oct 11 2012;367(15):1407-1416.

21. Ebbeling CB, Feldman HA, Osganian SK, Chomitz VR, Ellenbogen SJ, Ludwig DS. Effects of decreasing sugar-sweetened beverage consumption on body weight in adolescents: a randomized, controlled pilot study. Pediatrics. Mar 2006;117(3):673-680.

22. Bouton ME. Why behavior change is difficult to sustain. Prev Med. Nov 2014;68:29-36.

23. Healthy People 2020. 2020 Topics \& Objectives: Social Determinants of Health. 2014; http://www.healthypeople.gov/2020/topics-objectives/topic/social-determinants-health. Accessed March 17, 2015, 2015.

24. The White House Office of the First Lady. First Lady Michelle Obama Launches Let's Move: America's Move to Raise a Healthier Generation of Kids. 2010; https://www.whitehouse.gov/the-press-office/first-lady-michelle-obama-launches-letsmove-americas-move-raise-a-healthier-genera. Accessed March 17, 2015, 2015.

25. United States Department of Agriculture. Obama Administration Details Healthy Food Financing Initiative. In: Communications Oo, ed2010.

26. Story M, Kaphingst KM, Robinson-O'Brien R, Glanz K. Creating healthy food and eating environments: policy and environmental approaches. Annual review of public health. 2008;29:253-272.

27. Glanz K, Sallis JF, Saelens BE, Frank LD. Healthy nutrition environments: concepts and measures. American journal of health promotion : AJHP. May-Jun 2005;19(5):330-333, ii.

28. Charreire H, Casey R, Salze P, et al. Measuring the food environment using geographical information systems: a methodological review. Public Health Nutr. Nov 2010;13(11):1773-1785.

29. Liese AD, Barnes TL, Lamichhane AP, Hibbert JD, Colabianchi N, Lawson AB. Characterizing the food retail environment: impact of count, type, and geospatial error in 2 secondary data sources. J Nutr Educ Behav. Sep-Oct 2013;45(5):435-442.

30. Glanz K, Sallis JF, Saelens BE, Frank LD. Nutrition Environment Measures Survey in stores (NEMS-S): development and evaluation. Am J Prev Med. Apr 2007;32(4):282289.

31. Saelens BE, Glanz K, Sallis JF, Frank LD. Nutrition Environment Measures Study in restaurants (NEMS-R): development and evaluation. Am J Prev Med. Apr 2007;32(4):273-281.

32. Ghirardelli A, Quinn V, Sugerman S. Reliability of a retail food store survey and development of an accompanying retail scoring system to communicate survey findings 
and identify vendors for healthful food and marketing initiatives. Journal of nutrition education and behavior. 2011;43(4):S104-S112.

33. Ohri-Vachaspati P, Leviton LC. Measuring food environments: a guide to available instruments. American journal of health promotion : AJHP. Jul-Aug 2010;24(6):410-426.

34. McKinnon RA, Reedy J, Morrissette MA, Lytle LA, Yaroch AL. Measures of the food environment: a compilation of the literature, 1990-2007. Am J Prev Med. Apr 2009;36(4 Suppl):S124-133.

35. Lent MR, Vander Veur S, Mallya G, et al. Corner store purchases made by adults, adolescents and children: items, nutritional characteristics and amount spent. Public Health Nutr. Jun 2015;18(9):1706-1712.

36. Kiszko K, Cantor J, Abrams C, et al. Corner Store Purchases in a Low-Income Urban Community in NYC. Journal of community health. Dec 2015;40(6):1084-1090.

37. Langellier BA, Garza JR, Prelip ML, Glik D, Brookmeyer R, Ortega AN. Corner Store Inventories, Purchases, and Strategies for Intervention: A Review of the Literature. Californian journal of health promotion. 2013;11(3):1-13.

38. Lawman HG, Vander Veur S, Mallya G, et al. Changes in quantity, spending, and nutritional characteristics of adult, adolescent and child urban corner store purchases after an environmental intervention. Prev Med. May 2015;74:81-85.

39. Lent MR, Vander Veur SS, McCoy TA, et al. A randomized controlled study of a healthy corner store initiative on the purchases of urban, low-income youth. Obesity. Dec 2014;22(12):2494-2500.

40. Ayala GX, Baquero B, Laraia BA, Ji M, Linnan L. Efficacy of a store-based environmental change intervention compared with a delayed treatment control condition on store customers' intake of fruits and vegetables. Public Health Nutr. Nov 2013;16(11):1953-1960.

41. Cannuscio CC, Tappe K, Hillier A, Buttenheim A, Karpyn A, Glanz K. Urban food environments and residents' shopping behaviors. Am J Prev Med. Nov 2013;45(5):606614.

42. Cummins S, Petticrew M, Higgins C, Findlay A, Sparks L. Large scale food retailing as an intervention for diet and health: quasi-experimental evaluation of a natural experiment. Journal of epidemiology and community health. Dec 2005;59(12):1035-1040.

43. Wrigley N, Warm D, Margetts B. Deprivation, diet, and food-retail access: findings from the Leeds food deserts' study. Environment and Planning A. 2003;35(1):151-188.

44. Cummins S, Flint E, Matthews SA. New neighborhood grocery store increased awareness of food access but did not alter dietary habits or obesity. Health Aff (Millwood). Feb 2014;33(2):283-291.

45. Dubowitz T, Ghosh-Dastidar M, Cohen DA, et al. Diet And Perceptions Change With Supermarket Introduction In A Food Desert, But Not Because Of Supermarket Use. Health Aff (Millwood). Nov 2015;34(11):1858-1868.

46. Boone-Heinonen J, Gordon-Larsen P, Kiefe CI, Shikany JM, Lewis CE, Popkin BM. Fast food restaurants and food stores: longitudinal associations with diet in young to middleaged adults: the CARDIA study. Archives of internal medicine. Jul 11 2011;171(13):1162-1170.

47. Richardson AS, Meyer KA, Howard AG, et al. Multiple pathways from the neighborhood food environment to increased body mass index through dietary behaviors: A structural equation-based analysis in the CARDIA study. Health Place. Nov 2015;36:74-87. 
48. Smith D, Cummins S, Clark C, Stansfeld S. Does the local food environment around schools affect diet? Longitudinal associations in adolescents attending secondary schools in East London. BMC Public Health. 2013;13:70.

49. Black C, Moon G, Baird J. Dietary inequalities: what is the evidence for the effect of the neighbourhood food environment? Health Place. May 2014;27:229-242.

50. Engler-Stringer R, Le H, Gerrard A, Muhajarine N. The community and consumer food environment and children's diet: a systematic review. BMC Public Health. 2014;14:522.

51. Bodor JN, Rose D, Farley TA, Swalm C, Scott SK. Neighbourhood fruit and vegetable availability and consumption: the role of small food stores in an urban environment. Public Health Nutr. Apr 2008;11(4):413-420.

52. Edmonds J, Baranowski T, Baranowski J, Cullen KW, Myres D. Ecological and socioeconomic correlates of fruit, juice, and vegetable consumption among AfricanAmerican boys. Preventive Medicine. 2001;32(6):476-481.

53. Izumi BT, Zenk SN, Schulz AJ, Mentz GB, Wilson C. Associations between neighborhood availability and individual consumption of dark-green and orange vegetables among ethnically diverse adults in Detroit. $J$ Am Diet Assoc. Feb 2011;111(2):274-279.

54. Gustafson AA, Sharkey J, Samuel-Hodge CD, et al. Perceived and objective measures of the food store environment and the association with weight and diet among low-income women in North Carolina. Public Health Nutr. Jun 2011;14(6):1032-1038.

55. Hermstad AK, Swan DW, Kegler MC, Barnette J, Glanz K. Individual and environmental correlates of dietary fat intake in rural communities: a structural equation model analysis. Social Science \& Medicine. 2010;71(1):93-101.

56. Fuller D, Cummins S, Matthews SA. Does transportation mode modify associations between distance to food store, fruit and vegetable consumption, and BMI in low-income neighborhoods? Am J Clin Nutr. Jan 2013;97(1):167-172.

57. Aggarwal A, Cook AJ, Jiao J, et al. Access to supermarkets and fruit and vegetable consumption. Am J Public Health. May 2014;104(5):917-923.

58. Liese AD, Bell BA, Barnes TL, et al. Environmental influences on fruit and vegetable intake: results from a path analytic model. Public Health Nutr. Nov 6 2013:1-10.

59. Gustafson A, Christian JW, Lewis S, Moore K, Jilcott S. Food venue choice, consumer food environment, but not food venue availability within daily travel patterns are associated with dietary intake among adults, Lexington Kentucky 2011. Nutr J. 2013;12:17.

60. Malik VS, Schulze MB, Hu FB. Intake of sugar-sweetened beverages and weight gain: a systematic review. Am J Clin Nutr. Aug 2006;84(2):274-288.

61. Kumar GS, Pan L, Park S, et al. Sugar-sweetened beverage consumption among adults -18 states, 2012. MMWR. Morbidity and mortality weekly report. Aug 15 2014;63(32):686-690.

62. Kit BK, Fakhouri TH, Park S, Nielsen SJ, Ogden CL. Trends in sugar-sweetened beverage consumption among youth and adults in the United States: 1999-2010. Am J Clin Nutr. Jul 2013;98(1):180-188.

63. Kansagra SM, Kennelly MO, Nonas CA, et al. Reducing sugary drink consumption: New York City's approach. Am J Public Health. Apr 2015;105(4):e61-64.

64. Barragan NC, Noller AJ, Robles B, et al. The "sugar pack" health marketing campaign in Los Angeles County, 2011-2012. Health promotion practice. Mar 2014;15(2):208-216. 
65. Frizell S. Nation's First Soda Tax Passed in Californian City. Time2014.

66. Boles M, Adams A, Gredler A, Manhas S. Ability of a mass media campaign to influence knowledge, attitudes, and behaviors about sugary drinks and obesity. Prev Med. Oct 2014;67 Suppl 1:S40-45.

67. Colchero MA, Popkin BM, Rivera JA, Ng SW. Beverage purchases from stores in Mexico under the excise tax on sugar sweetened beverages: observational study. $B M J$. 2016;352:h6704.

68. Mexico fourth in soft drink consumption. Mexico Daily News. July 11, 2015, 2015.

69. Hawkes C. Dietary Implications of Supermarket Development: A Global Perspective. Dev Policy Rev. Nov 2008;26(6):657-692.

70. Popkin BM. Global nutrition dynamics: the world is shifting rapidly toward a diet linked with noncommunicable diseases. Am J Clin Nutr. Aug 2006;84(2):289-298.

71. Gustafson A, Hankins S, Jilcott S. Measures of the consumer food store environment: a systematic review of the evidence 2000-2011. Journal of community health. Aug 2012;37(4):897-911.

72. Caspi CE, Sorensen G, Subramanian SV, Kawachi I. The local food environment and diet: a systematic review. Health Place. Sep 2012;18(5):1172-1187.

73. Briefel RR, Crepinsek MK, Cabili C, Wilson A, Gleason PM. School food environments and practices affect dietary behaviors of US public school children. $J$ Am Diet Assoc. Feb 2009;109(2 Suppl):S91-107.

74. Jones SJ, Gonzalez W, Frongillo EA. Policies that restrict sweetened beverage availability may reduce consumption in elementary-school children. Public Health Nutr. Apr 2010;13(4):589-595.

75. Davy BM, You W, Almeida F, et al. Impact of individual and worksite environmental factors on water and sugar-sweetened beverage consumption among overweight employees. Prev Chronic Dis. 2014;11:E71.

76. Mills SD, Tanner LM, Adams J. Systematic literature review of the effects of food and drink advertising on food and drink-related behaviour, attitudes and beliefs in adult populations. Obesity reviews : an official journal of the International Association for the Study of Obesity. Apr 2013;14(4):303-314.

77. Cohen DA, Collins R, Hunter G, Ghosh-Dastidar B, Dubowitz T. Store Impulse Marketing Strategies and Body Mass Index. Am J Public Health. Dec 18 2014:e1-e7.

78. Lee JG, Henriksen L, Myers AE, Dauphinee AL, Ribisl KM. A systematic review of store audit methods for assessing tobacco marketing and products at the point of sale. Tobacco control. Mar 2014;23(2):98-106.

79. Kirkpatrick SI, Subar AF, Douglass D, et al. Performance of the Automated SelfAdministered 24-hour Recall relative to a measure of true intakes and to an intervieweradministered 24-h recall. Am J Clin Nutr. Apr 30 2014;100(1):233-240.

80. Rehm CD, Matte TD, Van Wye G, Young C, Frieden TR. Demographic and behavioral factors associated with daily sugar-sweetened soda consumption in New York City adults. Journal of urban health : bulletin of the New York Academy of Medicine. May 2008;85(3):375-385.

81. Rimkus L, Powell LM, Zenk SN, et al. Development and reliability testing of a food store observation form. J Nutr Educ Behav. Nov-Dec 2013;45(6):540-548.

82. Sturm R, Cohen D. Proximity to urban parks and mental health. The journal of mental health policy and economics. Mar 2014;17(1):19-24. 
83. Mejia N, Lightstone AS, Basurto-Davila R, Morales DM, Sturm R. Neighborhood Food Environment, Diet, and Obesity Among Los Angeles County Adults, 2011. Prev Chronic Dis. 2015;12:E143.

84. Tester JM, Yen IH, Pallis LC, Laraia BA. Healthy food availability and participation in WIC (Special Supplemental Nutrition Program for Women, Infants, and Children) in food stores around lower- and higher-income elementary schools. Public Health Nutr. Jun 2011;14(6):960-964.

85. Austin SB, Melly SJ, Sanchez BN, Patel A, Buka S, Gortmaker SL. Clustering of fastfood restaurants around schools: a novel application of spatial statistics to the study of food environments. Am J Public Health. Sep 2005;95(9):1575-1581.

86. Ghosh-Dastidar B, Cohen D, Hunter G, et al. Distance to store, food prices, and obesity in urban food deserts. Am J Prev Med. Nov 2014;47(5):587-595.

87. Dong D, Bilger M, van Dam RM, Finkelstein EA. Consumption Of Specific Foods And Beverages And Excess Weight Gain Among Children And Adolescents. Health Aff (Millwood). Nov 2015;34(11):1940-1948.

88. Mozaffarian D, Hao T, Rimm EB, Willett WC, Hu FB. Changes in diet and lifestyle and long-term weight gain in women and men. The New England journal of medicine. Jun 23 2011;364(25):2392-2404.

89. Fogelholm M, Anderssen S, Gunnarsdottir I, Lahti-Koski M. Dietary macronutrients and food consumption as determinants of long-term weight change in adult populations: a systematic literature review. Food \& nutrition research. 2012;56.

90. Han E, Powell LM. Consumption patterns of sugar-sweetened beverages in the United States. Journal of the Academy of Nutrition and Dietetics. Jan 2013;113(1):43-53.

91. Rummo PE, Meyer KA, Boone-Heinonen J, et al. Neighborhood availability of convenience stores and diet quality: findings from 20 years of follow-up in the coronary artery risk development in young adults study. Am J Public Health. May 2015;105(5):e65-73.

92. Wilcox S, Sharpe PA, Turner-McGrievy G, Granner M, Baruth M. Frequency of consumption at fast-food restaurants is associated with dietary intake in overweight and obese women recruited from financially disadvantaged neighborhoods. Nutrition research. Aug 2013;33(8):636-646.

93. Bowman SA, Vinyard BT. Fast food consumption of U.S. adults: impact on energy and nutrient intakes and overweight status. Journal of the American College of Nutrition. Apr 2004;23(2):163-168.

94. Park S, Blanck HM, Sherry B, Brener N, O'Toole T. Factors associated with sugarsweetened beverage intake among United States high school students. J Nutr. Feb 2012;142(2):306-312.

95. Powell LM, Nguyen BT. Fast-food and full-service restaurant consumption among children and adolescents: effect on energy, beverage, and nutrient intake. JAMA pediatrics. Jan 2013;167(1):14-20.

96. Drewnowski A, Aggarwal A, Hurvitz PM, Monsivais P, Moudon AV. Obesity and supermarket access: proximity or price? Am J Public Health. Aug 2012;102(8):e74-80.

97. Powell LM, Chriqui JF, Khan T, Wada R, Chaloupka FJ. Assessing the potential effectiveness of food and beverage taxes and subsidies for improving public health: a systematic review of prices, demand and body weight outcomes. Obesity reviews : an 
official journal of the International Association for the Study of Obesity. Feb 2013;14(2):110-128.

98. Thornton LE, Cameron AJ, McNaughton SA, Worsley A, Crawford DA. The availability of snack food displays that may trigger impulse purchases in Melbourne supermarkets. BMC Public Health. 2012;12:194.

99. Park S, Xu F, Town M, Blanck HM. Prevalence of Sugar-Sweetened Beverage Intake Among Adults - 23 States and the District of Columbia, 2013. MMWR. Morbidity and mortality weekly report. 2016;65(7):169-174.

100. Park S, McGuire LC, Galuska DA. Regional Differences in Sugar-Sweetened Beverage Intake among US Adults. Journal of the Academy of Nutrition and Dietetics. Dec 2015;115(12):1996-2002.

101. Striegel-Moore RH, Thompson D, Affenito SG, et al. Correlates of beverage intake in adolescent girls: the National Heart, Lung, and Blood Institute Growth and Health Study. The Journal of pediatrics. Feb 2006;148(2):183-187.

102. Arcan C, Kubik MY, Fulkerson JA, Story M. Sociodemographic differences in selected eating practices among alternative high school students. J Am Diet Assoc. May 2009;109(5):823-829.

103. LeDoux TF, Vojnovic I. Going outside the neighborhood: the shopping patterns and adaptations of disadvantaged consumers living in the lower eastside neighborhoods of Detroit, Michigan. Health Place. Jan 2013;19:1-14.

104. Odoms-Young AM, Zenk S, Mason M. Measuring food availability and access in African-American communities: implications for intervention and policy. Am J Prev Med. Apr 2009;36(4 Suppl):S145-150.

105. Atkins H. Dairy Queen joins Fast Food Chain Trend Removing Soda From Kids Menus. Forbes.com 2015.

106. Trotter G. Aldi putting more granola, less chocolate in checkout lanes. Chicago Tribune. January 12, 2016, 2015.

107. Kumar K. Target to test a checkout lane free of junk food (or less of it). StarTribune. September 17, 2015, 2015.

108. Lidl. Children's diets challenged by supermarket checkout chocolates. 2014; http://www.lidl.co.uk/en/5028.htm. Accessed January 19, 2016.

109. Emmett PM, Jones LR. Diet, growth, and obesity development throughout childhood in the Avon Longitudinal Study of Parents and Children. Nutrition reviews. Oct 2015;73 Suppl 3:175-206.

110. Wiles NJ, Northstone K, Emmett P, Lewis G. 'Junk food' diet and childhood behavioural problems: results from the ALSPAC cohort. Eur J Clin Nutr. Apr 2009;63(4):491-498.

111. Miedema MD, Petrone A, Shikany JM, et al. Association of Fruit and Vegetable Consumption During Early Adulthood With the Prevalence of Coronary Artery Calcium After 20 Years of Follow-Up: The Coronary Artery Risk Development in Young Adults (CARDIA) Study. Circulation. Nov 24 2015;132(21):1990-1998.

112. Krebs-Smith SM, Guenther PM, Subar AF, Kirkpatrick SI, Dodd KW. Americans do not meet federal dietary recommendations. J Nutr. Oct 2010;140(10):1832-1838.

113. Ervin RB, Kit BK, Carroll MD, Ogden CL. Consumption of Added Sugar among US Children and Adolescents, 2005-2008. NCHS Data Brief. No. 87. National Center for Health Statistics. 2012. 
114. Reedy J, Krebs-Smith SM. Dietary sources of energy, solid fats, and added sugars among children and adolescents in the United States. Journal of the American Dietetic Association. 2010;110(10):1477-1484.

115. McGinnis JM, Gootman JA, Kraak VI. Food marketing to children and youth: threat or opportunity? Washington, D.C.: National Academies Press; 2006.

116. Cairns G, Angus K, Hastings G, Caraher M. Systematic reviews of the evidence on the nature, extent and effects of food marketing to children. A retrospective summary. Appetite. Mar 2013;62:209-215.

117. Robinson TN, Borzekowski DL, Matheson DM, Kraemer HC. Effects of fast food branding on young children's taste preferences. Archives of pediatrics \& adolescent medicine. Aug 2007;161(8):792-797.

118. Kraak VI, Story M. Influence of food companies' brand mascots and entertainment companies' cartoon media characters on children's diet and health: a systematic review and research needs. Obesity Reviews. Feb 2015;16(2):107-126.

119. Harris JL, Schwartz MB, Brownell KD. Marketing foods to children and adolescents: licensed characters and other promotions on packaged foods in the supermarket. Public Health Nutrition. Mar 2010;13(3):409-417.

120. Kelly B, Halford JC, Boyland EJ, et al. Television food advertising to children: a global perspective. American journal of public health. Sep 2010;100(9):1730-1736.

121. Story M, French S. Food Advertising and Marketing Directed at Children and Adolescents in the US. International Journal of Behavior Nutrition and Physical Activity. Feb 10 2004;1(1):3.

122. Kelly B, King L, Chapman K, Boyland E, Bauman AE, Baur LA. A hierarchy of unhealthy food promotion effects: identifying methodological approaches and knowledge gaps. Am J Public Health. Apr 2015;105(4):e86-95.

123. Galst JP, White MA. The unhealthy persuader: the reinforcing value of television and children's purchase-influencing attempts at the supermarket. Child Development. 1976;47(4):1089-1096.

124. Ogba I-E, Johnson R. How packaging affects the product preferences of children and the buyer behaviour of their parents in the food industry. Young Consumers: Insight and Ideas for Responsible Marketers. 2010;11(1):77-89.

125. Spungin P. Parent power, not pester power. Young Consumers: Insight and Ideas for Responsible Marketers. 2004;5(3):37-40.

126. Henry HK, Borzekowski DL. The Nag Factor: A mixed-methodology study in the US of young children's requests for advertised products. Journal of Children and Media. 2011;5(3):298-317.

127. McDermott L, O'Sullivan T, Stead M, Hastings G. International food advertising, pester power and its effects. International Journal of Advertising. 2006;25(4):513-539.

128. Ebster C, Wagner U, Neumueller D. Children's influences on in-store purchases. Journal of Retailing and Consumer Services. 2009;16(2):145-154.

129. Morales E. The nag factor: measuring children's influence Understand child-parent interaction to make sense of nagging and maximise child influence on purchases. Admap. 2000;35(3 ISSU 404):35-37.

130. Buijzen M, Valkenburg PM. Observing Purchase-Related Parent-Child Communication in Retail Environments: A Developmental and Socialization Perspective. Human Communication Research. 2008;34(1):50-69. 
131. French SA, Shimotsu ST, Wall M, Gerlach AF. Capturing the spectrum of household food and beverage purchasing behavior: a review. J Am Diet Assoc. Dec 2008;108(12):2051-2058.

132. Horsley JA, Absalom KA, Akiens EM, Dunk RJ, Ferguson AM. The proportion of unhealthy foodstuffs children are exposed to at the checkout of convenience supermarkets. Public Health Nutr. Nov 2014;17(11):2453-2458.

133. Grigsby-Toussaint DS, Rooney MR. Food marketing targeting youth and families: what do we know about stores where moms actually shop? Journal of environmental and public health. 2013;2013:674181.

134. World Health Organization. Set of recommendations on the marketing of foods and nonalcoholic beverages to children. 2010.

135. Healthy Eating Research. Recommendations for Responsible Food Marketing to Children. Minneapolis, MN: Healthy Eating Research;2015.

136. Centers for Disease Control and Prevention (CDC), National Center for Health Statistics (NCHS). National Health and Nutrition Examination Survey Questionnaire - Dietary Screener. Hyattsville, MD: U.S. Department of Health and Human Services, Centers for Disease Control and Prevention; 2009-2010.

137. Kwai-Choi Lee C, Collins BA. Family decision making and coalition patterns. Eur J Marketing. 2000;34(9/10):1181-1198.

138. Williams LA, Burns AC. Exploring the Dimensionality of Children's Direct Influence Attempts. Advances in consumer research. 2000;27(1).

139. Cowan G, Drinkard J, MacGavin L. The effects of target, age, and gender on use of power strategies. Journal of personality and social psychology. 1984;47(6):1391.

140. World Health Organization. Guideline: Sugars intake for adults and children Geneva, Switzerland: WHO Press; 2015.

141. Ford CN, Ng SW, Popkin BM. Ten-year beverage intake trends among US preschool children: rapid declines between 2003 and 2010 but stagnancy in recent years. Pediatric obesity. Mar 22015.

142. Bleich SN, Wolfson JA. Trends in SSBs and snack consumption among children by age, body weight, and race/ethnicity. Obesity. May 2015;23(5):1039-1046.

143. Slining MM, Popkin BM. Trends in intakes and sources of solid fats and added sugars among U.S. children and adolescents: 1994-2010. Pediatric obesity. Aug 2013;8(4):307324.

144. Mesirow MS, Welsh JA. Changing beverage consumption patterns have resulted in fewer liquid calories in the diets of US children: National Health and Nutrition Examination Survey 2001-2010. Journal of the Academy of Nutrition and Dietetics. Apr 2015;115(4):559-566 e554.

145. Walker RW, Dumke KA, Goran MI. Fructose content in popular beverages made with and without high-fructose corn syrup. Nutrition. Jul-Aug 2014;30(7-8):928-935.

146. Munsell CR, Harris JL, Sarda V, Schwartz MB. Parents' beliefs about the healthfulness of sugary drink options: opportunities to address misperceptions. Public Health Nutr. Jan 2016;19(1):46-54.

147. Hennessy M, Bleakley A, Piotrowski JT, Mallya G, Jordan A. Sugar-Sweetened Beverage Consumption by Adult Caregivers and Their Children: The Role of Drink Features and Advertising Exposure. Health education \& behavior : the official publication of the Society for Public Health Education. Oct 2015;42(5):677-686. 
148. O'Dougherty M, Story M, Stang J. Observations of parent-child co-shoppers in supermarkets: children's involvement in food selections, parental yielding, and refusal strategies. J Nutr Educ Behav. May-Jun 2006;38(3):183-188.

149. Calloway EE, Roberts-Gray C, Ranjit N, et al. Method of assessing parent-child grocery store purchasing interactions using a micro-camcorder. Appetite. Dec 2014;83:1-9.

150. Chamberlain LJ, Wang Y, Robinson TN. Does children's screen time predict requests for advertised products? Cross-sectional and prospective analyses. Archives of Pediatrics and Adolescent Medicine. Apr 2006;160(4):363-368.

151. Guerrero AD, Chung PJ. Racial and Ethnic Disparities in Dietary Intake among California Children. Journal of the Academy of Nutrition and Dietetics. Sep 302015.

152. Beck AL, Patel A, Madsen K. Trends in sugar-sweetened beverage and $100 \%$ fruit juice consumption among California children. Academic pediatrics. Jul-Aug 2013;13(4):364370 .

153. Powell LM, Szczypka G, Chaloupka FJ. Trends in exposure to television food advertisements among children and adolescents in the United States. Archives of pediatrics \& adolescent medicine. Sep 2010;164(9):794-802.

154. Folkvord F, Anschutz DJ, Buijzen M, Valkenburg PM. The effect of playing advergames that promote energy-dense snacks or fruit on actual food intake among children. Am J Clin Nutr. Feb 2013;97(2):239-245.

155. Dias M, Agante L. Can advergames boost children's healthier eating habits? A comparison between healthy and non-healthy food. Journal of Consumer Behaviour. May-Jun 2011;10(3):152-160.

156. Huang C, Reisch LA, Gwozdz W, et al. Pester power and its consequences: Do European children's food purchasing requests relate to diet and weight outcomes? 2016.

157. Marshall D, O'Donohoe S, Kline S. Families, food, and pester power: beyond the blame game? Journal of Consumer Behaviour. 2007;6(4):164-181.

158. Van Lippevelde W, te Velde SJ, Verloigne M, et al. Associations between home- and family-related factors and fruit juice and soft drink intake among 10- to 12-year old children. The ENERGY project. Appetite. Feb 2013;61(1):59-65.

159. Grimm GC, Harnack L, Story M. Factors associated with soft drink consumption in school-aged children. J Am Diet Assoc. Aug 2004;104(8):1244-1249.

160. Harris TS, Ramsey M. Paternal modeling, household availability, and paternal intake as predictors of fruit, vegetable, and sweetened beverage consumption among African American children. Appetite. Feb 2015;85:171-177.

161. Olafsdottir S, Berg C, Eiben G, et al. Young children's screen activities, sweet drink consumption and anthropometry: results from a prospective European study. European Journal of Clinical Nutrition. Feb 2014;68(2):223-228.

162. Poti JM, Slining MM, Popkin BM. Where are kids getting their empty calories? Stores, schools, and fast-food restaurants each played an important role in empty calorie intake among US children during 2009-2010. Journal of the Academy of Nutrition and Dietetics. Jun 2014;114(6):908-917.

163. Human USDoAaUSDoHa, Services. Dietary Guidelines for Americans, 2010. Washington, DC: U.S. Government Printing Office; December 20102010.

164. Centers for Disease Control and Prevention. Chronic Disease State Policy Tracking System. http://nccd.cdc.gov/CDPHPPolicySearch/Default.aspx. Accessed April 14, $2015,2015$. 
165. Dodson EA, Fleming C, Boehmer TK, Haire-Joshu D, Luke DA, Brownson RC.

Preventing childhood obesity through state policy: qualitative assessment of enablers and barriers. Journal of public health policy. 2009;30 Suppl 1:S161-176.

166. Barry CL, Brescoll VL, Brownell KD, Schlesinger M. Obesity metaphors: how beliefs about the causes of obesity affect support for public policy. The Milbank quarterly. Mar 2009;87(1):7-47.

167. Watts RA, Heiss S, Moser M, Kolodinsky J, Johnson RK. Tobacco taxes vs soda taxes: A case study of a framing debate in vermont. Health Behavior and Policy Review. 2014;1(3):191-196.

168. Nixon L, Mejia P, Cheyne A, Dorfman L. Big Soda's long shadow: news coverage of local proposals to tax sugar-sweetened beverages in Richmond, El Monte and Telluride. Critical Public Health. 2015;25(3):333-347.

169. Perry CL, Creamer MR. The childhood obesity epidemic: lessons learned from tobacco. The Journal of pediatrics. Jan 2014;164(1):178-185.

170. Brownell KD, Warner KE. The perils of ignoring history: Big Tobacco played dirty and millions died. How similar is Big Food? The Milbank quarterly. Mar 2009;87(1):259294.

171. Pomeranz JL. Sugary beverage tax policy: lessons learned from tobacco. Am J Public Health. Mar 2014;104(3):e13-15.

172. Yanamadala S, Bragg MA, Roberto CA, Brownell KD. Food industry front groups and conflicts of interest: the case of Americans Against Food Taxes. Public Health Nutr. Aug 2012;15(8):1331-1332.

173. Brownell KD, Kersh R, Ludwig DS, et al. Personal responsibility and obesity: a constructive approach to a controversial issue. Health Aff (Millwood). Mar-Apr 2010;29(3):379-387.

174. New York City Department of Health and Mental Hygiene Board of Health. Notice of Adoption of an Amendment ( $\$ 81.53$ ) to Article 81 of the New York City Health Code. In: Hygiene NYCDoHaM, ed2012.

175. Malik VS, Popkin BM, Bray GA, Despres JP, Hu FB. Sugar-sweetened beverages, obesity, type 2 diabetes mellitus, and cardiovascular disease risk. Circulation. Mar 23 2010;121(11):1356-1364.

176. Jou J, Niederdeppe J, Barry CL, Gollust SE. Strategic messaging to promote taxation of sugar-sweetened beverages: lessons from recent political campaigns. Am J Public Health. May 2014;104(5):847-853.

177. Niederdeppe J, Gollust SE, Jarlenski MP, Nathanson AM, Barry CL. News coverage of sugar-sweetened beverage taxes: pro- and antitax arguments in public discourse. Am J Public Health. Jun 2013;103(6):e92-98.

178. Grynbaum MM. New York Plans to Ban Sale of Big Sizes of Sugary Drinks. New York Times. May 30, 2012.

179. Kolata G. Studies Question the Pairing of Food Deserts and Obesity. New York Times. April 17, 2012.

180. An R, Sturm R. School and residential neighborhood food environment and diet among California youth. Am J Prev Med. Feb 2012;42(2):129-135.

181. Lee $\mathrm{H}$. The role of local food availability in explaining obesity risk among young schoolaged children. Soc Sci Med. Apr 2012;74(8):1193-1203. 
182. Carnegie Mellon University, English; Do. DocuScope: Computer-aided Rhetorical Analysis. https://www.cmu.edu/hss/english/research/docuscope.html. Accessed 3/11/2016, 2016.

183. Bai X. Predicting consumer sentiments from online text. Decision Support Systems. 2011;50(4):732-742.

184. Biber D, Conrad S, Reppen R. Corpus linguistics: Investigating language structure and use. Cambridge University Press; 1998.

185. Barry CL, Niederdeppe J, Gollust SE. Taxes on sugar-sweetened beverages: results from a 2011 national public opinion survey. Am J Prev Med. Feb 2013;44(2):158-163.

186. Dorfman L. Talking about sugar sweetened-beverage taxes: will actions speak louder than words? Am J Prev Med. Feb 2013;44(2):194-195.

187. Wilson BM, Stolarz-Fantino S, Fantino E. Regulating the way to obesity: unintended consequences of limiting sugary drink sizes. PloS one. 2013;8(4):e61081.

188. O'Connor B, Balasubramanyan R, Routledge BR, Smith NA. From Tweets to Polls: Linking Text Sentiment to Public Opinion Time Series. ICWSM. 2010;11(122-129):1.2.

189. Feser K. Boom in grocery stores means a feast for builder. Houston Chronicle. May 6, 2013, 2013.

190. Wilson M. Costs Going Up: Annual study tracks cost of building and outfitting stores. 2013.

191. The Reinvestment Fund. Understanding the Grocery Industry. Financing Healthy Food Options: Implementation Handbook. Washington, D.C.: The Department of the Treasury. CDFI Fund. Capacity Building Initiative.; 2011.

192. Reagan C. What's Behind the Rush Into the Low-Margin Grocery Business. Consumer Nation 2013; http://www.cnbc.com/id/100794988. Accessed 2/5/2016, 2016.

193. Foster GD, Karpyn A, Wojtanowski AC, et al. Placement and promotion strategies to increase sales of healthier products in supermarkets in low-income, ethnically diverse neighborhoods: a randomized controlled trial. Am J Clin Nutr. Jun 2014;99(6):13591368.

194. Morain S, Mello MM. Survey finds public support for legal interventions directed at health behavior to fight noncommunicable disease. Health Aff (Millwood). Mar 2013;32(3):486-496.

195. Chaufan $\mathrm{C}$, Hong GH, Fox P. "Sin-food" taxes and sugar-sweetened beverages--the right policy for the wrong reasons? American journal of health promotion : AJHP. Nov-Dec 2010;25(2):87-90.

196. Khan LK, Sobush K, Keener D, et al. Recommended community strategies and measurements to prevent obesity in the United States. MMWR. Recommendations and reports : Morbidity and mortality weekly report. Recommendations and reports / Centers for Disease Control. Jul 24 2009;58(RR-7):1-26.

197. Studdert DM, Flanders J, Mello MM. Searching for Public Health Law's Sweet Spot: The Regulation of Sugar-Sweetened Beverages. PLoS medicine. Jul 2015;12(7):e1001848.

198. Niebylski ML, Redburn KA, Duhaney T, Campbell NR. Healthy food subsidies and unhealthy food taxation: A systematic review of the evidence. Nutrition. Jun 2015;31(6):787-795.

199. An R. Effectiveness of subsidies in promoting healthy food purchases and consumption: a review of field experiments. Public Health Nutr. Jul 2013;16(7):1215-1228. 
200. Epstein LH, Jankowiak N, Nederkoorn C, Raynor HA, French SA, Finkelstein E. Experimental research on the relation between food price changes and food-purchasing patterns: a targeted review. Am J Clin Nutr. Apr 2012;95(4):789-809.

201. Cawley J, Frisvold D. The Incidence of Taxes on Sugar-Sweetened Beverages: The Case of Berkeley, California. National Bureau of Economic Research;2015.

202. Falbe J, Rojas N, Grummon AH, Madsen KA. Higher Retail Prices of Sugar-Sweetened Beverages 3 Months After Implementation of an Excise Tax in Berkeley, California. Am J Public Health. Nov 2015;105(11):2194-2201.

203. Ng SW, Silver L, Ryan-Ibarra S, et al. Berkeley Evaluation of Soda Tax (BEST) Study Preliminary Findings. Paper presented at: American Public Health Association 143rd Annual Meeting; November 3, 2015, 2016; Chicago, IL.

204. Grogger J. Soda taxes and the prices of sodas and other drinks: evidence from Mexico. National Bureau of Economic Research;2015.

205. Lochner T. Berkeley: First-in-nation soda tax begins to show results. Mercury News. 11/19/2015, 2015.

206. Cohn M. Baltimore officials want warnings on sugary drinks. Baltimore Sun. January 11, 2016, 2016.

207. Greene R. [ssb-listserv] new SSB legislation. In: ssb-listserv, ed2016.

208. The Field Poll. Voters see a close linkage between kids regularly drinking sugary beverages and their developing serious health conditions, like Type-2 diabetes. Broadbased support for both government and beverage company actions to address the problem. San Francisco, CA: Field Research Corporation; February 4, 20162016.

209. Roberto CA, Wong D, Musicus A, Hammond D. The Influence of Sugar-Sweetened Beverage Health Warning Labels on Parents' Choices. Pediatrics. Feb 2016;137(2):1-10.

210. Waterlander WE, Steenhuis IH, de Boer MR, Schuit AJ, Seidell JC. Effects of different discount levels on healthy products coupled with a healthy choice label, special offer label or both: results from a web-based supermarket experiment. The international journal of behavioral nutrition and physical activity. 2013;10:59.

211. Elbel B, Taksler GB, Mijanovich T, Abrams CB, Dixon LB. Promotion of healthy eating through public policy: a controlled experiment. Am J Prev Med. Jul 2013;45(1):49-55.

212. Robinson MN, Tansil KA, Elder RW, et al. Mass media health communication campaigns combined with health-related product distribution: a community guide systematic review. Am J Prev Med. Sep 2014;47(3):360-371.

213. Evans WD, Wasserman J, Bertolotti E, Martino S. Branding behavior: The strategy behind the truthsm campaign. Social Marketing Quarterly. 2002;8(3):17-29.

214. Hicks JJ. The strategy behind Florida's "truth" campaign. Tobacco control. Mar 2001;10(1):3-5.

215. Jeong M, Gilmore JS, Bleakley A, Jordan A. Local news media framing of obesity in the context of a sugar-sweetened beverage reduction media campaign. J Nutr Educ Behav. Nov-Dec 2014;46(6):583-588. 


\section{Appendices}

\section{Appendix A}

\section{Fast food frequency}

We investigated whether fast food frequency was associated with food environment variables. The supplementary table (see below) shows results from an ordered logit where environmental characteristics predict fast food frequency category. To use the first food environment measure, distance to the closest store as an example, the proportional odds ratio indicates that for a one unit change in distance, the odds of highest fast food frequency ("More than 5 times/week") versus the other categories ("Never", "Less than 1 time/week", "1-2 times/week", and "3-5 times/week") combined is 0.71 in 2011.

Distance, density, and characteristics of the major food store did not predict frequency of going to fast food restaurants. Shopping at convenience stores and was strongly associated with fast food frequency at baseline and at follow-up. "Sometimes" shopping at neighborhoods was associated with greater odds of fast food frequency.

Males and younger participants were more likely to be frequent fast food patrons (data not shown).

\section{Table A-1. Associations between the food environment and frequency of going to a fast food restaurant, PHRESH 2011}

\begin{tabular}{|c|c|c|}
\hline \multirow{3}{*}{ Distance (miles) to closest } & \multicolumn{2}{|c|}{ Predictor variable, one at a time } \\
\hline & Proportional OR & $\mathrm{p}$-value \\
\hline & & \\
\hline Store & 0.71 & 0.3577 \\
\hline Supermarket & 1.42 & 0.2000 \\
\hline Corner store ${ }^{\dagger}$ & 0.69 & 0.3269 \\
\hline Store with SSB marketing & 0.60 & 0.1745 \\
\hline SSB at check out & 0.60 & 0.1562 \\
\hline SSB visible from main & 0.57 & 0.0812 \\
\hline Any SSB displays & 0.90 & 0.6428 \\
\hline Restaurant, any type & 1.15 & 0.6252 \\
\hline Restaurant, fast food & 1.06 & 0.8503 \\
\hline Density (counts within 0.25 & & \\
\hline Stores & 1.02 & 0.6984 \\
\hline Supermarkets & 1.00 & \\
\hline Corner stores ${ }^{\dagger}$ & 1.03 & 0.6985 \\
\hline Stores with SSB marketing & 1.05 & 0.4987 \\
\hline
\end{tabular}


Predictor variable, one at a time

Proportional OR p-value

\begin{tabular}{lll}
\hline \hline SSB at check out & 1.09 & 0.4080 \\
SSB visible from main & 1.01 & 0.9011 \\
Number of SSB displays & 1.04 & 0.5925 \\
Restaurants, any type & 0.97 & 0.4467 \\
Restaurants, fast food & 0.97 & 0.7098 \\
Modified Retail Food Environment Index (mRFEI) & 1.00 & 0.7312 \\
\hline Frequency & & \\
Supermarkets (1=Never, 4=Often) & 0.99 & 0.9063 \\
Convenience stores (Ref=Never) & & \\
$\quad$ Occasionally & 1.92 & 0.0001 \\
$\quad$ Sometimes & 2.05 & 0.0002 \\
Often & 3.17 & 0.0000 \\
Neighborhood stores (Ref=Never) & & \\
Occasionally & 1.45 & 0.0388 \\
$\quad$ Sometimes & 2.09 & 0.0002 \\
Often & 2.23 & 0.0030 \\
\hline Characteristics of major store for food shopping & & 0.1840 \\
Not full-service supermarket & 1.31 & 0.1650 \\
No. of SSB displays & 1.00 & 0.7161 \\
Monthly exposure to SSB displays & 1.00 & 0.0544 \\
Has SSB at check out (\%) & 0.62 & 0.5309 \\
Has SSB visible from main (\%) & 1.02 & 0.90 \\
High price index (\%) & & \\
\hline
\end{tabular}

* indicates pOR is significantly different from one after Bonferroni's correction $\dagger$ chain convenience or neighborhood store mRFEI = $100 \times$ (\# of supermarkets, supercenters, wholesale, and farmstand retailers) / (\# of supermarkets, supercenters, wholesale, farmstand, convenience, and fast food retailers) High price index = store sells basket of common items at a price above the median for all stores Note: Ordered logistic regression, controlling for sex, black/African American, children in household, highest education, marital status, age, and adjusted income. Analyses including preferred store characteristics also control for the preferred store not being an full-service supermarket. 


\section{Appendix B}

We conducted a polychoric factor analysis to identify the contribution of the five parent-child shopping items to the construct of pester power. Factor analysis is a dimension reduction technique for correlation information. Polychoric factor analysis adjusts for the ordinal, versus continuous, nature of the data. The factor analysis identified a one-factor solution where the variable for how often the child requests a sweet or snack had the highest loading (see below). Factor scores were calculated using the maximum likelihood method. Sensitivity checks using principal factor and iterated principal factor methods yielded qualitatively similar results.

Table B-1. Factor loading for one factor maximum likelihood solution

\begin{tabular}{lcc} 
Variable & $\begin{array}{c}\text { Pestering } \\
\text { Factor }\end{array}$ & Uniqueness \\
\hline \hline Parent takes child shopping & 0.149 & 0.978 \\
Child helps plan and shop & 0.220 & 0.952 \\
Child puts items in cart & 0.757 & 0.427 \\
Child requests sweet or snack & 0.839 & 0.296 \\
Child is upset if parent doesn't buy requested item & 0.664 & 0.560 \\
\hline
\end{tabular}




\section{Appendix C}

Results from multivariate models of SSB consumption where OLS and negative binomial model results differed are shown below.

Table C-1. Association between food promotion factors and total SSB consumption

\begin{tabular}{lcccc} 
& \multicolumn{5}{c}{ Total SSBs } \\
& \multicolumn{2}{c}{ OLS } & \multicolumn{2}{c}{ Negative binomial } \\
& b & p-value & AME & p-value \\
\hline \hline Parent SSB consumption, daily (oz) & 0.82 & 0.051 & $0.86^{*}$ & 0.009 \\
SSBs visible at main & 9.83 & 0.121 & 9.11 & 0.248 \\
Request (ref = Never/Rarely/Sometimes) & & & & \\
$\quad$ Often & 5.84 & 0.557 & 1.82 & 0.834 \\
$\quad$ Always & 19.82 & 0.056 & 16.76 & 0.126 \\
Regular soda in the home & 5.24 & 0.548 & 4.30 & 0.665 \\
\hline
\end{tabular}

